\title{
LA TEMPERATURA DEL EQUILIBRIO ENTRE LAS FASES SÓLIDA Y LÍQUIDA \\ DE LAS SUSTANCIAS PURAS REALES
}

Edgar Méndez Lango

Tesis Doctoral

junio 2000

Dr. Fernando del Rio (UAM-I) Dr. John Ancsin (NRC) Asesores 


\section{El da la nieve como lana. y derrama la escarcha como ceniza. Echa su hielo como pedazos: ante su frío ¿quién resistirá? Enviará su palabra y los derritirá: "soplara su viento, y flurín las aguas (Salmo $147: 16-18)$}

Agradezco a mis asesores y amigos, Dr. John Ancsin (NRC) y Dr. Fernando del Río, (UAM-I) por su valiosa dirección.

Agradezco al Centro Nacional de Metrología por la oportunidad de desarrollar esta tesis mientras he estado trabajando de tiempo completo para este Centro.

Indudablemente este proyecto no hubiera sido posible sin la valiosa asistencia de muchos colegas y amigos de la UAM-I, del CENAM y del NRC. De donde me permito mencionar a: Ileana Benitez, Agustín Hayashi, Miguel Angel Olivares, Héctor Nava, Juan M. Figueroa, René Carranza, David Licea, Sergio Ledesma, Felipe Hernández, David Avilés, Marco A. Escobar, Micheline Thomas, Cristina Segura, Antonio Guardado, Guadalupe Barreiro, Rubén Lazos, Daniel St-Jean, Ken Hill, C. K Ma, Alan Steele,...

Agradezco al Jurado: Dr. Angel Manzur, Dr. Arturo Trejo, Dr. Francisco Guzmán, Dr. Rafael Torres, Dr. John Ancsin y Dr. Andrés Estrada, por sus valiosas aportaciones.

Agradezco a mi abuelita Emilia Palomares y a mi hermano, amigo y compañero, Dr. Héctor Méndez (Mata), por su apoyo.

Les agradezco a mis más cercanos amigos Jessé Méndez, Eldad Méndez y Lic. Rubí Fonseca, por su amor y confianza.

Y sobre todo a $T i$, Señor $y$ Creador, gracias por permitirme jugar un poquito con lo mucho que has hecho. 
Introducción

A. La Metrología y las propiedades físicas de la materia

B. La escala internacional de temperatura y el equilibrio entre fases

C. Referencias

\section{Curvas de fusión y sus modelos}

I. 1 Introducción

I.2 Equilibrio entre las fases sólida y líquida de soluciones

I.2.1 Términos generales

I.3 Modelo de equilibrio termodinámico

I.4 Modelo $1 / F$ o de van't Hoff

I.5 Modelo de gradiente de concentración en la porción sólida o de Gulliver

I.6 Ley de distribución de Nernst

I.7 Modelo compuesto

I.8 Modelo pseudoternario

I.9 Resumen

I.9 Referencias

\section{Técnicas experimentales}

II. 1 Introducción

II.2 Termómetros

II.3 Obtención de curvas de fusión

II.3.1 Fusión continua

II.3.2 Aparato de punto de fusión de mercurio

II.3.3 Calorimetria adiabática

II. 4 Curvas de fusión de mercurio

II.4.1 Descripción del aparato

II.4.2 Resultados

II.6 Referencias

\section{Soluciones de oxigeno}

III.1 Introducción

III.2 Modelo Compuesto $\quad 53$

III.2.1 Para obtener $k$ para cada tipo de solución binaria $\quad 54$

III.2.2 Soluciones de oxigeno con gases nobles $\quad 55$

$\begin{array}{ll}\text { III.2.3 Análisis de resultados } & 60\end{array}$

$\begin{array}{ll}\text { III.3 Modelo pseudoternario } & 61\end{array}$

III.3.1 Análisis de una muestra comercial $\quad 62$

III.3.2 Comparación de puntos fijos de la EIT-90 65

III.3.3 Efecto de degasado $\quad 65$

III.4 Conclusiones $\quad 66$

$\begin{array}{ll}\text { III.5 Referencias } & 67\end{array}$ 


\section{Otros sistemas}

IV.1 Introducción

IV.2 Punto triple de argón

IV.2.1 Crióstato para calibración de TRPs en el punto triple de $\mathrm{Ar}$

IV.2.2 Procedimiento experimental

IV.2.3 Resultados

72

IV.2.4 Comparación con otros resultados

75

IV.2.5 Comparación de TRPs

78

IV.3 Punto triple de xenón

80

IV.3.1 Análisis de datos experimentales

80

IV.4 Otros efectos

82

IV. 5 Conclusión

83

IV.6 Referencias

V. Análisis térmico

86

V.1 Introducción

V.2. Calorimetro diferencial de barrido

V.2.1 Experimental

V.2.2 Discusión

V.3 Zinc

90

V.4 Conclusión

91

V.5 Referencias

Conclusiones

93

Apéndice. Artículos publicados derivados de la tesis 


\section{INTRODUCCIÓN}

\section{A. La Metrologia y el estudio de las propiedades físicas de la materia}

Para dar un primer contexto donde se desarrolló este trabajo voy a citar dos definiciones del vocabulario internacional de Metrologia [1]: a) Medición: conjunto de operaciones que tiene por objeto determinar el valor de una magnitud; b) Metrologia: ciencia de la medición.

La Metrologia estudia aquellos fenómenos naturales que por su estabilidad y reproducibilidad pueden emplearse como referencias o patrones para mediciones de alguna magnitud. En este contexto, la Metrologia es la ciencia de los patrones de medición. Su objetivo es proponer, desarrollar y mantener patrones primarios, secundarios y de transferencia. Para lograrlo requiere la interpretación objetiva de los datos experimentales a la luz de modelos y teorias adecuados [2]. El incremento en la capacidad de observación, tanto en alcance como en resolución, exige a su vez el desarrollo de teorias para la descripción de los resultados, así: "Reconocemos que nuestra visión del mundo se ha desarrollado via innumerables mediciones y se va transformando conforme las mediciones dan luz para el desarrollo de las teorias" [3].

Definición de un problema de medición. Supongamos que tenemos un termómetro clinico con minima división de un décimo de grado Celsius. Este termómetro lo podemos utilizar con confianza si estamos apercibidos que su fabricante tuvo cuidado de colocar cada marca en el lugar adecuado. Supongamos, a su vez, que ese fabricante tiene un termómetro con 
incertidumbre de centésimo de grado. Podemos suponer, además, que ese termómetro funciona razonablemente bien durante un tiempo pero, ¿cómo se puede garantizar que sus caracteristicas metrológicas (tales como repetibilidad, estabilidad, deriva, etc.) han permanecido en el tiempo tales que esa incertidumbre de centésimo sea adecuada? Para estar seguro, el fabricante deberá apoyarse en un laboratorio que tenga, dentro de sus sistemas de medición, un termómetro que sea capaz de medir algo mejor que $0,01{ }^{\circ} \mathrm{C}$, digamos unos cuantos milésimos de grado. A este punto es posible que imaginemos que la historia se volverá a repetir muchas veces más pero, sorprendentemente, estamos al fin de la misma: ¡no hay disponibles (por el momento) termómetros tan exactos como un milésimo de grado!

El problema de tener una referencia de temperatura, con incertidumbre tal que se garantice una medida mejor que la milésima de grado, ha sido resuelto vía el uso, de la temperatura de equilibrio entre fases de sustancias puras. Estas referencias, llamadas puntos fijos, cubren el intervalo donde se realizan la mayoria de las mediciones y son uno de los componentes de una escala de temperatura. La construcción de la escala queda completa cuando se definen, además de los puntos fijos, los instrumentos y las reglas para la interpolación de la medición de temperatura entre los puntos fijos. Actualmente está vigente la Escala Internacional de Temperatura de 1990 (EIT-90) [4]. En la EIT-90 encontramos, por ejemplo, que el punto de fusión de galio tiene asignado el valor $302,9146 \mathrm{~K}\left(29,7646{ }^{\circ} \mathrm{C}\right.$, exacto por definición) con $0,05 \mathrm{mK}\left(0,00005^{\circ} \mathrm{C}\right)$ de incertidumbre en su realización práctica. Con la definición de la temperatura del equilibrio entre fases de una sustancia pura con tal exactitud se resuelve el problema desde el punto de vista teórico pero se plantea uno experimental.

Definición del problema experimental: obtener la mejor realización del la temperatura del equilibrio termodinámico entre fases de una sustancia pura. Esta realización implica la obtención de sustancias puras, la obtención de sus fases, la obtención de equilibrio termodinámico entre ellas y que el método de 
medición de su temperatura no altere el equilibrio entre las fases, entre otros.

Experimentalmente, sólo tenemos una aproximación a cada una de las condiciones mencionadas. Para corregir los errores sistemáticos generados por cada aproximación son necesarios modelos. Es decir, es necesaria la investigación de la temperatura del equilibrio entre fases para conocer su dependencia con algunas variables de influencia tal como las impurezas y su distribución en las fases, la disposición geométrica del experimento, los gradientes térmicos y de composición, la rapidez de formación de cada fase, la perturbación durante la medición, etcêtera.

La investigación experimental junto con la de los modelos para la interpretación objetiva de los resultados experimentales mejora el conocimiento del equilibrio entre fases de las sustancias puras reales y contribuye al avance de la Metrologia, de la Física y de la Química.

\section{B. La escala internacional de temperatura y el equilibrio entre fases}

La Escala Internacional de Temperatura de 1990 (EIT-90), consiste en puntos fijos de definición, instrumentos y reglas de interpolación. La EIT-90 está definida desde $0,65 \mathrm{~K}$ hasta la más alta temperatura prácticamente mensurable y dividida en intervalos de acuerdo al tipo de termómetro que se emplea para su interpolación: de 0,65 K a 24,556 K se emplean termómetros de gas, de 13,803 $\mathrm{K}$ a $1234,93 \mathrm{~K}$ termómetros de resistencia de platino y para temperaturas mayores a 1234,93 $\mathrm{K}$ se define en función de la ley de radiación de Planck [4]. 
La EIT-90 define la temperatura (T90) de 17 puntos fijos (tabla I). De esos, 14 son equilibrio entre fases (puntos triples, de solidificación o de fusión) de sustancias puras. Los valores de temperatura asignados a los puntos fijos son indistinguibles, dentro de la incertidumbre, a las mejores determinaciones termodinámicas de los mismos [5].

En la reproducción de los puntos fijos, definidos en función de equilibrios entre fases, se usan muestras de la más alta pureza disponible [5]. No obstante, toda muestra tiene residuos o trazas de impurezas. Una manera de trabajar con tales muestras es considerarlas como muestras de soluciones en las cuales el disolvente es la sustancia pura y el soluto está compuesto por las impurezas.

Tabla I. Puntos fijos de definición de la EIT-90. En la segunda columna se presentan los valores asignados, en la tercera y cuarta la incertidumbre en su determinación termodinámica $\mathrm{y}$ con termometria secundaria [5].

\begin{tabular}{|c|c|c|c|}
\hline Punto Fijo (estado) & $T_{90} / \mathrm{K}$ & $\Delta \mathbf{T}_{1} / \mathbf{m K}$ & $\Delta \mathbf{T}_{2} / \mathbf{m K}$ \\
\hline He (vapor) & $3-5$ & 0,3 & 0,1 \\
\hline e- $\mathrm{H}_{2}$ (triple) & 13,8033 & 0,5 & 0,1 \\
\hline e- $\mathrm{H}_{2}$ (vapor) & $\approx 17$ & 0,5 & 0,2 \\
\hline e- $\mathrm{H}_{2}$ (vapor) & $\approx 20,3$ & 0,5 & 0,2 \\
\hline Ne (triple) & 24,5561 & 0,5 & 0,2 \\
\hline $\mathrm{O}_{2}$ (triple) & 54,3584 & 1 & 0,1 \\
\hline Ar (triple) & 83,8058 & 1,5 & 0,1 \\
\hline Hg (triple) & 234,3156 & 1,5 & 0,05 \\
\hline $\mathrm{H}_{2} \mathrm{O}$ (triple) & 273,16 & 0 & 0,02 \\
\hline Ga (fusión) & 302,9146 & 1 & 0,05 \\
\hline In (solidificación) & 429,7485 & 3 & 0,1 \\
\hline Sn (solidificación) & 505,078 & 5 & 0,1 \\
\hline Zn (solidificación) & 692,677 & 13 & 0,1 \\
\hline Al (solidificación) & 933,473 & 25 & 0,3 \\
\hline Ag (solidificación) & 1234,93 & 40 & 1010 a \\
\hline Au (solidificación) & 1064,18 & 50 & 10 \\
\hline $\mathrm{Cu}$ (solidificación) & 1084,62 & 60 & 15 \\
\hline
\end{tabular}

a $1 \mathrm{mK}$ si se usa termometria de resistencia de platino y $10 \mathrm{mK}$ en caso de termometria de radiación

Así, los valores experimentales de la temperatura ( $\left.T_{\exp }\right)$ de la realización de los puntos fijos, tienen que ser corregidos para obtener la temperatura correspondiente a la sustancia pura ideal o teórica $\left(T_{0}\right)$, para hacerlo es necesario contar con un modelo. 
El problema complementario de la reproducción de los puntos fijos de la EIT-90 es el de la determinación de la pureza de materiales a partir de su comportamiento durante la solidificación o fusión: análisis térmico (la única diferencia que hacemos, en este estudio, entre fusión y solidificación es la dirección en la que se realiza el cambio de fase: fusión, si es de sólido a líquido y solidificación en la dirección contraria).

Al medir la temperatura de fusión de una muestra, se observa que la temperatura depende de la proporción de la cantidad de sustancia líquida con respecto al total de la muestra. En este contexto definimos "curva de fusión" a aquella que se obtiene al graficar los valores de temperatura $\left(T_{\exp }\right)$ como función de la fracción líquida $(F)$ de la muestra.

Existen básicamente dos técnicas para obtener curvas de fusión: calorimetria adiabática y fusión continua. En los experimentos que hemos realizado [6], encontramos que la técnica de calorimetria adiabática tiene mejor reproducibilidad. De donde hemos aplicado esta técnica en los experimentos descritos en la tesis.

Por otro lado, afirmamos que es la presencia de las impurezas y su distribución en las fases, durante la fusión o la solidificación, la que genera y determina el perfil de las curvas de fusión. De donde, los modelos que discutiremos, están basados sobre una hipótesis de cómo se distribuye el soluto en las fases.

El estado del arte en este campo se puede apreciar a partir de las siguientes dos referencias. En 1957, la Unión Internacional de Química Pura y Aplicada (IUPAC) organizó un simposio sobre "Control de Pureza via Análisis Térmico" [7]. En la clausura de la reunión el profesor J. G. Aston hizo la siguiente moción: “... es evidente que una curva de fusión (o de solidificación) no siempre es un criterio confiable de pureza. Por lo tanto el Simposio sobre Control de Pureza via Análisis Térmico recomienda como resultado de la reunión que este hecho sea reconocido...”. 
En 1999, el grupo 1 del Comité consultatif de thermometrie (CCT) publicó, para su $20^{a}$ reunión, el documento On the influence of impurities on fixed-point temperatures [8] en el cual una de sus conclusiones es: "En virtud de la carencia de datos suficientes del comportamiento de las impurezas en los materiales de los puntos fijos de definición, para asignar la calidad de la realización de los puntos fijos al más alto nivel de exactitud, es crucial comparar directamente las celdas de los puntos fijos que han sido construidas con materiales de diferentes fuentes (si existen) o aquellos que tienen diferentes purezas". En la última reunión del CCT [9] se recomendó con la investigación en el tema.

Los modelos teóricos disponibles para interpretar los resultados de los experimentos no son satisfactorios. En consecuencia, si el más alto nivel de exactitud, de la reproducción de la EIT-90, sólo se puede lograr vía la comparación de artefactos, entonces la objetividad de la Escala es cuestionable. Así la EIT-90 sólo provee la guía para obtener buenas referencias termométricas pero, falla en su propósito al carecer de modelos adecuados para la evaluación de errores sistemáticos, generados por el contenido de impurezas en las muestras. Por ello, como parte de esta tesis proponemos un nuevo modelo llamado el "modelo compuesto", describimos los experimentos realizados y sus resultados, que junto los experimentos de otros autores, permiten poner a prueba el modelo, además de proveer información directa de valor para los sistemas estudiados.

Para proveer el contexto de nuestra propuesta, en el capitulo I, revisamos algunos modelos que se emplean tanto en la termometria primaria como en crioscopia. Estos modelos son aplicables a soluciones binarias o pseudobinarias. El modelo compuesto lo construimos con el modelo de gradiente de concentración en la porción sólida y la ley de distribución de Nernst. El modelo compuesto es aplicable al caso cuando se conocen los componentes de las impurezas y su efecto en la fusión de soluciones binarias: cada componente de las impurezas en solución con la sustancia pura. Para el 
caso en que se desconocen los componentes de la solución, o su efecto en el proceso de fusión, entonces el modelo compuesto se ha simplificado para tratar una solución multicomponente como una solución pseudoternaria.

En el capitulo II revisamos las dos técnicas principales para la medición de temperatura de equilibrio entre fases: calorimetria adiabática y fusión continua. Se presentan ejemplos de mediciones del punto triple de mercurio, con varios aparatos para su realización, y se contrastan sus resultados.

En el capítulo III aplicamos los modelos compuesto y pseudoternario al equilibrio entre fases de soluciones de gases nobles en oxígeno.

En la primera parte del capítulo IV presentamos un resumen del avance de la reproducción de la EIT-90 en México; mostramos, como ejemplo, el trabajo realizado en el punto triple de argón. En la segunda parte presentamos un ejercicio hecho con una celda de punto triple de xenón.

En el capitulo V presentamos ejemplos de aplicación del modelo pseudoternario en la determinación de pureza por análisis térmico. Se analizan datos obtenidos en un calorimetro diferencial de barrido (DSC) para muestras de indio usadas en la calibración y puesta a punto de esos aparatos. En la segunda parte de este capítulo presentamos los resultados obtenidos en la estimación de impurezas en una muestra de zinc, donde el análisis se hace a datos obtenidos con la técnica de fusión continua.

\section{Referencias}

1. International vocabulary of basic and general terms in metrology (1993). Bureau International des Poids et Measures, Paris, Francia. 
2. E. Méndez Lango (1997). Sobre el quehacer de la Metrología. Notas de curso CENAM. Querétaro, México.

3. F. del Río (1990). Medición y comprensión del mundo fisico. El Arte de Investigar. Universidad Autónoma Metropolitana. Iztapalapa, México.

4. H. Preston-Thomas (1990). The International Temperature Scale of 1990 (ITS90). Metrologia 27, 3-10,107. Paris, Francia.

J. M. Figueroa Estrada, J. Valencia Rodriguez, E. Méndez Lango, E. Martines López (1994). Escala Internacional de Temperatura de 1990 (EIT-90). Reporte Técnico CNM-MET-PT-0004. CENAM, Querétaro, México.

5. Supplementary Information for the International Temperature Scale of 1990 (1990). Bureau International des Poids et Measures, Paris, Francia.

6. E. Méndez Lango, J. Ancsin (1996). Triple Point and Melting Point of Mercury. Thermochimica Acta 287, 183-190. Amsterdam, Países Bajos.

7. J. G Aston (1957). Motion. En Purity Control by thermal analysis. Editado por W. M. Smit. Elseiver Publishing Co., p. 180. Amsterdam, Paises Bajos.

8. B. W. Mangum, P. Bloembergen, B. Fellmuth, P. Marcarino, A. I. Pokhodum (1999). On the influence of impurities on fixed-point temperatures. CCT99-11. Comite Consultatif de Thermometrie, 20me sesion. Paris Francia

9. La $20^{a}$ reunión del CCT se realizó del 12 al 14 de abril de 2000 en el BIPM, en Paris, Francia. 


\section{CAPÍTULO UNO \\ CURVAS DE FUSIÓN Y SUS MODELOS}

\section{I.1 Introducción}

En este capitulo propondremos el modelo compuesto para la interpretación de las curvas de fusión de sustancias puras reales. La descripción la iniciamos con la aproximación de una sustancia pura real (con trazas de impurezas) a una solución donde la sustancia pura es el disolvente y las impurezas el soluto. Revisaremos los modelos que actualmente se emplean. Estos modelos se construyen sobre la base de una hipótesis de cómo se distribuye el soluto en las fases sólida y liquida. El primer modelo (termodinámico o de Mastrangelo) considera que se alcanza el equilibrio termodinámico en la fusión o solidificación. El modelo $1 / F$ o de van't Hoff lo obtendremos como un caso particular del anterior. Posteriormente, deduciremos el modelo de gradiente de concentración o de Gulliver el cual considera que sólo se alcanza el equilibrio térmico pero no el termodinámico: se generan gradientes de concentración en la fracción sólida durante su formación. Finalmente, emplearemos este modelo y la Ley de distribución de Nernst para construir el modelo compuesto y su simplificación que da origen al modelo pseudoternario.

\section{I.2 Equilibrio entre las fases sólida y liquida de soluciones}

La descripción del experimento de equilibrio entre las fases sólida y líquida de una sustancia pura real la aproximaremos a la de una solución donde el 
disolvente es la sustancia pura y el soluto está compuesto por las impurezas. Consideraremos el caso general en el que tanto la fase líquida como la sólida son soluciones.

Supongamos que tenemos una muestra de una solución en dos fases: sólida y líquida. Definimos a la fracción liquida $(F)$ de la muestra como la cantidad de sustancia de la solución en estado líquido $\left(b_{l}\right)$ con respecto a la cantidad de sustancia total de la solución,

$$
F=\frac{b_{l}}{b_{l}+b_{s}}
$$

donde, $b_{s}$ es la cantidad de sustancia de la solución en estado sólido.

En el proceso de fusión de una solución sólida, observamos que la temperatura $T$ depende de la fracción liquida $F$ : la temperatura aumenta conforme $F$ aumenta. Al graficar los valores de $T(F)$ contra $F$ obtenemos una curva: la curva de fusión. Por ejemplo, en la fig. I.1 se muestran puntos experimentales de la fusión de una muestra de argón. El experimento se realizó en un crióstato adiabático diseñado para la calibración de termómetros de resistencia de platino (TRP) de tallo largo [1]. El TRP tiene resistencia nominal de $25,5 \Omega$ en el punto triple de agua con sensibilidad, a la temperatura del punto triple de Ar, de $0,11 \Omega / \mathrm{K}$.

Como primera aproximación, vamos a trabajar con una solución binaria: el soluto compuesto por una sola especie. A partir del diagrama de fases temperatura - concentración $(T-x)$ de la solución, y con diferentes hipótesis de cómo se distribuye el soluto en las fases, para diferentes valores de $F$, obtendremos diferentes modelos para describir la curva de fusión. 


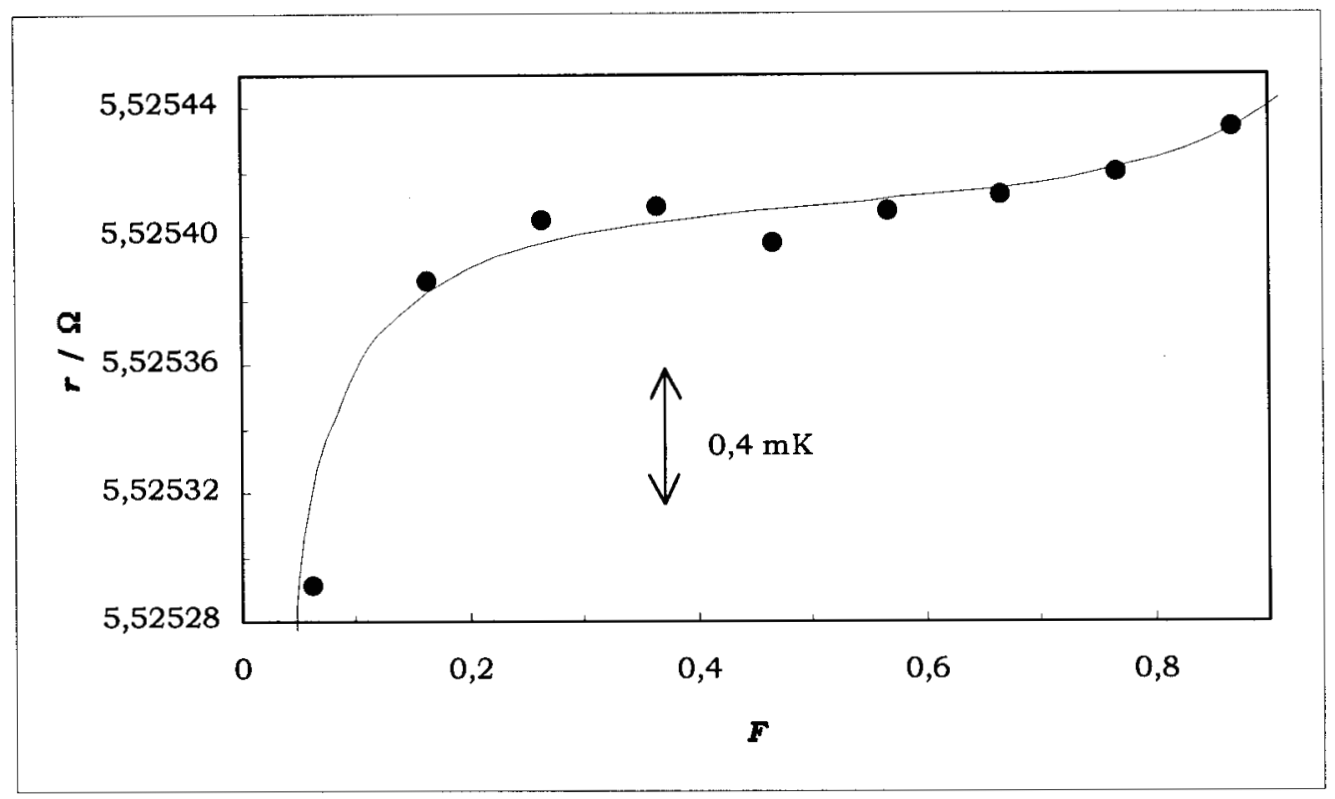

Figura 1.1. Curva de fusión de una muestra de argón. La temperatura se midió con un termómetro de resistencia eléctrica de platino. La escala vertical completa equivale a 1,6 $\mathrm{mK}$. La linea ajustada a los datos experimentales se calculó con el modelo pseudoternario que se verá al final del capitulo.

Las hipótesis que trataremos son tres:

i) las fracciones de la cantidad de sustancia (o molares [2]) de soluto en las fases sólida y líquida $\left(x_{\mathrm{s}}\right.$ y $\left.x_{1}\right)$ es la que resulta del equilibrio termodinámico;

ii) la fase sólida está compuesta por el disolvente puro y

iii) al alcanzar el equilibrio térmico la fase líquida es homogénea en concentración y está en equilibrio térmico con un sólido en el que existen gradientes de concentración.

En la siguiente sección desarrollaremos los términos comunes a los modelos. 


\section{I.2.1 Términos generales}

Las curvas en un diagrama de fases $T-x$ de una solución binaria, representan los valores de temperatura y los valores de equilibrio para las fracciones de cantidad de sustancia de soluto en las fases sólida $\left(x_{s}\right)$ y liquida $\left(x_{l}\right)$. Por ejemplo, en la figura I.2, $T_{\mathrm{e}}$ es la temperatura a la que la fase sólida, con fracción de cantidad de sustancia de soluto $x_{\mathrm{s}, e}$, está en equilibrio termodinámico con la fase líquida con fracción de cantidad de sustancia de soluto $x_{l, \text { e. }}$ La línea sobre la que están los puntos $T_{\mathrm{A}}, \mathrm{c}, \mathrm{d}$ y $T_{\mathrm{B}}$ es la linea liquidus; la que está sobre los puntos $T_{\mathrm{A}}$, a, b y $T_{\mathrm{B}}$ es la línea sólidus.

Definimos el coeficiente de distribución $k$ como el cociente de la fracción de cantidad de sustancia de soluto en el sólido dividida por la fracción de cantidad de sustancia de soluto en el líquido, i.e.

$$
k=\frac{x_{s, e}}{x_{l, e}}
$$

En la fig. I.2, se representa el caso en el que la presencia del soluto B "eleva" el punto de fusión del disolvente A, i.e. la temperatura de fusión de la solución es más alta que la del disolvente $\left(T_{\mathrm{A}}\right)$. En el otro extremo del diagrama, la presencia del soluto $A$ en el disolvente $B$ describe una solución con un punto de fusión más bajo $T_{\mathrm{B}}$, i. e. la presencia del soluto "abate" el punto de fusión del disolvente o el intervalo de fusión de la solución está por debajo de $\mathrm{T}_{\mathrm{B}}$.

Si bien el diagrama de la fig. I.2 representa el equilibrio termodinámico entre las fases, también se puede usar para describir la transición de fases de la solución via un proceso cuasiestático. 


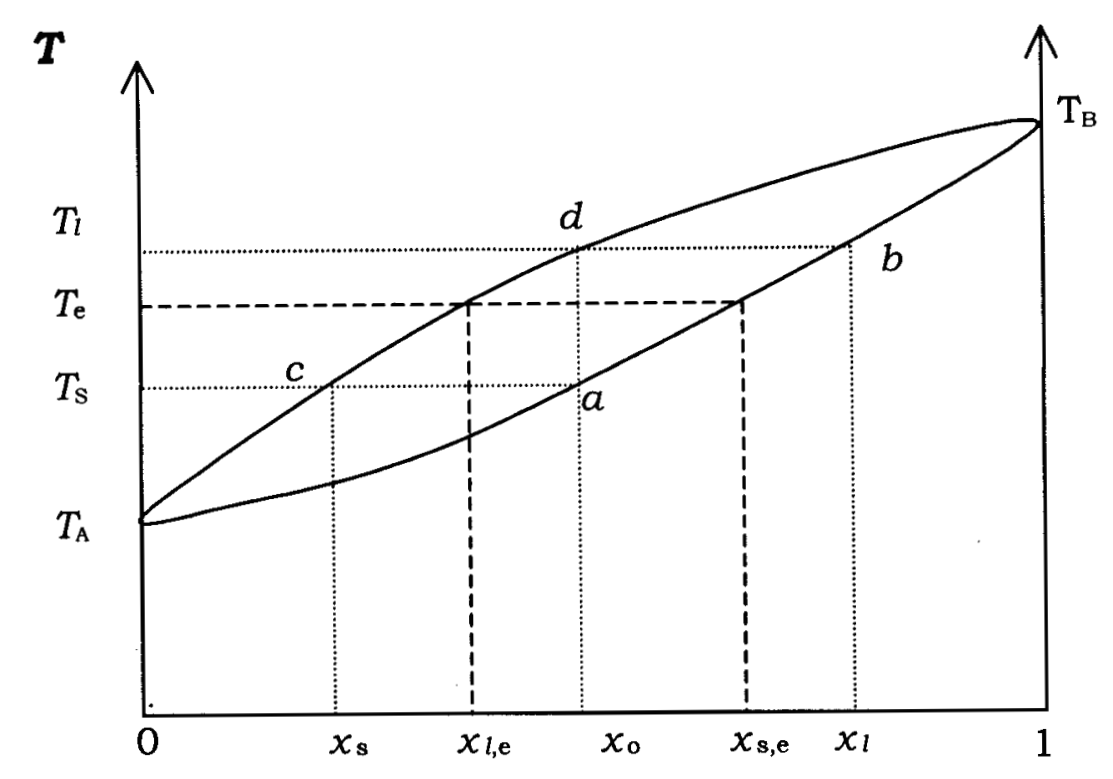

fracción de cantidad de sustancia de B

Figura I.2. Diagrama de fases $T-x$ de una mezcla binaria (componentes A y B) a presión constante. A la temperatura de equilibrio $T_{\mathrm{e}}$, la mezcla tiene los valores de fracción de cantidad de sustancia de $\mathrm{B}, x_{\mathrm{s}, \mathrm{e}} \mathrm{y} x_{l, \mathrm{e}}$ en las fases sólida y liquida, respectivamente.

Supongamos que se tiene una solución con disolvente $A$, con $x_{0}$ fracción de cantidad de sustancia de soluto B y en estado sólido. Se calienta la muestra hasta que aparece la primera porción liquida, a la temperatura $T_{\mathrm{s}}$ (punto $a$ en el diagrama, fig. 1.2). En este punto el resto de la muestra en estado sólido está en equilibrio con la porción líquida; si la porción líquida es infima, con respecto al total de la muestra, entonces $T_{\mathrm{s}}$ es el punto sólidus. Por otro lado, si inicialmente la muestra es liquida y se enfría, entonces a la temperatura $T_{l}$, (punto $d$ ) aparecerá la primera porción sólida, que si es infima entonces $T_{l}$ es el punto liquidus. Se observa que $T_{l}$ es mayor o igual que $T_{\mathrm{s}}$. Al intervalo $T_{l}-T_{s}$ se le llama intervalo de fusión. Este intervalo se emplea como criterio de pureza: el menor valor del intervalo la máxima pureza. Deducimos así que, no existe el punto de fusión de una solución binaria sino un intervalo de fusión limitado por los puntos sólidus y líquidus. Además, el punto de fusión del disolvente puro $T_{\mathrm{A}}$ no está contenido en este intervalo. 


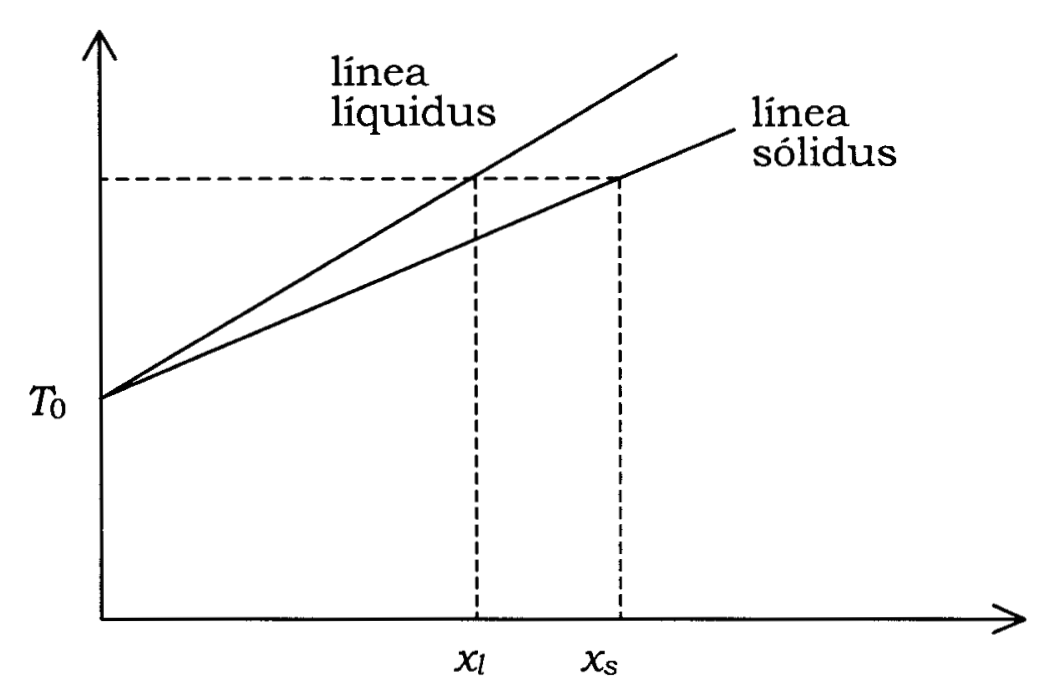

fracción de cantidad de sustancia de soluto

Figura I.3. Diagrama de fases $T-x$ (a presión constante) para una mezcla binaria en el limite de alta pureza. $T_{0}$ es el punto de fusión del disolvente puro.

En el limite de alta pureza (fig. I.3) las curvas líquidus y sólidus se pueden aproximar por lineas rectas, equivalente a una aproximación de primer orden de un desarrollo de serie de Taylor alrededor del punto $x=0$, para obtener

$$
\begin{aligned}
T_{l}\left(x_{l}\right) & =T_{l}(0)+T_{l}^{\prime}(0)\left(x_{l}-0\right) \\
\mathrm{y} & T_{s}\left(x_{s}\right)=T_{s}(0)+T_{s}^{\prime}(0)\left(x_{s}-0\right)
\end{aligned}
$$

A la temperatura de equilibrio $T_{\mathrm{e}}$, se cumple que $T_{l}$ y $T_{\mathrm{s}}$ tienen el mismo valor, a partir de la ec. I.3 se obtiene

$$
\begin{aligned}
x_{s} & =\left(\frac{C_{l}}{C_{s}}\right) x_{l}, \\
0 \quad x_{s} & =k x_{l},
\end{aligned}
$$


donde $C_{l}=T_{l}^{\prime}(0), C_{s}=T_{s}^{\prime}(0)$ y $k$ (coeficiente de distribución) es el cociente de las pendientes de las rectas aproximadas a las curvas líquidus y sólidus evaluadas en $x=0$.

La ecuación propuesta por van't Hoff [3] para el caso en que la fase sólida es una solución es

$$
\frac{d T}{d x}=\frac{1}{A}(k-1)
$$

donde $A$ es la primera constante crioscópica definida por

$$
A=\frac{\Delta_{\text {fus }} H_{m}}{R T_{0}^{2}}
$$

donde $\Delta_{f u s} H_{m}$ es cambio de la entalpia por mol en la fusión, $R$ la constante de los gases y $T_{0}$ la temperatura absoluta de solidificación del disolvente.

Así, encontramos que

$$
C_{l}=\frac{k-1}{A}
$$

De la ec. I.7 muestra que la pendiente de la curva líquidus $\left(C_{l}\right)$ depende, de la constante crioscópica del disolvente y del coeficiente de distribución $(k)$ que, a su vez, depende del sistema binario disolvente-soluto en particular. Este resultado es contrario a lo que algunos autores afirman: $C_{l}$ sólo depende de la constante crioscópica del disolvente [4].

De las ecuaciónes I.4 y I.7 obtenemos la relación entre $C_{s}, C_{l}$ y $A$ : 


$$
A=C_{s}^{-1}-C_{l}^{-1}
$$

La relación I.8 tiene una aplicación práctica que usaremos en el tratamiento de datos experimentales: basta con conocer uno de los parámetros $C_{s}, C_{l} \circ \mathrm{ky}$ los otros dos quedan determinados vía la constante crioscópica $A$.

Al sustituir la ec. I.7 en I.4 obtenemos la expresión de la recta aproximada a la curva líquidus

$$
T_{l}\left(x_{l}\right)=T_{0}+\frac{(k-1)}{A} x_{l}
$$

Para cada solución $k$ tendrá un valor particular en el intervalo desde cero hasta $+\propto$. El valor de $k$ indica dónde se encuentra el intervalo de fusión $(\Delta T)$ de la solución con respecto al punto de fusión del disolvente $T_{0}$ : Si $k$ es mayor que uno, entonces $\Delta T$ está por arriba de $T_{0} \mathrm{y}$, si $k$ es menor que uno, entonces $\Delta T$ está por debajo de $T_{0}$.

Discutiremos ahora tres casos especiales: $k=1, k=0$ y $k \rightarrow+\infty$.

El primer caso se da cuando las líneas sólidus y líquidus tienen la misma pendiente. Si las pendientes son iguales a cero entonces, por un lado $k$ está indefinido y por otro lado las sustancias A como B tienen el mismo punto de fusión y la presencia de B en A (y viceversa) no afecta el punto de fusión del disolvente. Un ejemplo trivial de este caso es cuando A y B son una y la misma sustancia. Si las pendientes son diferentes a cero y dado que el punto $T_{0}$ es común a las rectas entonces las dos rectas son una misma: En el equilibrio ambas fases tienen la misma concentración, su intervalo de fusión es cero (similar al de una sustancia pura) y su punto de fusión es distinto a $T_{0}$. Así, $k=1$ es una línea eutéctica en el diagrama $T-x$. Pero, de acuerdo al primer teorema de Gibbs-Konoválov [5]: "la temperatura de coexistencia de un sistema binario, pasa por un valor extremo (máximo, mínimo o punto de inflexión con 
tangente horizontal) si la concentración de las fases es la misma" o "si, a presión constante, la temperatura de coexistencia pasa por un valor extremo, entonces las dos fases deben tener la misma concentración”. Deducimos que el caso $k=1$ está excluido porque sobre una línea recta con pendiente diferente de cero no hay valores extremos con pendiente cero, es decir, no existen lineas eutécticas. Adicionalmente, por un lado la constante crioscópica $A$ es mayor cero (ec. I.6) pero, por otro lado si $C_{s}$ es igual a $C_{l}$, entonces A es igual con cero lo que es contradictorio. Concluimos pues que la curva líquidus (o sólidus) no pueden ser aproximada por la ec. I.3 si en su vecindad, alrededor del límite de alta 'pureza, existe $\mathrm{n}$ punto eutéctico.

El segundo caso $(k=0)$ es el límite del caso $k<1$ el cual se presenta si la línea sólidus tiende al eje vertical del diagrama de fases o la pendiente de la línea líquidus tiende a cero. Se presenta entonces la segregación total del soluto del sólido hacia el líquido durante la solidificación: el sólido está formado por el disolvente puro.

El caso $k \rightarrow+\infty$ es el límite de $k>1$. Sucede cuando la linea líquidus tiende al eje vertical del diagrama de fases o la pendiente de la linea sólidus tiende a cero. Se presenta entonces la segregación total del soluto del líquido al sólido durante la solidificación, y se presenta la precipitación del soluto puro.

\section{I.3 Modelo de equilibrio termodinámico $[3,6]$}

Sea una muestra de una solución binaria con disolvente A y fracción de cantidad de sustancia $x_{0}$ de soluto B (fig.I.2). Si al inicio la temperatura de la solución es tal que toda ella es líquida y que está rodeada por paredes adiabáticas excepto en una sección donde se puede intercambiar la pared adiabática por una diatérmica y viceversa. En la parte exterior de esta sección 
se tiene una fuente térmica a temperatura $T_{\mathrm{f}}$ más baja que la del punto de solidificación de la muestra. Se coloca la pared diatérmica y se observa que la temperatura de la solución disminuye. Se continúa el proceso hasta que aparece la primera porción sólida (punto $d$ ) en ese momento se coloca la pared adiabática entre la fuente y la muestra, se deja que ésta alcance el equilibrio termodinámico $\mathrm{y}$, finalmente, se toma la lectura de la temperatura de equilibrio.

Se continúa con el proceso colocando la pared diatérmica un intervalo de tiempo $\Delta t$, después se coloca nuevamente la pared adiabática y se le permite a la solución que alcance su nuevo equilibrio termodinámico; Se toma el valor de la temperatura y se vuelve a repetir el proceso. En cada paso la fracción de cantidad de sustancia de soluto en ambas fases cambia y la temperatura de equilibrio también. Los cambios de temperatura y fracción de la cantidad de sustancia de soluto de la porción sólida describen la línea sólidus desde el punto $b$ (punto líquidus) hasta el punto $a$ (fig. I.2). Similarmente, para la fase líquida los cambios en la temperatura y su fracción de cantidad de sustancia de soluto describen sobre la línea líquidus, desde el punto $d$ hasta el punto $c$ (punto líquidus).

Para obtener el modelo correspondiente al equilibrio termodinámico de las fases, vamos a considerar una solidificación "paso a paso". En cada paso una fracción $b$ de cantidad de sustancia de la solución se solidifica y se espera hasta que se alcance el equilibrio entre las fases. Si $B$ es la cantidad de sustancia total de la solución entonces la cantidad de sustancia total de soluto $\left(B x_{0}\right)$ es constante e igual a la suma de la cantidad de sustancia de soluto que hay en la porción sólida más la que hay en la líquida. Después de n pasos se tiene

$$
B x_{0}=b x_{s, 1}+b x_{s, 2}+\cdots+b x_{s, n}+(B-n b) x_{l}(n) \quad,
$$

donde $b x_{s, i}$ es la cantidad de sustancia de soluto contenida en la i-ésima 
porción sólida y $x_{l}(n)$ es la fracción de cantidad de sustancia de soluto en el líquido restante después de $n$ porciones sólidas formadas.

Si se espera a que relaje el gradiente en concentración después de que cada porción $b$ de sólido es formada, entonces la fracción de cantidad de sustancia de soluto es la misma para todas las porciones y la ec. I.10 se puede escribir como

$$
\begin{aligned}
B x_{0} & =n b x_{s}(n)+(B-n b) x_{l}(n) \\
\circ \quad B x_{0} & =n b k x_{l}(n)+(B-n b) x_{l}(n)
\end{aligned}
$$

La fracción líquida de la muestra de la solución $F$ la expresamos como

$$
F=1-n \frac{b}{B}
$$

Al despejar $x_{l}$ de la ec. I.12, y emplear esta expresión de $F$, obtenemos

$$
x_{l}(F)=\frac{\frac{x_{0}}{1-k}}{\frac{k}{1-k}+F},
$$

La ec. I.14 se sustituye en la ecuación de la recta liqquidus (I.3) para obtener

$$
T_{l}(F)=T_{0}-\frac{1}{A} \frac{x_{0}}{\frac{k}{1-k}+F}
$$

Los parámetros $T_{0}, x_{o}$ y $k$ de la ec. I.15 se ajustan a los datos experimentales. Este modelo fue propuesto por Mastrangelo en 1955 [6] como una corrección al 
modelo de segregación total del soluto de la fase sólida o $1 / F$ para el caso cuando el sólido es también una solución y está en equilibrio termodinámico con la fase liquida.

En su trabajo Mastrangelo señala que su modelo es útil para estimar $T_{0}$, con incertidumbre de décimas de grado. Esta incertidumbre está lejos de ser adecuada para los experimentos que se presentarán más adelante, en los que se tienen incertidumbres, en $T$, del orden de diez milésimas de grado: tres órdenes de magnitud mejor que la estimación de Mastrangelo. También, como el mismo autor señala, este modelo sólo aplica a soluciones binarias.

Experimentalmente, la condición de equilibrio químico en el sólido, es prácticamente imposible de alcanzar. Los tiempos característicos de los experimentos de fusión o solidificación (del orden de horas) son mucho más cortos que los requeridos para la relajación de los gradientes de concentración en el sólido, del orden de años [7].

\section{I.4 Modelo 1/F o de van't Hoff $[3,4]$}

El modelo $1 / F$ (referido por algunos autores como de van't Hoff [4]) se obtiene como caso particular del termodinámico. Este modelo considera que en el proceso de solidificación el soluto es segregado del sólido a la fase líquida $(k=0)$. Su expresión es

$$
T_{l}(F)=T_{0}-\frac{1}{A} \frac{x_{0}}{F}
$$

La hipótesis $k=0$ significa: a) los intervalos de fusión siempre estarán a una temperatura más baja que $T_{0}$; y b) toda mezcla binaria tiene al menos un punto 
eutéctico.

\section{I.5 Modelo de gradiente de concentración en la porción sólida o de Gulliver [8]}

En un experimento de solidificación a pasos, el tiempo que tarda la muestra en alcanzar el equilibrio térmico, después de haber sido perturbada, es del orden de minutos. En este lapso es prácticamente imposible que relajen los gradientes de concentración en la porción sólida. Por otro lado, en este tiempo es posible que los gradientes en la porción líquida relajen via los procesos de convección y difusión. En el tercer modelo vamos a incorporar estos dos aspectos: la inmovilidad del soluto en la solución sólida y la homogeneidad de la fase liquida.

Supongamos que la solución es líquida y que tiene concentración inicial $x_{l, 0}$; al formarse la primera porción sólida $b_{\mathrm{s}, 1}$ parte del soluto es segregado del sólido al líquido $(k<1)$ hasta que la porción sólida y el líquido restante alcanzan sus composiciones de equilibrio: $x_{s, 1}$ y $x_{l, 1}$, respectivamente. En este caso la concentración $x_{l, 1}$ del líquido restante es mayor que la inicial $x_{l, 0}$. Al realizarse el siguiente paso, la nueva porción sólida tendrá la concentración $x_{\mathrm{s}, 2}$ que le corresponda estar en equilibrio con la fase líquida de concentración $x_{1,1}$, de manera que $x_{s, 2}>x_{s, 1}$ i. e. la porción sólida que se forma en un paso tiene una concentración mayor de soluto que la formada en el paso anterior: se construye un gradiente de concentración en el sólido a medida que éste crece.

Para construir el modelo partimos de la ec. I.10

$$
B x_{0}=b x_{s, 1}+b x_{s, 2}+\cdots+b x_{s, n}+(B-n b) x_{l}(n) \quad,
$$


la cual podemos escribir como

$$
B x_{0}=b \sum_{1}^{n} x_{s, i}+(B-n b) x_{l}(n)
$$

al expresar $x_{s}$ en función de $x_{l}$, se tiene

$$
B x_{0}=n b k\left[\frac{1}{n} \sum_{1}^{n} x_{l, i}\right]+(B-n b) x_{l}(n),
$$

donde $\frac{1}{n} \sum_{1}^{n} x_{l, i}$ es la concentración promedio de la fracción liquida desde el inicio de la solidificación hasta el paso n. La ec. I.18 se puede emplear para obtener la ecuación de recurrencia de $x_{l, i}$.

La ec. I.18 se puede escribir en función de la fracción líquida $(F)$ como

$$
x_{0}=(1-F) k \overline{x_{l}}(F)+F x_{l}(F)
$$

donde $\overline{x_{l}}(F)$ es la concentración promedio del líquido desde el inicio de la solidificación hasta que se alcance la fracción liquida $F$.

La ec. I.19 la usaremos para obtener la expresión para el caso continuo $(b \rightarrow 0)$ :

$$
x_{0}=k \int_{1}^{1-F} x_{l}(y) d y+F x_{l}(F)
$$

resolvemos la ecuación integral y usamos con la condición inicial $x_{l}(1)=x_{0}$, para obtener 


$$
x_{l}(F)=x_{0} F^{k-1}
$$

El modelo de la ec. I.21 describe la concentración de la fase liquida como función de $F$. Este es el modelo de Gulliver [8] el cual se ha empleado principalmente en el desarrollo de técnicas de refinación por zonas de metales. El mismo modelo fue empleado por McLaren [9] para describir el perfil radial de concentración en muestras cilíndricas, de metales de alta pureza, solidificadas usando varias técnicas experimentales.

Sustituimos la ec. I.21 en la aproximación de la línea líquidus para obtener

$$
T_{l}(F)=T_{0}+\frac{k-1}{A} x_{0} F^{k-1}
$$

Al comparar las expresiones del modelo de Gulliver (I.22) con el de equilibrio termodinámico (I.15) observamos que convergen cuando $F$ tiende a uno i.e. son indistinguibles en el punto liquidus. Este hecho fortalece la propuesta de Ancsin de usar el valor de la temperatura en el punto líquidus como una característica de una muestra en particular [10]. Por otro lado, en el punto sólidus ( $F \sim 0$ ) los modelos divergen.

En sus experimentos McLaren encontró [9] que las muestras sólidas presentaban gradientes de concentración. Este hecho nos induce a considerar que el modelo de gradiente de concentración es el más adecuado para la descripción de las curvas de fusión, sin embargo este modelo está limitado a muestras de soluciones binarias o pseudobinarias. 


\section{I.6 Ley de distribución de Nernst [11]}

Si en una solución el soluto está compuesto por las especies $\mathrm{B}$ y $\mathrm{C}$ tal que la solución binaria del disolvente A con el soluto B tiene $k>1$ (su intervalo de fusión está a una temperatura más alta que el punto de fusiôn del disolvente $T_{0}$ ) y la solución binaria de A con $\mathrm{C}$ tiene $k<1$ (su intervalo de fusión está por debajo de $T_{0}$ ), entonces para la solución ternaria del disolvente $\mathrm{A}$ con el soluto compuesto por B y C, ¿cuál será el intervalo de fusión resultante? Para contestar la pregunta es necesaria una regla para sumar los efectos individuales de cada soluto en el disolvente A.

Un caso aún más general es cuando el soluto está compuesto por varios tipos de moléculas. Para tratar este caso vamos a aplicar la ley de distribución de Nernst: "si las moléculas de un componente del soluto tienen la misma masa molecular en ambas fases, entonces existe una razón de concentraciones $\left(x_{s} / x_{l}\right)$ en el sólido y en el líquido que depende únicamente de la presión y la temperatura y es independiente de la presencia de otros tipos de moléculas" [11]. En los modelos revisados el coeficiente de distribución $(k)$ determinan el perfil de la curva. Si el coeficiente de una especie que forma el soluto no es afectado por la presencia de otras especies entonces proponemos una forma simple de tratar el caso cuando el soluto está formado por varios especies: la suma de los efectos individuales de cada soluto.

\section{I.7 Modelo compuesto}

Con el modelo compuesto consideramos los casos cuando el soluto se compone por varias especies y durante la solidificación se forman gradientes de concentración en el sólido. En este modelo sintetizamos la idea de la existencia 
de gradientes de concentración, en la fracción sólida, con la de que la distribución de las moléculas de tipo $i$, componente del soluto, se distribuyen de acuerdo al coeficiente de distribución $k_{i}$ y no se ve afectado por la presencia de otro tipo de moléculas. Entonces, a partir de la ec. I.22, el modelo compuesto es:

$$
T_{l}(F)=T_{0}+\left(\frac{1}{A}\right)\left[\left(k_{1}-1\right) x_{1} F^{k_{1}-1}+\left(k_{2}-1\right) x_{2} F^{k_{2}-1}+\left(k_{3}-1\right) x_{3} F^{k_{3}-1}+\cdots\right] \quad, \text { I. } 23
$$

donde cada subíndice está asociado a una especie de moléculas que componen al soluto. Si se conocen los componentes del soluto y se dispone de los valores de los coeficientes de distribución, entonces este modelo tiene como parámetros ajustables $T_{0}$ y la fracción de cantidad de sustancia $x_{i}$ de cada componente del soluto.

\section{I.8 Modelo pseudoternario}

Este modelo es una aproximación al modelo compuesto que consiste en que una solución multicomponente es aproximada a una solución pseudoternaria, donde la sustancia pura es el disolvente y el soluto está compuesto por dos especies. En la solución los componentes del soluto tienen fracciones de cantidad sustancia $x+y \quad x$ y coeficientes de distribución $k+\mathrm{y} k$-, donde el símbolo " " se ha empleado para denotar al componente cuya solución binaria con el disolvente tiene el intervalo de fusión por arriba de $T_{0}$ y el signo ".” para el otro componente que en solución binaria tiene su intervalo de fusión por debajo de $T_{0}$. La ec. I.24 es la correspondiente al modelo pseudoternario. 


$$
T_{l}(F)=T_{0}+\left(\frac{1}{A}\right)\left[\left(k_{+}-1\right) x_{1} F^{k_{+}-1}+\left(k_{-}-1\right) x_{2} F^{k_{-}-1}\right]
$$

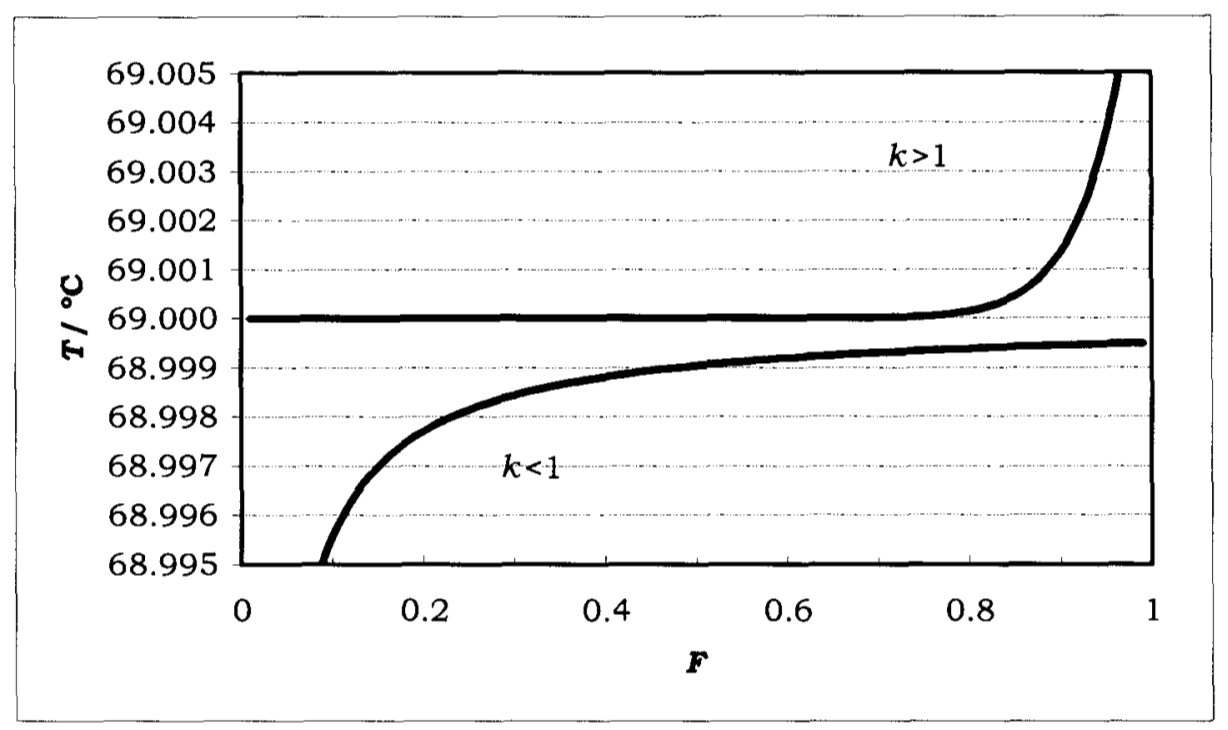

Figura 1.4. Curvas de fusión de acuerdo al modelo de gradiente de concentración. La fracción de cantidad de sustancia es en ambos casos $1 \times 10^{-5}$. Los valores de $k$ son 20 y 0,05 para $k>1$ y $k<1$, respectivamente.

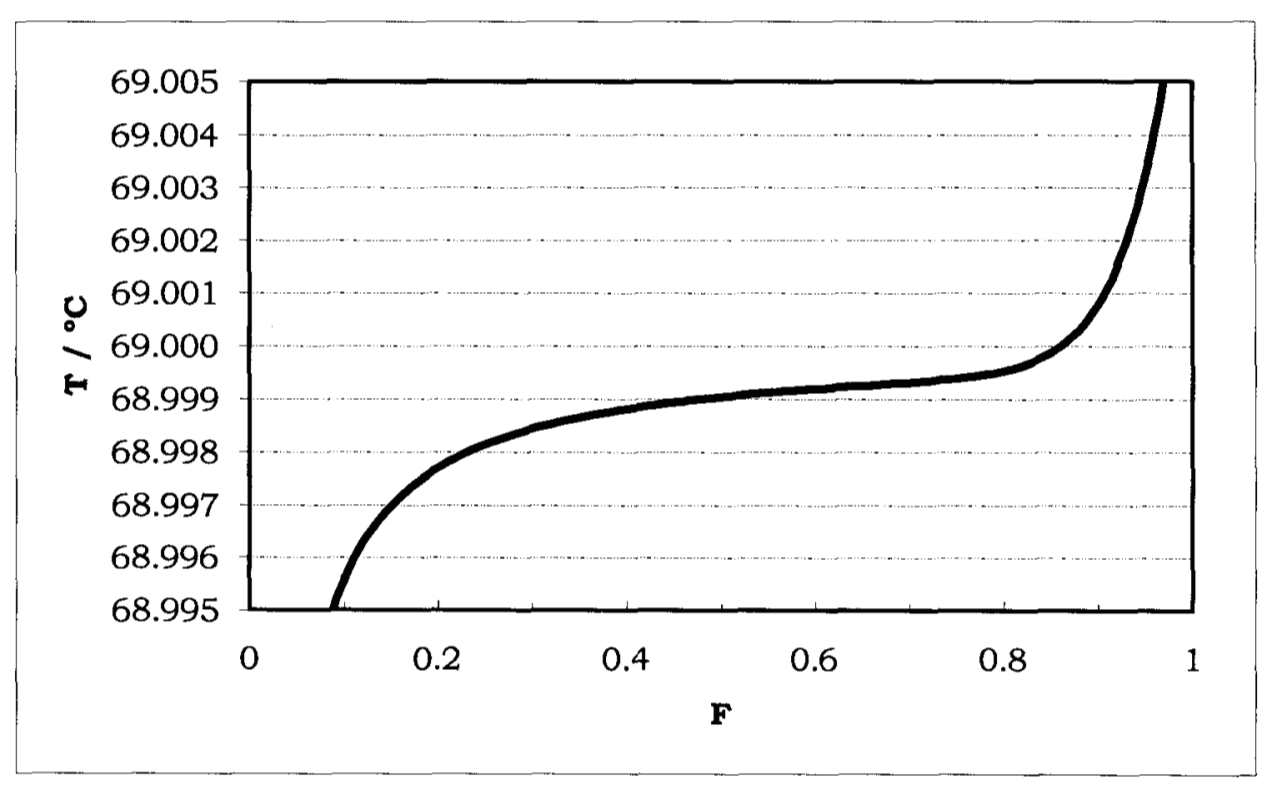

Figura I.5. Curva obtenida con el modelo pseudoternario, resultados de la suma de las curvas de la fig. I.4. 
En la fig. I.4 se presentan dos curvas para soluciones que tienen $A=0,019 \mathrm{~K}^{-1}$. La curva " $\mathrm{K}>1$ " corresponde a $x_{1}=1 \times 10-5$ con $k_{+}=20$ y la otra " $k<1$ " con $x_{2}=1 \times 10-5$ y $k=0,05$. Ambas con $\mathrm{T}_{0}=333,150 \mathrm{~K}\left(69,000^{\circ} \mathrm{C}\right)$. En la fig. I.5 se muestra la suma de estas dos curvas.

\section{I.9 Resumen}

Lo adecuado de un modelo está en función de su capacidad de describir los resultados experimentales. Si un componente del soluto tiene el mayor efecto sobre el intervalo de fusión de una solución multicomponente, entonces los modelos obtenidos para soluciones binarias (los primeros tres) pueden ser aplicados al aproximar la solución multicomponente a una pseudobinaria.

El modelo compuesto es aplicable si se conoce la composición química de la solución. En el siguiente capitulo se expondrá un método experimental para reducir el número de parámetros ajustables en este modelo, vía la determinación de $C_{l}$ por experimentos complementarios. Al medir $C_{l}, k$ está determinado $\mathrm{y}$, consecuentemente, el número de parámetros ajustables se reduce de $2 n+1$ a $n+1$ ( $n$ es el número de componentes en el soluto). Al igual que los modelos para soluciones binarias, el modelo pseudoternario puede ser empleado para aproximar la descripción de una curva de fusión de una solución multicomponente.

En la tabla I.I, presentamos los parámetros a calcular de acuerdo a cada modelo. 
Tabla I.I. Resumen de parámetros ajustables de los modelos de curvas de fusión.

\begin{tabular}{|c|c|c|}
\hline Modelo & Parámetros & Comentarios \\
\hline $\begin{array}{l}\text { Termodinámico } \\
\text { (ec. I.10) }\end{array}$ & $T_{0}, x, k$ & para $0<k<+\infty$. Para cualquier tipo de solución binaria. \\
\hline $\begin{array}{c}1 / F \\
\text { (ec. I.14) }\end{array}$ & $T_{0}, x$ & $k=0$. La fase sólida está compuesta por el disolvente puro. \\
\hline $\begin{array}{l}\text { Gradiente de } \\
\text { concentración } \\
\text { (ec. I. 21) }\end{array}$ & $T_{0}, x, k$ & $\begin{array}{l}\text { para } 0<k<+\infty \text {. Para cualquier tipo de solución binaria con } \\
\text { gradiente de concentración en la porción sólida. }\end{array}$ \\
\hline $\begin{array}{l}\text { compuesto } \\
\text { (ec. I.22) }\end{array}$ & $T_{0}, n(x, k)$ & $\begin{array}{l}\text { Se requiere el conocimiento de la composición química de } \\
\text { la solución; n es el número de componentes del soluto. } k \\
\text { puede ser medido en experimentos complementarios. }\end{array}$ \\
\hline $\begin{array}{c}\text { pseudoternario } \\
\text { (ec. 1.23) }\end{array}$ & $\begin{array}{l}T_{0}, x_{+}, k_{+}, x \\
k\end{array}$ & 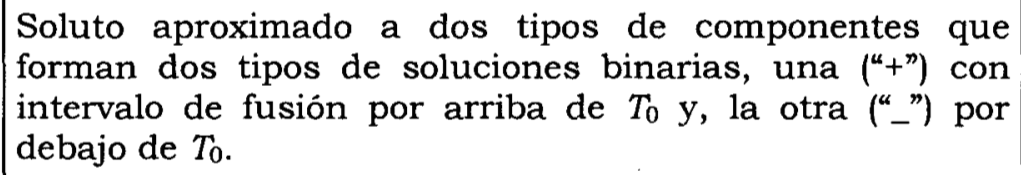 \\
\hline
\end{tabular}

\section{I.10 Referencias}

1. E. Méndez-Lango, J. Ancsin (1999) Argon triple point realization at CENAM, México. en $7^{\text {th }}$ International Symposium on Temperature and Thermal Measurements in Industry and Science. NMI Van Swinden Laboratorium. 84-88, Delft, Paises Bajos.

2. T. J. Quinn, I. M. Mills (1998) The use and abuse of the terms percent, parts per million and parts in 10n. Metrologia, 35, 807-810. Paris, Francia.

T. Cvitaš (1996). Quantities describing compositions of mixtures. Metrologia 33, 35-39. Paris, Francia.

3. G. N. Lewis, M. Randall (1961). Thermodynamics. Cap. 19. The Laws of the Dilute Solution, 231-241,. McGraw Hill Book Co.. Nueva York, Estados Unidos. 
4. B. W. Mangum, G. T. Furukawa (1990). Guidlines for realizing the International Temperature Scale of 1990 (ITS-90). Cap. 3.2.1 Effect of impurities, pp. 28-29. NIST Technical Note 1265. Washington, Estados Unidos.

Y. I. Alexandrov, A. G. Ivanova, A. I. Pokhodun (1993). On the definition of freezing Points of the ITS-90. Metrologia, 30, 49-52. Paris, Francia.

5. I. Prigogine, R. Defay (1954). Chemical Thermodynamics. Cap. XVIII, sec. 6 The Gibbs-Konovalow Theorems y sec.9 Identification of upper and lower critical solution temperatures, pp. 278-282 y 284-288. Longmans, Green and Co. LTD. Londres, Reino Unido.

6. S. V. R. Mastrangelo y R. W. Dornte (1955). Solid Solutions Treatment of Calorimetric Purity Data. J. Am. Chem. Soc.77, 6200-6201.

7. C. K. Ma (1995). Critical viewpoints on the methods of realizing the metal freezing points of the ITS-90. Rev. Sci. Instrum. 66 (8), 4233-4240. Nueva York, Estados Unidos.

8. W. G. Pfann (1958). Zone Melting. Cap. 2 Normal Freezing and the Distruibution Coefficient, 7-22. John Wiley \& Sons. Inc.. Nueva York, Estados Unidos.

G. H. Gulliver (1922). Metallic Alloys. Apendice The Effect of the rate of Cooling upon the Constitution of Binary Alloys, 307-426. Chas. Griffin and Co. Londres, Reino Unido.

9. F. Weinberg, E. H. McLaren (1963). The solidification of Dilute Binary Alloys. Transactions of the Metallurgical Society of AIME, 227, 112-124. Estados Unidos.

10. J. Ancsin (1970). The Triple Point of Oxygen and its Change by Noble Gas Impurities. Metrologia 6, 53-56. Paris, Francia.

11. M. Planck (1945). Treatise on Thermodynamics. Parte IV, Cap. V Dilute Solutions, 229-271. Dover Publications Inc. Nueva York, Estados Unidos. 


\section{CAPÍTULO DOS \\ TÉCNICAS EXPERIMENTALES}

\section{II.1 Introducción}

En este capitulo describimos la instrumentación empleada en la medición de la temperatura. Posteriormente presentamos dos técnicas para obtener curvas de fusión: fusión continua y calorimetría adiabática. En la descripción de la técnica de fusión continua, mencionamos su aplicación en la construcción de patrones de transferencia y como ejemplo un aparato construido para medir el punto de fusión de mercurio. De la técnica de calorimetria adiabática describiremos los principios generales de construcción de crióstatos; presentaremos el construido para la reproducción del punto triple de mercurio. Este aparato lo usamos para obtener curvas de fusión de mercurio de dos muestras y discutimos los resultados.

\section{II.2 Termómetros}

La Escala Internacional de Temperatura de 1990 (EIT-90) [1] define el uso de los termómetros de resistencia eléctrica de platino (TRP) como instrumentos de interpolación para el intervalo de $13 \mathrm{~K}$ a $1235 \mathrm{~K}$. La elección se hizo en base a la estabilidad y resolución de estos instrumentos [2].

La relación de la resistencia eléctrica con la temperatura, de los TRP, se normaliza via la función $W(T)$ definida como 


$$
W(T)=\frac{r(T)}{r_{0}} \quad
$$

donde $\eta(T)$ es la resistencia eléctrica del termómetro a la temperatura $T$ y $r_{0}$ es su resistencia a la temperatura del punto triple del agua $(273,16 \mathrm{~K})$. La calibración de un TRP consiste en hallar la desviación de su $W(T)$ con respecto a una $W$ de referencia $\left(W_{r}\right)$ que aparece en el texto de la EIT-90. Los puntos de calibración son los puntos fijos a los cuales se les ha asignado su valor correspondiente de $W_{\mathrm{r}}$. En la tabla II.I presentamos los valores de $W_{\mathrm{r}}$ en algunos puntos fijos así como su primer derivada con respecto a la temperatura.

Tabla II.I. $W_{\mathrm{r}}$ y $\mathrm{d} W_{\mathrm{r}} / \mathrm{d} T$ de algunos puntos fijos de la EIT-90 [1].

\begin{tabular}{|c|c|c|c|}
\hline Punto fijo & $T / \mathbf{K}$ & $W_{\mathbf{r}}$ & $10^{3}\left(\mathrm{~d} W_{\mathrm{r}} / \mathrm{d} T\right) / \mathrm{K}^{-1}$ \\
\hline $\mathrm{O}_{2}$ (triple) & 54,3584 & 0,09171804 & 4,25 \\
\hline Ar (triple) & 83,8058 & 0,21585975 & 4,17 \\
\hline Hg (triple) & 234,3156 & 0,84414211 & 4,03 \\
\hline $\mathrm{H}_{2} \mathrm{O}$ (triple) & 273,16 & 1,0000000 & 4,00 \\
\hline Ga (fusión) & 302,9146 & 1,11813889 & 3,95 \\
\hline In (solidificación) & 429,7485 & 1,60980185 & 3,80 \\
\hline Sn (solidificación) & 505,078 & 1,89279768 & 3,72 \\
\hline Zn (solidificación) & 692,677 & 2,56891730 & 3,48 \\
\hline Al (solidificación) & 933,473 & 3,37600860 & 3,22 \\
\hline Ag (solidificación) & 1234,93 & 4,28642053 & 2,85 \\
\hline
\end{tabular}

Para medir la resistencia de los termómetros se emplean puentes en los que se determina el valor de $\eta(T)$ con relación a una resistencia eléctrica de referencia $r_{s .}$ En este trabajo hemos empleado puentes termométricos de corriente alterna, marca Automatic System Laboratories, modelo F18, con resolución de 0,1 ppm de la lectura, que equivale a $10 \mu \mathrm{K}$ para termómetros con resistencia nominal de $25,5 \Omega$ con $r_{s}$ de $100 \Omega$. El puente usa $r_{s}$ externas de tipo Wilkins, marca Tinsley modelo $5685 \mathrm{~A}$ estabilizadas a $36^{\circ} \mathrm{C}$. Estas resistencias son mantenidas en hornos a $36,0 \pm 0,1^{\circ} \mathrm{C}$. 
Los TRP pueden ser de cápsula $(5 \mathrm{~cm}$ de longitud) o de tallo largo $(60 \mathrm{~cm}$ de longitud), en ambos casos la longitud del sensor es similar: de 3 a $5 \mathrm{~cm}$. La sensibilidad de estos TRP la obtenemos de la relación

$$
\frac{d r}{d T}=\frac{d W_{r}}{d T} r_{0}
$$

Por ejemplo, para un termómetro con $r_{0}$ de $25,5 \Omega$, a la temperatura del punto triple de mercurio se tiene que $\mathrm{d} r / \mathrm{d} T=0,103 \Omega / \mathrm{K}$.

La incertidumbre combinada del termómetro, resistencia de referencia y puente es de $0,02 \mathrm{mK}$, en el intervalo $13 \mathrm{~K}$ a $693 \mathrm{~K}$ [3]. En un estudio sobre la reproducibilidad de algunos puntos fijos de la EIT-90 y sobre la estabilidad de los TRP encontramos [4] que en ciclos térmicos por arriba de $693 \mathrm{~K}$ (punto de solidificación de $\mathrm{Zn}$ ) los TRP presentan comportamientos erráticos de donde no es posible asignar una incertidumbre nominal de la capacidad de medición en el intervalo por arriba de esa temperatura.

\title{
II.3 Obtención de curvas de fusión
}

Para obtener puntos experimentales de una curva de fusión de una muestra, se mide la temperatura $(T)$ como función de la fracción líquida en la muestra $(F)$.

\begin{abstract}
Al enfriar un liquido, de sustancias que al solidificar cristalizan, no aparece la fase sólida tan pronto alcanza la temperatura de solidificación (punto líquidus), éste puede ser sobreenfriado. La magnitud del sobreenfriamiento depende de la sustancia, del contenido de impurezas y del método experimental. Por ejemplo, el sobreenfriamiento en zinc es menor a $1 \mathrm{~K}$; en estaño una muestra varió entre 4 y $6 \mathrm{~K}$ y otra entre de 13 a $15 \mathrm{~K}$ [5]; en mercurio observamos entre 4 y $24 \mathrm{~K}$ [6] para una misma muestra.
\end{abstract}


Este estado metaestable desaparece tan pronto como aparece aleatoriamente la nueva fase en un proceso denominado recalescencia. La diferencia de entalpía al formarse la nueva fase es tal que incrementa la temperatura de la muestra desde el punto de máximo sobreenfriamiento hasta su punto de fusión. En la fig. II. 1 presentamos un ejemplo del sobreenfriamiento y recalescencia de una muestra de estaño. La muestra pertenece al patrón nacional de temperatura de México.

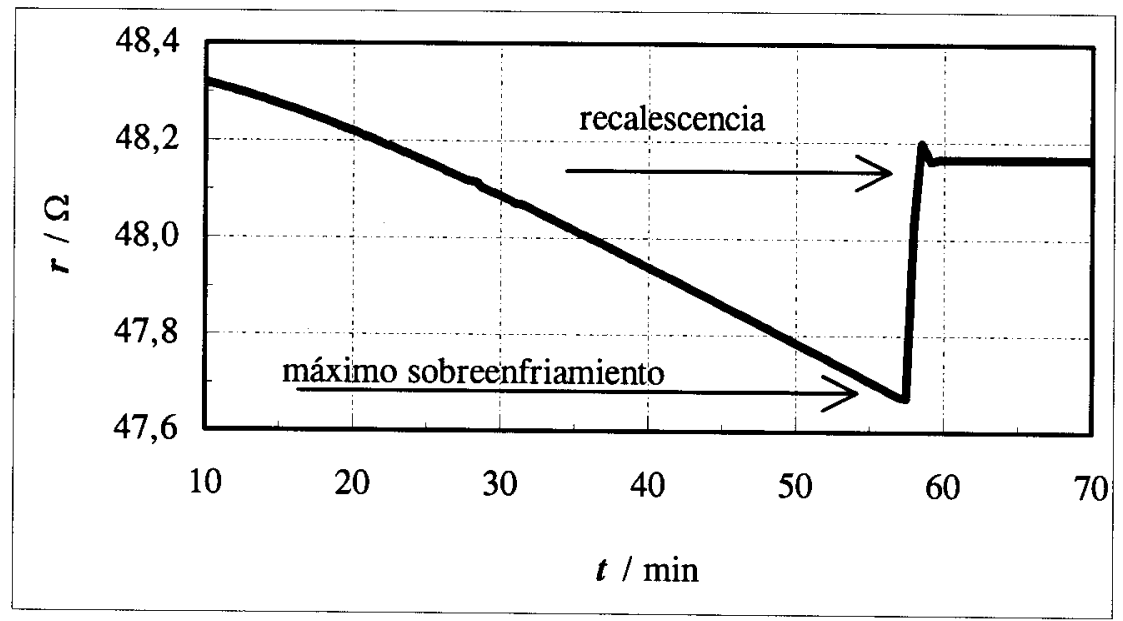

Figura II.1. Sobreenfriamiento y recalescencia de una muestra de estaño. La temperatura fue medida con un TRP de 25,5 $\Omega$ resistencia nominal en el punto triple de agua. La diferencia de temperatura entre el máximo sobreenfriamiento y la temperatura después de la recalescencia es aproximadamente $5 \mathrm{~K}$.

En un experimento de solidificación, el fenómeno de sobreenfriamiento seguido de la recalescencia dificulta las mediciones cerca del punto líquidus de la muestra $(F \sim 1)$ :

a) porque la disposición física del sólido es generalmente en forma de pequeñas partículas suspendidas en el liquido, las cuales migran, por efecto de la gravedad, hacia uno de los extremos verticales del contenedor de la muestra [7];

b) en consecuencia el tiempo en alcanzar el equilibrio térmico aumenta;

c) la cantidad de sólido que se forma depende del sobreenfriamiento de la muestra (del cual no se tiene control experimental);

d) incrementa la incertidumbre en la determinación de la fracción líquida $(F)$ y 
e) no es posible obtener puntos ( $T, F$ para valores de $F$ en el intervalo entre 1 y el valor de $\mathrm{F}$ que corresponde al momento de presentarse la recalescencia.

Estos problemas no se presentan en el proceso de fusión porque no existen los sólidos "sobrecalentados". En una muestra sólida la primer fracción líquida aparece tan pronto como la muestra alcanza su punto sólidus. Por esta razón elegimos el proceso de fusión para la realización de los experimentos.

Para realizar un experimento de fusión de una muestra, existen dos técnicas: fusión continua y calorimetria adiabática.

\section{II.3.1 Fusión continua}

En la técnica de fusión continua, a la muestra se le transfiere energía en forma constante y continua en el tiempo. Al hacerlo, se observa que la temperatura de la muestra incrementa proporcionalmente con el tiempo. Al alcanzar la temperatura de fusión (punto sólidus) la razón de cambio de la temperatura con el tiempo disminuye y este cambio indica que la fusión ha iniciado.

Conforme la fusión evoluciona, se observa que la temperatura cambia linealmente con el tiempo con una pendiente que tiende a cero. A la porción de la curva donde el cambio de la temperatura es lineal y con pendiente cercana a cero se le llama meseta o plataforma. Se continúa con la transferencia de energia y se reconoce que la fusión ha terminado cuando la temperatura de la muestra vuelve a tomar una razón de cambio con el tiempo similar a la que tenía antes de iniciar la fusión.

La estimación de la fracción sólida se hace de la siguiente manera: se utiliza un calefactor con potencia constante: la cantidad de energía transferida a la muestra es proporcional al tiempo. Se registran los tiempos de inicio y de término de la meseta (curva de fusión), digamos $t_{a}$ y $t_{b}$, respectivamente. Asi, la fracción líquida $(F)$ a un tiempo $t$, medido desde que se inició el cambio de fase, se calcula con la relación 


$$
F(t)=\frac{t-t_{a}}{t_{b}-t_{a}}
$$

La incertidumbre relativa en la determinación de $t_{a}$ es menor al uno por ciento. En cambio, Ancsin encontró, en experimentos de punto triple de argón, que el final de la meseta $t_{b}$ se presentó al tener 40 por ciento de sólido en la muestra [8]. Es decir, la meseta terminó antes que la muestra alcanzara el punto liquidus. En experimentos realizados con muestras de $\mathrm{Sn}$ y $\mathrm{Zn}$ nosotros hemos encontrado resultados similares. En la fig. II.2 presentamos una curva de fsuión de una muestra de $\mathrm{Zn}$. La temperatura fue medida con un TRP de 25,5 resistencia nominal en el punto triple de agua.
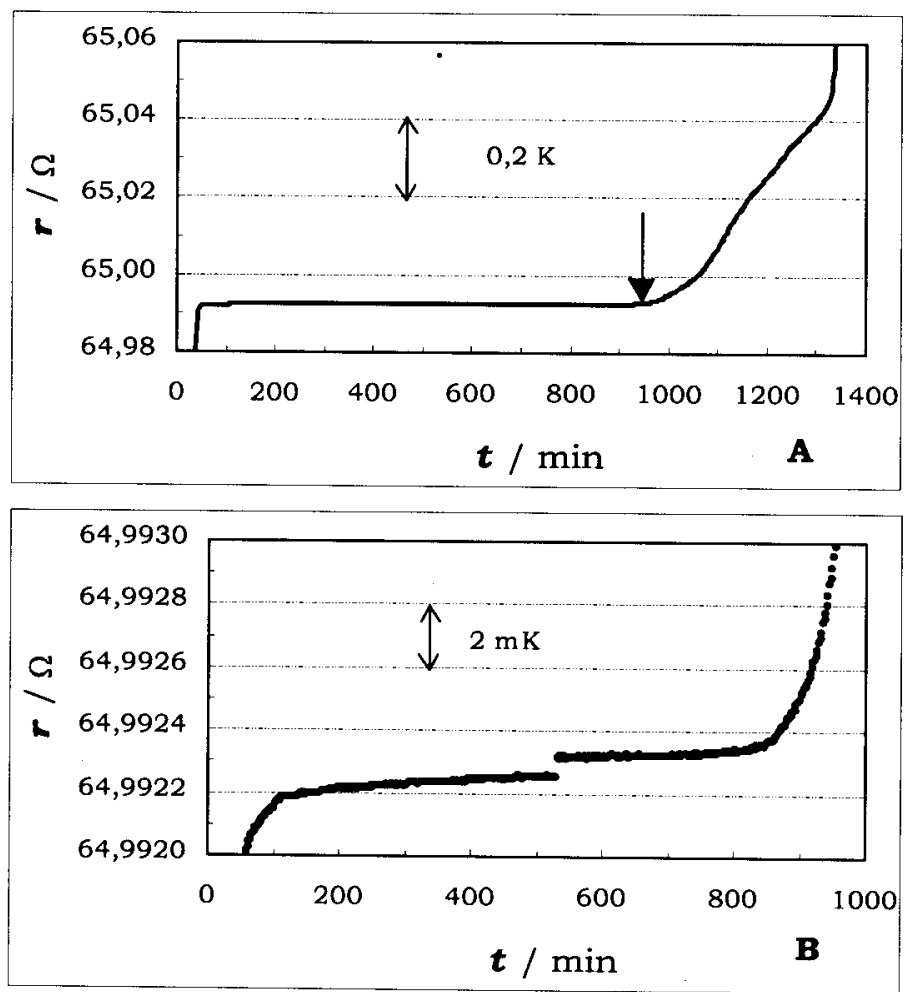

Figura II.2 Curva de fusión de $\mathrm{Zn}$. De la gráfica A se puede obtener el tiempo total del procesos de fusión, aproximadamente $21,7 \mathrm{~h}$. En la gráfica $B$ se observa que la meseta de fusión duró aproximadamente $15 \mathrm{~h}$ (aproximadamente el 70 por ciento del total).

En principio, se espera que la meseta se mantenga hasta que la última porción de sólido se funda (punto líquidus) pero, no sucede así. La discrepancia se 
genera por: a) los gradientes térmicos, b) las dimensiones fisicas del termómetro y c) la disposición geométrica de los calefactores, la muestra y el termómetro.

\section{a) Los gradientes térmicos}

Los gradientes térmicos se originan principalmente por la ubicación de la muestra y el termómetro con respecto a los calefactores y a los puntos donde el contenedor de la muestra intercambia calor con sus alrededores: fugas térmicas. Al inicio de la fusión, el efecto de los gradientes no es notorio porque la porción del sólido cerca de los calefactores se funde, la energia transferida a la muestra se emplea en la transición de fase y la temperatura se mantiene constante en el punto de fusión. Cuando la fusión ha avanzado, en la proximidad del calefactor sólo hay líquido que puede estar a una temperatura mayor que la del punto de fusión. Por otro lado, las porciones sólidas de la muestra cercanas a las fugas térmicas o alejadas del calefactor serán las últimas en fundirse, por lo que éstas permanecerán a una temperatura menor o igual que la temperatura de fusión.

b) Las dimensiones del termómetro

La parte sensora del TRP (de 3 a $5 \mathrm{~cm}$ de largo) puede estar en contacto térmico, simultáneamente, con la porción sólida de la muestra, la interfase y o la porción líquida. En este caso, es imposible distinguir si un valor de temperatura es de equilibrio o es el promedio de las temperaturas (distintas entre ellas) de las porciones de la muestra que están en contacto térmico con el sensor del TRP.

c) La disposición geométrica

La posición de los calefactores afecta el proceso de la fusión: inicia cerca de éstos y termina en los puntos más alejados de ellos. Los contenedores de las muestras (celdas) se diseñan para que el termómetro tenga buen contacto térmico con la muestra. El TRP puede estar dentro de la muestra o entre la muestra y los calefactores. En el segundo caso se tiene una fuente adicional de error porque el TRP puede medir la temperatura del exterior que rodea a la muestra. Si el TRP está dentro de la muestra, el termómetro no puede medir la temperatura del exterior mientras esté rodeado de sólido. Sin embargo, la posición de los calefactores y su eficiencia en transferir energia a la muestra (que depende de su contacto térmico), puede provocar fusión direccional y la 
formación de canales de liquido que vayan desde los calefactores hasta el termómetro. En este último caso se presenta otra fuente de error que puede conducir a medir temperaturas más altas que las del punto de fusión, a medida que $F$ tiende a uno.

Al emplear la técnica de fusión continua, se intenta reducir los errores mencionados via la obtención de mesetas muy largas en el tiempo, con la idea de que la muestra esté, en todo tiempo, en equilibrio têrmico interno (porción sólida, interfase y fase líquida) y externo con el termómetro. De aquí que uno de los criterios de calidad propuestos de estos experimentos es la duración de la meseta $[9,10,11]$. Pero la condición necesaria en estos experimentos es que el medio que rodea a la muestra siempre esté a una temperatura mayor que la de su punto líquidus, esta condición genera inevitablemente un error sistemático $[12,13,14]$.

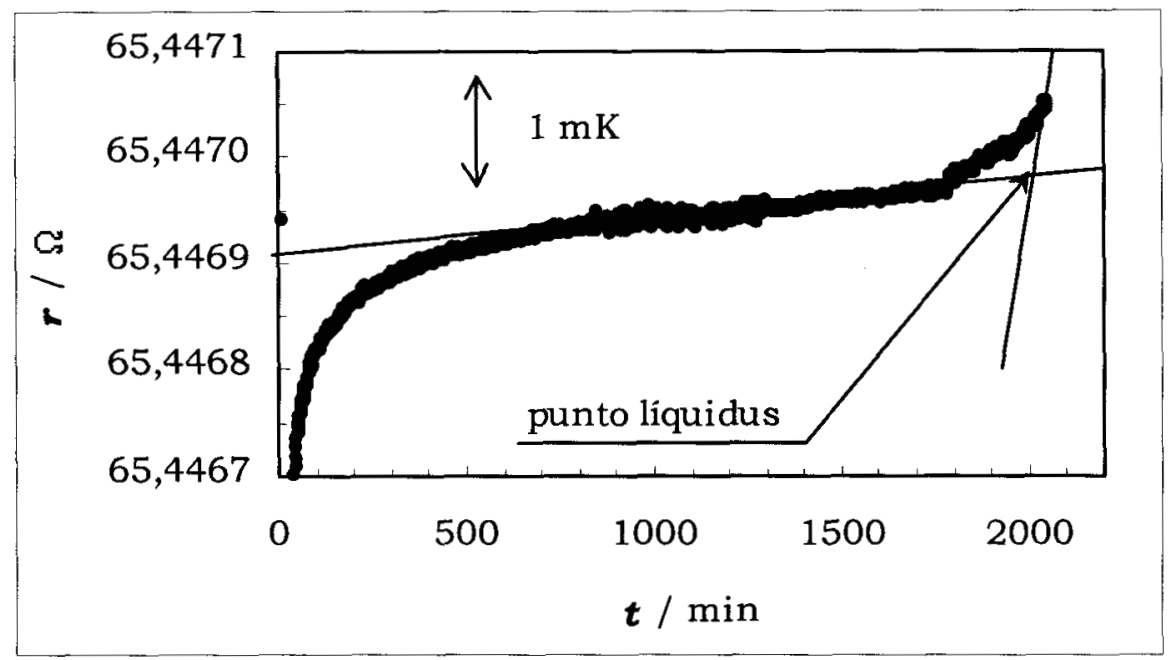

Figura II.3. Fusión de una muestra de zinc. El punto liquidus se estima por la intersección de las rectas ajustadas a la parte plana de la "meseta" y a la recta que describe la razón de cambio de la temperatura como función del tiempo. La escala vertical completa es 4,4 $\mathrm{mK}$.

Una muestra se puede caracterizar al escoger algún punto $(T, F)$ dentro del intervalo de fusión. Se ha propuesto, por ejemplo, asignar el valor de $T_{0}$ a la temperatura que corresponde a $F=0,5$ [15]. Los inconvenientes a esta propuesta son: a) la EIT-90 define los valores de temperatura de sustancias puras; no está en función de una técnica particular de realización; b) se introduce una fuente 
de incertidumbre adicional, en la realización del punto fijo, via la determinación de $F=0,5$ cuya determinación depende de la disposición geométrica del experimento y la técnica de realización.

En experimentos de fusión continua el punto líquidus se estima por la intersección de la recta ajustada a la parte lineal de la curva de fusión con la recta que se ajusta a la razón de calentamiento, una vez que se terminó la fusión. Por ejemplo, en la figura II. 3 presentamos una curva de una muestra de Zinc [17]. La temperatura fue medida con un TRP con sensibilidad $0,09 \Omega / \mathrm{K}$. Hemos encontrado que la repetibilidad del punto liquidus es un orden de magnitud mejor que la del intervalo de fusión y que puede ser empleado para caracterizar a la muestra $[4,16,17]$. La ventaja que tiene este criterio, sobre el anterior $(F=0,5)$, es que no depende de cómo se obtiene la curva de fusión. Además, se propone el uso del punto líquidus como caracteristico de la muestra pero no equivalente a $T_{o}$ : queda pendiente la determinación de la relación entre el punto líquidus y el punto de fusión de la sustancia pura.

La repetibilidad en la determinación del punto líquidus es adecuada para construir un patrón de transferencia de algunos puntos fijos de la EIT-90. Por ejemplo, construimos un conjunto de celdas cilindricas, de $2,5 \mathrm{~cm}$ de diámetro y 22,5 cm de largo para los puntos fijos de $\mathrm{Zn}, \mathrm{Sn}, \mathrm{In}, \mathrm{Ga}, \mathrm{y} \mathrm{Hg}$. En las celdas el pozo para el termómetro está en el eje de simetria. La dispersión de los valores observados del punto líquidus, al repetir los experimentos, es menor a $1 \mathrm{mK}$. Este resultado permitió hacer la comparación de las escalas nacionales de temperatura mantenidas en Canadá y México [17]. En ese ejercicio encontramos que ambas escalas son indistinguibles dentro de la incertidumbre experimental de 0,5 $\mathrm{mK}$.

La transferencia de la exactitud del patrón nacional de temperatura a los laboratorios secundarios se realiza via termómetros calibrados. Esta transferencia requiere de la calibración periódica de los termómetros patrones de referencia de los laboratorios.

La bondad del sistema de transferencia, usado en la comparación de las escalas de México y Canadá, puede usarse para construir patrones de transferencia a la metrología secundaria de los laboratorios del Sistema Nacional de 
Calibración (SNC). Estos laboratorios reducirian su incertidumbre de medición de $20 \mathrm{mK}$ a $2 \mathrm{mK}$.

\section{II.3.2 Aparato de punto de fusión de mercurio}

Presentamos el diseño de un aparato que fue construido para reproducir el punto de mercurio [21]. Este aparato funciona por el método de la fusión continua y se diseñó para ser empleado como sistema de transferencia y calibración en los laboratorios secundarios del SNC.

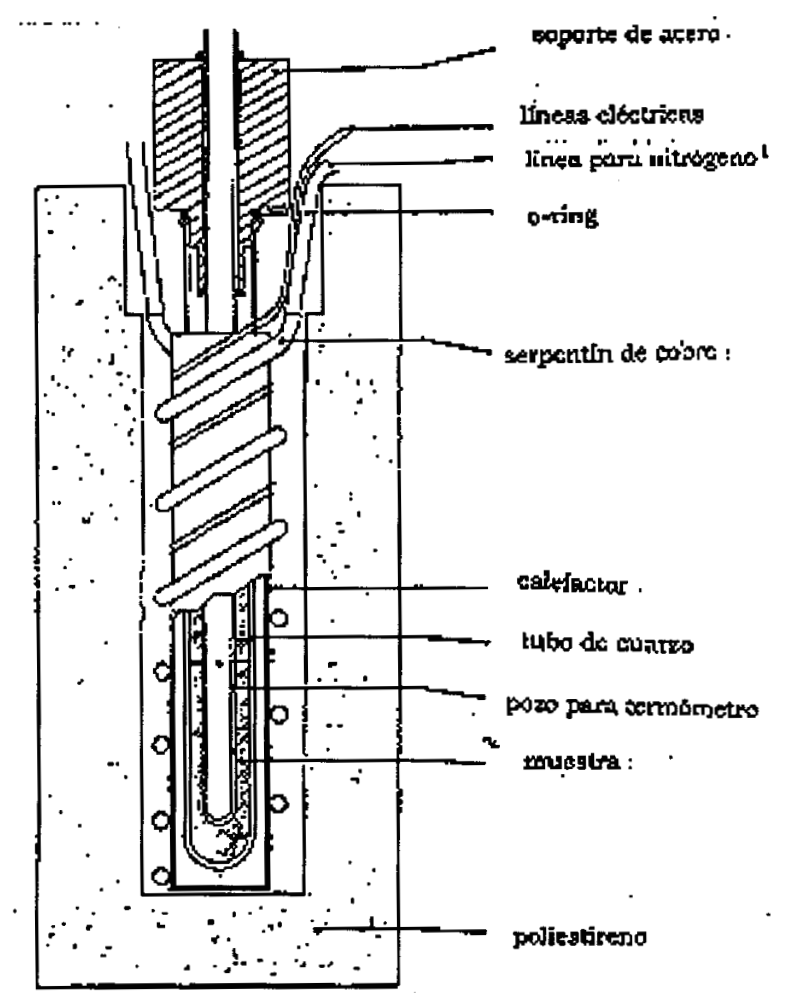

Figura II.4. Aparato de punto de fusión de mercurio que emplea la técnica de fusión continua.

El aparato (fig. II.4) fue construido con dos tubos de cuarzo concéntricos de pared de $1 \mathrm{~mm}$ de espesor con 0,7 y $2,0 \mathrm{~cm}$ de diámetro respectivamente, ambos con $25 \mathrm{~cm}$ de longitud. El tubo exterior se llenó con $800 \mathrm{~g}$ de mercurio tridestilado (marca Thomas Scientific ACTESA). El tubo interior se usó como pozo para el termómetro. Para mantener en su posición el tubo interior y evitar 
su flotación, se utilizó una pieza de acero inoxidable (de $3,8 \mathrm{~cm}$ de diámetro por $4,4 \mathrm{~cm}$ de largo la sección superior y $1,85 \mathrm{~cm}$ de diámetro por $3,2 \mathrm{~cm}$ de largo la sección inferior) acoplada en la parte superior del aparato.

Los tubos se colocan dentro de una camisa de cobre a la cual se le ha soldado un serpentín de cobre para circular nitrógeno líquido. Un calefactor eléctrico fue así mismo devanado y cementado sobre la camisa. El aparato se colocó en una caja de espuma de poliestireno de paredes de $4 \mathrm{~cm}$ de espesor. Se agregó etanol en el pozo del termómetro para mejorar el contacto térmico entre la muestra y el termómetro.

Se enfrió la muestra al circular nitrógeno líquido por el serpentín. En 10 minutos se alcanzó el punto de solidificación y en 5 minutos más se solidificó por completo. Cuando el termómetro indicó que la temperatura de la muestra estaba $4 \mathrm{~K}$ por debajo del punto de fusión se detuvo el flujo de nitrógeno y se encendió el calefactor. Se calentó la muestra hasta $1 \mathrm{~K}$ por debajo del punto de fusión, se apagó el calefactor y se dejó que la muestra se fundiera con la energia transferida del ambiente a la muestra a través de las paredes de espuma poliestireno.

La temperatura se estabilizó una vez que se alcanzó el punto de fusión y la meseta duró de 20 a $40 \mathrm{~min}$. La reproducibilidad observada del punto líquidus es de 0,5 mK y se presentó 4,5 mK más alto que el punto triple. Este valor para el punto de fusión a presión atmosférica concuerda, dentro de la incertidumbre de $0,5 \mathrm{mK}$, con los obtenidos con celdas de punto triple usadas en CENAM en la reproducción de este punto [6], después de hacer la corrección por presión atmosférica local $(\mathrm{d} T / \mathrm{d} p=5,4 \mathrm{E}-8 \mathrm{~K} / \mathrm{Pa})$; equivale a $4,3 \mathrm{mK}$ para la presión atmosférica de $81 \mathrm{kPa}$, presión nominal en CENAM.

Aparatos como el descrito pueden ser construidos y calibrados con el patrón nacional para usarse como patrones de transferencia, con la ventaja de que, si se preserva la pureza del material, su estabilidad es mejor que la de cualquier termómetro.

No obstante la repetibilidad del punto líquidus, y sus buenos resultados en la construcción de patrones de transferencia, estos experimentos no son adecuados para obtener puntos $(T, F)$ confiables de una curva de fusión. Por 
ejemplo, en la fig. II.3 observamos que cerca del punto liquidus $(1700<\mathrm{t} / \mathrm{min}<2000)$ no es posible distinguir los valores de equilibrio de los que provienen de los gradientes inducidos por la técnica de realización. Este intervalo representa el 15 por ciento de la curva de fusión.

\section{II.3.3 Calorimetria adiabática}

En las técnicas de calorimetria se intenta aislar térmicamente a la muestra de sus alrededores. En esta sección vamos a describir algunos aparatos (crióstatos) que hemos usado en la realización de puntos fijos de la EIT-90 de baja temperatura $(T<273,15 \mathrm{~K})$. La misma técnica se puede aplicar para los puntos de alta temperatura $[4,18]$

El conjunto de medición (celda, calefactor, muestra y termómetro) se suspende de materiales de baja conducción térmica (como hilos de algodón). Además, se usan cables de conexión delgados (por ejemplo, de 0,06 mm de diámetro: AWG42), se mantiene a vacio y se coloca una pantalla de temperatura controlada alrededor de la muestra. La temperatura de la pantalla se controla de tal manera que siga los cambios de temperatura de la muestra [19].

En esas condiciones, a la muestra se le transfiere energia por pulsos que pueden ser de la muestra hacia sus alrededores vía interruptores mecánicos que establecen el contacto térmico de una fuente fría con la muestra. Si la transferencia de energía es de los alrededores a la muestra se puede usar un calefactor eléctrico de potencia conocida. En este caso, el calefactor está cementado sobre el contenedor de la muestra. Se transfieren pulsos de energia al conectar el calefactor a una fuente de tensión por tiempos $\Delta t$ y se miden simultáneamente la tensión y corriente eléctricas. Después de cada pulso se permite que la muestra alcance su equilibrio térmico.

Por ejemplo, con la muestra inicialmente sólida se observa que su cambio de temperatura es proporcional al pulso, de donde se calcula la capacidad térmica del conjunto (muestra, celda, soportes, termómetros, calefactores, etc.). Al 
alcanzar el punto de fusión se observa que la capacidad térmica del conjunto toma valores muy grandes (al menos dos órdenes de magnitud mayores que el medido antes de iniciar la transición). Se repiten los ciclos pulso - equilibrio térmico y una vez alcanzado el equilibrio térmico en cada ciclo se registra la temperatura. Se continúa hasta que se observa que la capacidad térmica, del conjunto, vuelve a tomar valores similares a los observados antes de iniciar el cambio de fase. Se toman los valores de $T$ de equilibrio para cada uno de los pulsos.

La entalpia de fusión de la muestra es la suma de la energía transferida a la muestra en cada pulso durante la transición. La fracción sólida se estima como la fracción de energia transferida con respecto a la entalpía de fusión.

En esta técnica, el tiempo no es una variable relevante, sin embargo, se procura, en el diseño experimental, que el tiempo de relajación, para alcanzar el equilibrio térmico, sea lo mâs corto posible (del orden de minutos). Tiempos largos de relajación pueden acusar la construcción de gradientes y que, en lugar de tener condiciones de equilibrio, se tengan condiciones de estado estacionario. En este último caso, la temperatura alcanzaría un estado de aparente equilibrio debido a que existe un balance de fugas térmicas. Por otro lado, las fugas térmicas residuales, insignificantes en corto tiempo, pueden generar un error sistemático significativo en la determinación de $F$ por la acumulación de su efecto en experimentos de larga duración.

\section{II.3.3.1 Calorimetria adiabática y puntos fijos}

Los diseños de calorimetros adiabáticos iniciaron a principios de siglo para medir capacidad térmica [19] y fue propuesta por Ancsin como una técnica adecuada para medir puntos fijos de la Escala de Temperatura $[8,20]$.

Con relación al manejo de la muestra, la configuración del crióstato puede ser abierta o cerrada. Es abierta cuando la celda de medición está conectada a un tubo de llenado que llega hasta el exterior del crióstato, donde se encuentran 
una serie de válvulas, manómetros y contenedores para la manipulación de la muestra. Si el crióstato es cerrado entonces se usan celdas selladas que contienen a la muestra. En este caso el crióstato tiene un recipiente porta celda el cual tiene, por lo general, devanado y cementado un calefactor eléctrico. En la Fig. II.5 se muestra un esquema de los principales componentes de un crióstato.

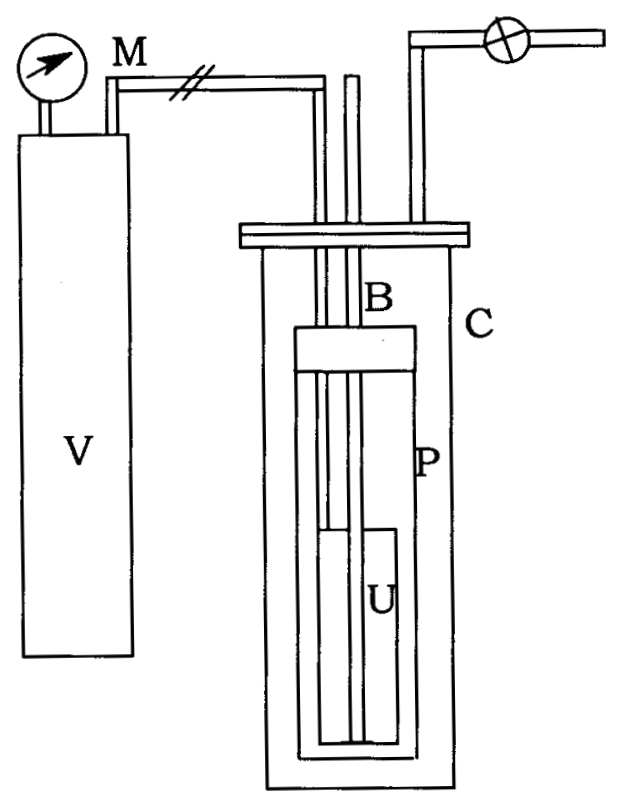

Figura II.5. Esquema de un crióstato. Si es abierto la unidad de medición (U) donde se encuentra la celda está conectada con un volumen (V) externo. Dentro de la campana de vacio (C) se tiene también un bloque (B) que está anclado térmicamente al baño frio. La pantalla $(\mathrm{P})$ rodea a la unidad de medición.

El crióstato se coloca en un baño de baja temperatura que puede ser de ciclo cerrado, de $\mathrm{CO}_{2}$ sólido, de nitrógeno liquido, o de helio líquido. La elección depende del punto de fusión de la muestra: la temperatura del baño debe ser la más cercana, pero menor, a la del punto de fusión de la muestra. 
Las fugas térmicas a través de los conectores, soportes y linea de llenado se reducen al anclarlos térmicamente al baño termoestático antes de que lleguen al bloque de medición.

$\mathrm{El}$ ancla térmica tiene generalmente dos etapas. La primera usa uno de los puntos más fríos del crióstato; por ejemplo, la tapa superior de la cámara de vacío, la cual está en contacto directo con el baño. La segunda, es un bloque, desacoplado térmicamente del baño. Este bloque tiene devanado un calefactor y está anclado a la primera etapa por un alambre de cobre. El calibre del alambre de cobre se escoge de manera que, por prueba error, la potencia disipada por el calefactor sea la menor pero que permita el control de temperatura del bloque. Si está sobre-anclado entonces la disipación de energía en el calefactor es muy grande y, como consecuencia, se merma la eficiencia del baño. Si el anclaje no es suficiente, entonces se observa que el bloque tiende a aumentar su temperatura sistemáticamente y no hay control de temperatura.

La pantalla se fija al bloque de la segunda etapa del ancla térmica. La pantalla se fabrica de cobre, de espesor delgado $(1 \mathrm{~mm})$ a fin de que siga los cambios de temperatura del bloque a la que está sujeta. En ocasiones se devana un calefactor sobre la pantalla para cambiar su temperatura rápidamente.

El control de la temperatura del bloque se hace con respecto a la temperatura del conjunto de medición. Hemos usado termopares diferenciales tipo T (cobreconstantán) para tal propósito. La señal del termopar diferencial se mide con un medidor de tensión eléctrica (microvóltmetro). El microvóltmetro que empleamos (Keithley modelo 155) tiene una salida analógica de $\pm 1 \mathrm{~V}$, proporcional a su lectura, la cual empleamos para controlar la fuente de tensión continua que alimenta el calefactor del bloque. La sensibilidad del termopar tipo $\mathrm{T}$ es $40 \mu \mathrm{V} / \mathrm{K}$, la resolución del microvoltmetro es $\pm 0,02 \mu \mathrm{V}$. Esta combinación permite el control de la temperatura de la pantalla con $\pm 0,5 \mathrm{mK}$ con respecto al bloque de medición. El punto de control se escoge vía el ajuste en el cero del microvóltmetro hasta obtener la mínima deriva de la temperatura al tener a la muestra en una sola fase. Con este sistema hemos obtenido derivas de temperatura del bloque de medición de $1 \mathrm{mK} / \mathrm{h}$ o menores. 
Preparación de la muestra

Para el crióstato abierto la muestra se maneja en estado de vapor a temperatura ambiente. $\mathrm{El}$ aparato tiene un volumen externo (de $2 \mathrm{dm}^{3}$ ) usado como contenedor de la muestra. Para el llenado del sistema, se hace vacío con bomba de difusión, en todo el sistema desde la celda de medición (de $20 \mathrm{~cm}^{3}$ ) hasta el contenedor de la muestra, por varias horas. Luego se "enjuaga" con gas del mismo lote de donde se va a tomar la muestra via tres ciclos de llenado vacío. Finalmente se llena el contenedor de la muestra a presión diferencial de $200 \mathrm{kPa}$ a temperatura ambiente.

En caso del crióstato cerrado, el aparato se desarma para tener acceso al porta celda, se coloca la celda y los termómetros (tipo cápsula) y se vuelve a ensamblar el crióstato. Hemos usado alambre de indio (de 0,5 $\mathrm{mm}$ de diámetro) para los sellos de vacío. Después de colocar la celda en su lugar, se revisa la continuidad de las conexiones eléctricas y la hermeticidad de los sellos de vacío.

\section{Operación}

Para iniciar el enfriamiento primero se inyecta gas helio en la campana de vacio y se coloca el crióstato en el baño refrigerante. Se mantiene el helio en la campana de vacío hasta que se observa que la muestra se ha solidificado completamente. Se vacía la campana de vacio y se inicia el control de temperatura de la pantalla.

El tiempo requerido para llegar a las condiciones adecuadas para iniciar las mediciones, depende del tamaño mismo del crióstato, la capacidad de la bomba de vacío y el diseño de construcción del crióstato. Conforme pasa el tiempo el vacio mejora hasta alcanzar un punto, alrededor de 0,01 $\mathrm{Pa}$, en el que el control del crióstato es insensible a los cambios en la presión del gas residual en la campana de vacío.

En esas condiciones, se transfiere energia a la muestra por el calefactor hasta que alcanza la temperatura de $1 \mathrm{~K}$ por debajo del punto sólidus. A continuación, a través de ensayo - error, se encuentra el ajuste del cero del microvóltmetro para que la temperatura de la pantalla sea la más cercana a la del conjunto de medición. El control de la temperatura de la pantalla se estimó 
adecuado al observar que la deriva en la temperatura de la muestra es menor a $1 \mathrm{mK} / \mathrm{h}$. A partir de esta condición se procede a la obtención de los puntos de la curva de fusión.

\section{II.4 Curvas de fusión de mercurio}

Se presenta la descripción de un crióstato para medir el punto triple de mercurio. Este punto es uno de definición de la Escala de Temperatura de 1990 EIT-90 [1]; se le asignó el valor de $234,3156 \mathrm{~K}\left(-38,8344^{\circ} \mathrm{C}\right)$. Con este aparato se obtuvieron curvas de fusión con las técnicas de calorimetria adiabática y de fusión continua [21].

\section{II.4.1 Descripción del aparato}

En el diseño del aparato se tuvo en cuenta que el mercurio tiene muy baja conductividad térmica $[6,9 \mathrm{~W} /(\mathrm{mK})]$, del orden de la mitad del acero inoxidable [12,3 W/(mK)] [22]. El experimento se diseñó para poder calibrar TRP de tallo largo, por lo que la muestra tenía que ser lo suficientemente grande para cubrir la parte sensora del termómetro, pero lo menor posible para reducir los tiempos de relajación (después de los ciclos de calentamiento) además de reducir los gradientes térmicos.

Se utilizó una muestra de $200 \mathrm{~g}$ de mercurio. El contenedor de la muestra es un cascarón cilíndrico de polietileno de $2 \mathrm{~mm}$ de espesor, $5 \mathrm{~cm}$ de diámetro y 5 $\mathrm{cm}$ de altura (fig. II.6). El cascarón cilíndrico rodea la parte inferior de un bloque cilindrico de un bloque (de medición) de cobre de $15 \mathrm{~cm}$ de altura. Se insertaron cuatro tubos de acero (dos de 6,35 $\mathrm{mm}$ y otros dos de 7,94 $\mathrm{mm}$ de diámetro interior) de pared delgada $(0,2 \mathrm{~mm})$ en el bloque de medición que son los pozos para los termómetros. El fondo de los pozos coincide con la parte 
inferior del bloque para que la parte sensora de los termómetros esté rodeada por la muestra.

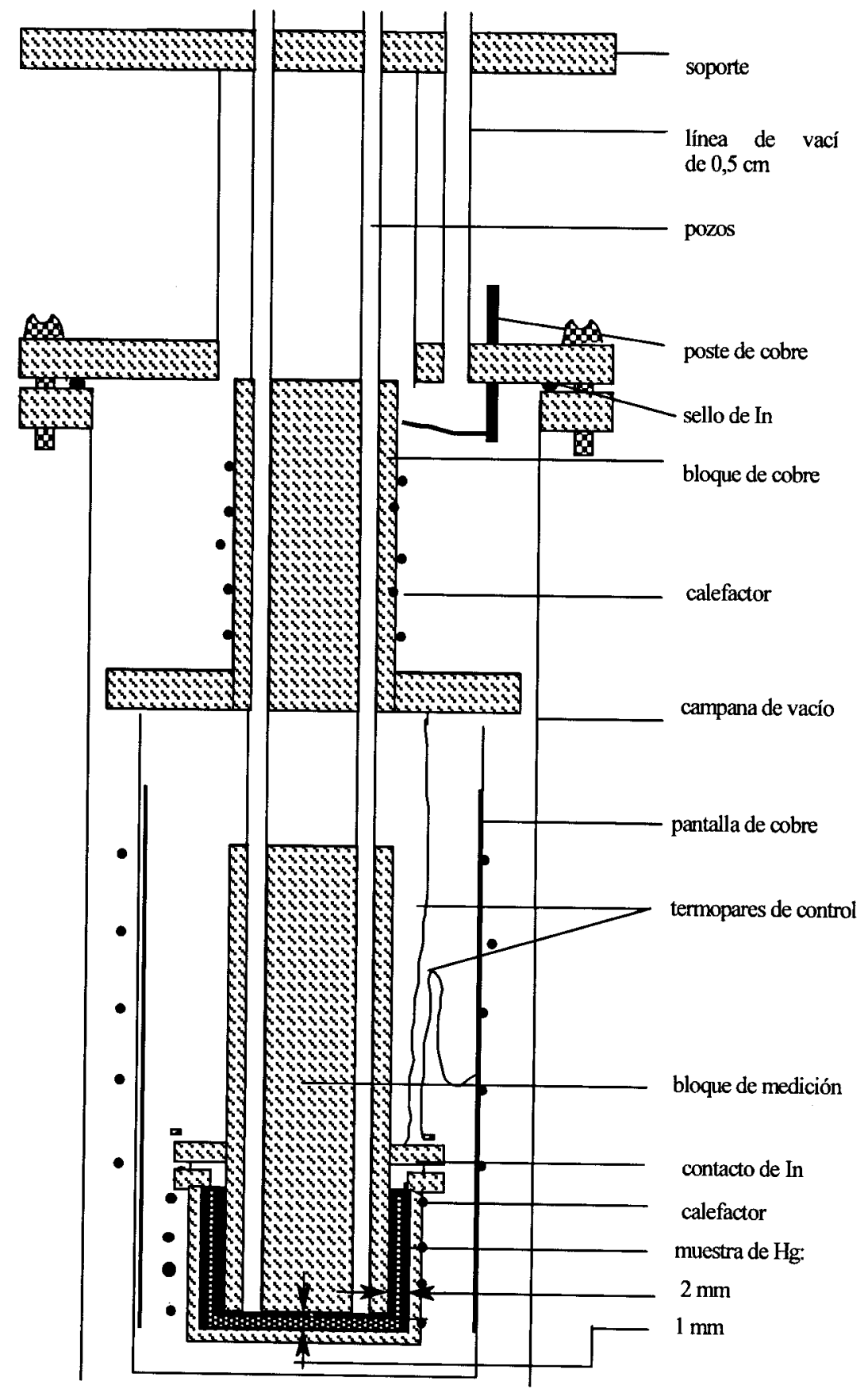

Figura. II.6 Crióstato de mercurio. La muestra de mercurio forma un cascarón cilindrico que rodea la parte inferior de la unidad de medición, a la misma altura donde se colocan la parte sensora de los TRP. 
Alrededor del bloque de medición se tiene una pantalla de cobre de $8 \mathrm{~cm}$ de diámetro y 1,1 mm de espesor. Se colocó un termopar diferencial tipo $\mathrm{T}$ entre la muestra y la pantalla para medir la diferencia de temperatura entre ellas. El microvóltmetro usado para la lectura de la señal del termopar tiene una salida analógica de $\pm 1 \mathrm{~V}$ proporcional a la lectura. Esta salida se usa para controlar una fuente de tensión de corriente directa que alimenta el calefactor de la pantalla. La pantalla y el bloque de medición están dentro de la cámara de vacío. Como baño de temperatura se usó un Dewar de acero, el cuál se llenó con $\mathrm{CO}_{2}$ sólido molido.

\section{II.4.2 Resultados}

Para iniciar el experimento se solidificó la muestra. Durante el enfriamiento se inyectó helio en la cámara de vacío y se colocó $\mathrm{CO}_{2}$ sólido molido en uno de los pozos. A partir de temperatura ambiente se encontró que la muestra se solidificó en 40 minutos. Después de la solidificación, se hizo vacío y se inició el control de temperatura de la pantalla. Una vez que el vacío quedó estable $(0,01$ $\mathrm{Pa}$ ), se inició la puesta a punto del crióstato, que consiste en encontrar, vía prueba - error. el ajuste del cero en el microvóltmetro para observar deriva en la temperatura menor a $1 \mathrm{mK} / \mathrm{h}$.

En los experimentos preliminares se determinó la capacidad térmica del conjunto con la muestra sólida, la entalpia de fusión y la capacidad calorífica del conjunto con la muestra líquida. Con esta información se procedió a obtener puntos en la curva de fusión.

Se obtuvo la curva de fusión de una muestra con contenido de impurezas menor a $1 \mathrm{ppm}$ (fig. II.7). El intervalo de fusión, entre 5 y 90 por ciento de la muestra en estado liquido, fue de $0,4 \mathrm{mK}$. La repetibilidad para 30 experimentos de fusión en un periodo de 50 dias fue de 0,3 $\mathrm{mK}$. De la misma muestra se obtuvo una curva de fusión via la técnica de fusión continua. En este caso la meseta duró $2,5 \mathrm{~h}$ (curva II de la fig. II.8). El intervalo de fusión 
aumentó a $8 \mathrm{mK}$ y el punto líquidus aparece $20 \mathrm{mK}$ por arriba del obtenido en el caso anterior.

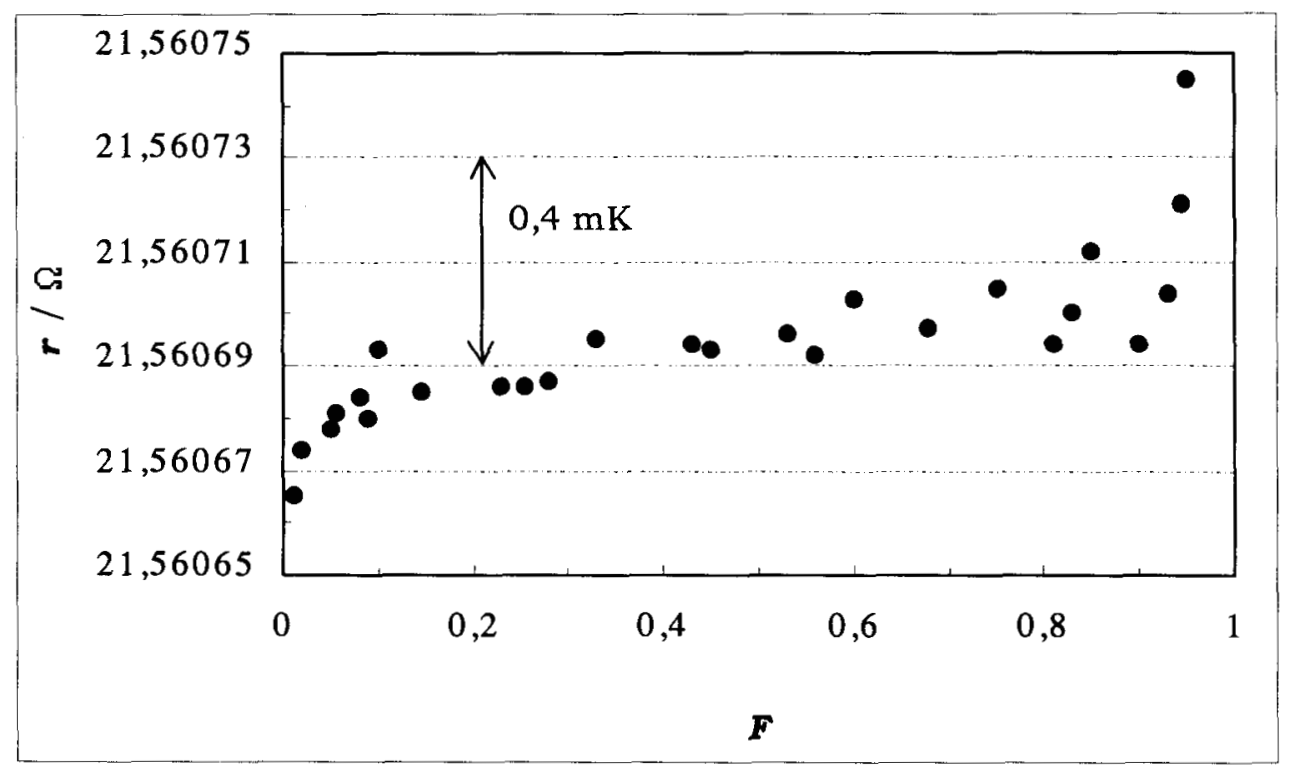

Figura II.7. Curva de fusión de mercurio. Muestra de algunos puntos experimentales obtenidos en un crióstato adiabático. La temperatura se midió con un termómetro de resistencia de platino con sensibilidad de $0,102 \Omega / K$. La escala vertical completa equivale a $1 \mathrm{mK}$.

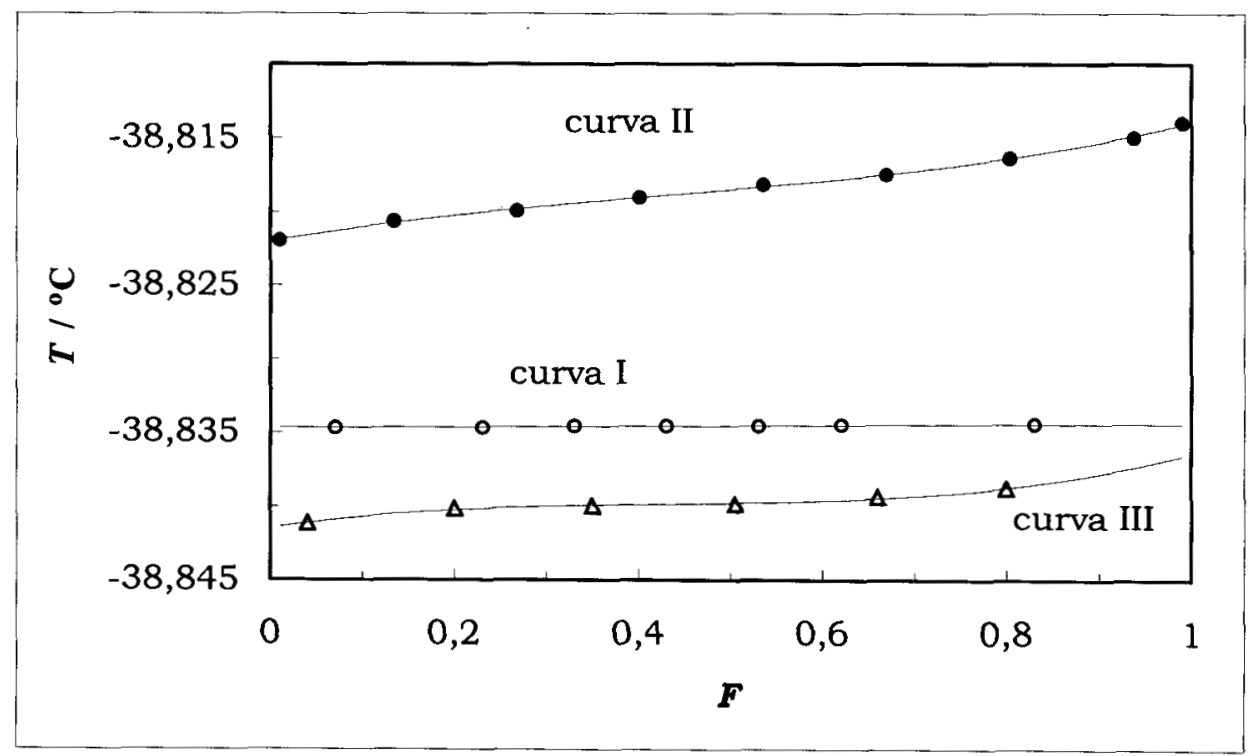

Figura II.8. Curvas de fusión de mercurio. La curva I corresponde a una muestra de alta pureza medida con calorimetria adiabática. La curva II es la misma muestra pero fue obtenida con la técnica de fusión continua; la curva III fue obtenida por calorimetria adiabática y se empleó una muestra de composición química desconocida. 
Durante el trabajo de puesta a punto del aparato se empleó una muestra de mercurio de pureza desconocida, la cual presentaba evidentes signos de contaminación (polvo, óxido y aceite). En la figura II.8 (curva III) se muestra la curva de fusión, obtenida por calorimetria adiabática, de esta muestra. $\mathrm{El}$ intervalo de fusión es de $3,5 \mathrm{mK}$ y su punto líquidus se está $4 \mathrm{mK}$ por debajo de la curva obtenida con la muestra de alta pureza y vía calorimetria adiabática.

Encontramos que la técnica de fusión continua generó un error sistemático en la temperatura del punto líquidus de $0,02 \mathrm{~K}$ e incrementa el intervalo de fusión de $0,2 \mathrm{mK}$ a $7 \mathrm{mK}$. En este ejemplo el error por el uso de la técnica de fusión continua resultó mayor que el de la contaminación de la muestra por impurezas desconocidas.

\section{II.5 Conclusión}

Para la medición de las curvas de fusión encontramos que el proceso de fusión permite una mejor determinación de $F$ particularmente en aquellas sustancias que presentan sobreenfriaminetos de varios Kelvin.

La repetibilidad del punto líquidus por medio de la técnica de fusión continua es adecuado para construir patrones de transferencia pero no es adecuado para obtener datos de la curva de fusión: los errores en la determinación de $F$ pueden ser del 20 por ciento o mayores.

La técnica de calorimetria adiabática para obtener curvas de fusión resultó ser la mejor para la obtención de datos $(T, F)$. En el capitulo siguiente vamos a analizar curvas de fusión obtenidas con esta técnica para evaluar los modelos compuesto y pseudoternario presentados en el capítulo I. 


\section{II.6 Referencias}

1. H. Preston-Thomas (1990). The International Temperature Scale of 1990 (ITS90). Metrologia 27, 3-10,107. Paris, Francia.

2. Supplementary Information for the International Temperature Scale of 1990 (1990). Bureau International des Poids et Measures, Paris, Francia.

3. J. Valencia, E. Mendez, D. Licea, M. Tischler, P.. da Fonseca, S. Garcia Petrovic, L. A. Suarez, P. Young, B. Giron, H. Postigo, L Mussio (1999). Report on the comparison of thermometric fixed-points cells of the national laboratories of the Americas. Sistema Interamericano de Metrologia, 1-16. Querétaro, México.

4. J Ancsin, E. Méndez Lango (1999). The reproducibility of some thermometric fixed points and the accuracy of temperature measurements using platinum resistance thermometers. Metrologia 36, 117-139. Paris, Francia.

5. J. Ancsin (1998). Comunicación Personal.

6. E. Méndez Lango, J. Valencia Rodriguez, J. M. Figueroa Estrada (1994). Mercury Triple Point Measurements realized at the Thermometry Laboratory of CENAM. XIII IMEKO World Congress. IMEKO 2672-2675.Turin, Italia.

7. E: Méndez Lango (1993). El punto triple del triclorofluorometano como referencia termométrica. Tesis de Maestria en Física. Universidad Autónoma Metropolitana - Iztapalapa.

8. J. Ancsin (1969). Triple Point of Argon. Metrologia 5, 77-80. Paris, Francia.

9. B. W. Mangum, P. Bloembergen, M. V. Chattle, P. Marcarino, A. P. Pokhodun (1996). Recommended techniques for improved realization and intercomparisons of defining fixed points. Working Documents submited to the $19^{\text {th }}$ meeting of the Comite Consultatif de Thermometrie, CCT96-8, 1-28. Paris, Francia.

10. E. Méndez Lango, M. L. Chávez, F. Guzmán (1992). The Triple Point of Thrichlorofluoromethane. Temperature 6, 277-279. Nueva York, Estados Unidos.

11. C. K. Ma (1995). Critical viewpoints on the methods of realizing the metal freezing points of the ITS-90. Rev. Sci. Instrum. 66 (8), 4233-4240. Nueva York, Estados Unidos. 
12. J. Ancsin (1989). A Study of the Realization of the melting and Freezing Points of Silver. Metrologia 26, 167-174. Paris, Francia.

13. J. Ancsin (1992). Freezing and melting points of aluminum and an analysis of the characteristics of fixed-point fumace. Temperature 6, 343-348. Nueva York Estados Unidos.

14. J. Ancsin (1990). About the Reproducibility of teh "Melting" and "Freezing" Points of Binary Eutectics. Metrologia 27, 89-93. Paris Francia.

15. Y. I. Alexandrov, A. G. Ivanova, A. I. Pokhodun (1993). On the definition of freezing Points of the ITS-90. Metrologia, 30, 49-52.

16. J. Ancsin (1988). Triple Point of Xenon. Metrologia 25, 221-225. Paris Francia.

17. J. Ancsin, E. Méndez Lango (1996). Comparison of realization of thermometric fixed points of the ITS-90 between Canada and Mexico. Metrologia 33, 415-420. Paris, Francia.

18. J. Ancsin (1992). Freezing and melting points of aluminum and an analysis of the characteristics of a fixed-point furnace. Temperature 6, 277-279. Nueva York, Estados Unidos.

19. E. F. Westrum Jr., G.T. Furukawa, J. P. McCullough (1968). Adiabatic Lowtemperature Calorimetry. En Experimental Thermodynamics Vol. I, Ed. J. P. McCullough, D. W. Scott. Londres, Reino Unido.

20. F. Pavese, D. Ferri (1982). Ten Years of Research on Sealed Cells for Phase Transition Studies of Gases at IMGC. Temperature 5, 217-227. Nueva York, EUA.

21. E. Méndez Lango, J. Ancsin (1996). Triple Point and Melting Point of Mercury. Thermochimica Acta 287, 183-190. Amsterdam, Paises Bajos.

22. G. K. White (1959). Cap. VI Heat Transfer. En Experimental Techniques in Low-temperature Physics, pp 178-191. Clarendon Press. Londres, Reino Unido 


\section{CAPÍTULO TRES \\ SOLUCIONES DE OXÍGENO}

\section{III.1 Introducción}

Vamos a presentar la aplicación del modelo compuesto y pseudoternario. En la primera parte del capitulo describimos cómo se obtienen los coeficientes de distribución de soluciones binarias. Los coeficientes así obtenidos se emplean para el ajuste del modelo compuesto de curvas de fusión. Se ajusta el modelo compuesto a un conjunto de curvas de fusión de gases nobles en oxigeno. Se tratan particularmente los casos de $\mathrm{Ar}$ y $\mathrm{Kr}$.

En la segunda parte del capítulo ajustamos el modelo pseudoternario a una muestra comercial de oxígeno. Sus resultados se comparan con los obtenidos con el modelo compuesto.

\section{III.2 Modelo Compuesto}

En el capítulo I dedujimos el modelo compuesto (ec. III.1) para la descripción de las curvas de fusión de soluciones que tiene el soluto compuesto por varias especies.

$$
T_{l}(F)=T_{0}+\left(\frac{1}{A}\right)\left[\left(k_{1}-1\right) x_{1} F^{k_{1}-1}+\left(k_{2}-1\right) x_{2} F^{k_{2}-1}+\left(k_{3}-1\right) x_{3} F^{k_{3}-1}+\cdots\right], \text { III. } 1
$$

donde $T_{0}$ es el la temperatura de fusión del disolvente puro; $k_{\mathrm{i}}$ y $x_{\mathrm{i}}$ son el coeficientes de distribución y la fracción de cantidad de sustancia del i-ésimo 
componente del soluto; A es la constante crioscópica definida por (ec. I.6)

$$
A=\frac{\Delta_{\text {fus }} H_{m}}{R T_{0}^{2}} \quad,
$$

$\Delta_{f u s} H_{m}$ es cambio de la entalpia por mol de solución en la fusión, $R$ la constante de los gases y $T_{0}$ la temperatura absoluta de solidificación del disolvente.

El modelo compuesto tiene como parámetros ajustables a la temperatura de fusión del disolvente puro $\left(T_{0}\right)$ y dos parámetros por cada componente del soluto: la fracción de cantidad de sustancia $\left(x_{i}\right)$ y su coeficiente de distribución en las fases $\left(k_{\mathrm{i}}\right)$. En la siguiente sección presentamos un método para medir los coeficientes de distribución.

\section{III.2 1 Para obtener $k$ para cada solución binaria}

A partir del modelo compuesto, se puede determinar el cambio del punto liquidus $(F \approx 1)$ de la solución como función de la fracción de cantidad de sustancia $x_{i}$, del i-ésimo componente del soluto. La derivada parcial de la ec. III. 1 con respecto a la fracción de cantidad de sustancia $x_{i}$ es

$$
\frac{\partial T}{\partial x_{i}}=\frac{k_{i}-1}{A} F^{k_{i}-1} \equiv C_{i}(F)
$$

que evaluada en el punto liquidus corresponde a la pendiente de la recta aproximada a la curva liquidus, de la solución binaria formada por el disolvente con el i-ésimo componente del soluto,

$$
C_{l, i}=\frac{k_{i}-1}{A}
$$

La pendiente $C_{l, i}$ se puede estimar al medir el cambio del punto líquidus $\left(\Delta T_{l, i}\right)$ debido a un incremento $\left(\Delta x_{i}\right)$ de la fracción de cantidad de sustancia del i-ésimo 
componente del soluto

$$
C_{l, i} \approx \frac{\Delta T_{l, i}}{\Delta x_{i}}
$$

Para evaluar la validez de la aproximación lineal se obtienen puntos líquidus de la solución para diferentes valores de fracción de cantidad de sustancia del soluto y se grafican contra los incrementos de soluto. La aproximación será válida en la medida de que los puntos se ajusten a una línea recta.

Con el valor del la pendiente $C_{l, i}$, se calcula el coeficiente de distribución (a partir de la ec. III.3) con

$$
k_{i}=1+A C_{l, i}
$$

Una vez obtenidos los valores de los coeficientes de distribución, las fracciones de cantidad de sustancia $x_{i}$ (que componen al soluto) y la temperatura de fusión del disolvente puro se ajustan a los datos experimentales.

Aplicaremos este tratamiento a los datos experimentales obtenidos por Ancsin $[1,2,3]$, de soluciones de oxígeno con soluto compuesto por gases nobles y nitrógeno.

\section{III.2.2 Soluciones de oxigeno con gases nobles}

Los datos experimentales, empleados en este capitulo, fueron tomados experimentos realizados por Ancsin en un crióstato adiabático abierto $[1,2,3]$. El contenedor para la muestra (celda) fue hecho de cobre de $0,25 \mathrm{~mm}$ de espesor, cilíndrico de $1,5 \mathrm{~cm}$ de diámetro y de $6,5 \mathrm{~cm}$ de largo. El volumen para la muestra es aproximadamente de $10 \mathrm{~cm}^{3}$. La celda se construyó alrededor de un termómetro de resistencia de platino (TRP) tipo cápsula. Se usó el método de calorimetria adiabática para la obtención de los puntos sobre la curva de 
fusión.

Se empleó un TRP tipo cápsula de $25,5 \Omega$ en el punto triple de agua, el cual tiene sensibilidad de $0,11 \Omega / \mathrm{K}$ a la temperatura del punto triple de $\mathrm{O}_{2}$. La resistencia eléctrica se midió con un puente termométrico de corriente directa. El conjunto TRP-puente tiene resolución de 0,01 $\mathrm{mK}$.

El procedimiento que se siguió en los experimentos fue primero obtener la curva de fusión de una muestra de referencia, después se le agregaron cantidades conocidas de soluto $(\Delta x)$ de gases nobles a la muestra. Se empleo un contenedor de volumen de $9,6 \mathrm{~cm}^{3}$ y un manómetro absoluto de cápsula aneroide acoplado al contenedor externo de la muestra de $2 \mathrm{dm}^{3}$ [1]. Conocidos los volúmenes y las presiones antes y después de la mezcla se puede determinar la fracción de cantidad de sustancia de impureza con incertidumbre relativa de 10 por ciento.

En la fig. III.1 mostramos las curvas de fusión obtenidas al agregar argón (gráfica a) y kriptón (gráfica b) a la muestra de referencia. Los símbolos en las gráficas representan a los puntos experimentales. Las etiquetas A1 a A5 corresponden a las curvas de fusión obtenidas al agregar $\mathrm{Ar}$ a la muestra de referencia y las etiquetas $\mathrm{K} 1$ a $\mathrm{K} 5$ representan las curvas obtenidas al agregar $\mathrm{Kr}$ a la muestra de referencia. En la tabla III.I presentamos la cantidad de Ar y $\mathrm{Kr}$ añadida a la muestra de referencia.

Tabla III.I. Se presentan la identificación de las muestras con las cantidades de fracción de cantidad de sustancia de Ar (curvas Ai) y de $\mathrm{Kr}$ (curvas Ki). También se presenta la resistencia del termómetro en el punto liquidus $(n)$ de cada curva (estimada gráficamente).

\begin{tabular}{|c|c|c|c|c|c|}
\hline curva & $\boldsymbol{x}_{\mathbf{A r}} * \mathbf{1 0}$ & $\boldsymbol{r}_{\boldsymbol{l}} / \Omega$ & curva & $\boldsymbol{x}_{\mathbf{K r}}{ }^{* 10^{6}}$ & $\boldsymbol{r}_{\boldsymbol{l}} / \Omega$ \\
\hline $\mathbf{A 1}$ & 61 & 2,34428 & $\mathbf{K 1}$ & 63 & 2,34418 \\
\hline $\mathbf{A 2}$ & 116 & 2,34436 & $\mathbf{K 2}$ & 190 & 2,34412 \\
\hline $\mathbf{A 3}$ & 232 & 2,34446 & $\mathbf{K 3}$ & 365 & 2,34406 \\
\hline $\mathbf{A 4}$ & 554 & 2,34474 & $\mathbf{K 4}$ & 581 & 2,34396 \\
\hline $\mathbf{A 5}$ & 778 & 2,34506 & $\mathbf{K 5}$ & 806 & 2,34389 \\
\hline
\end{tabular}



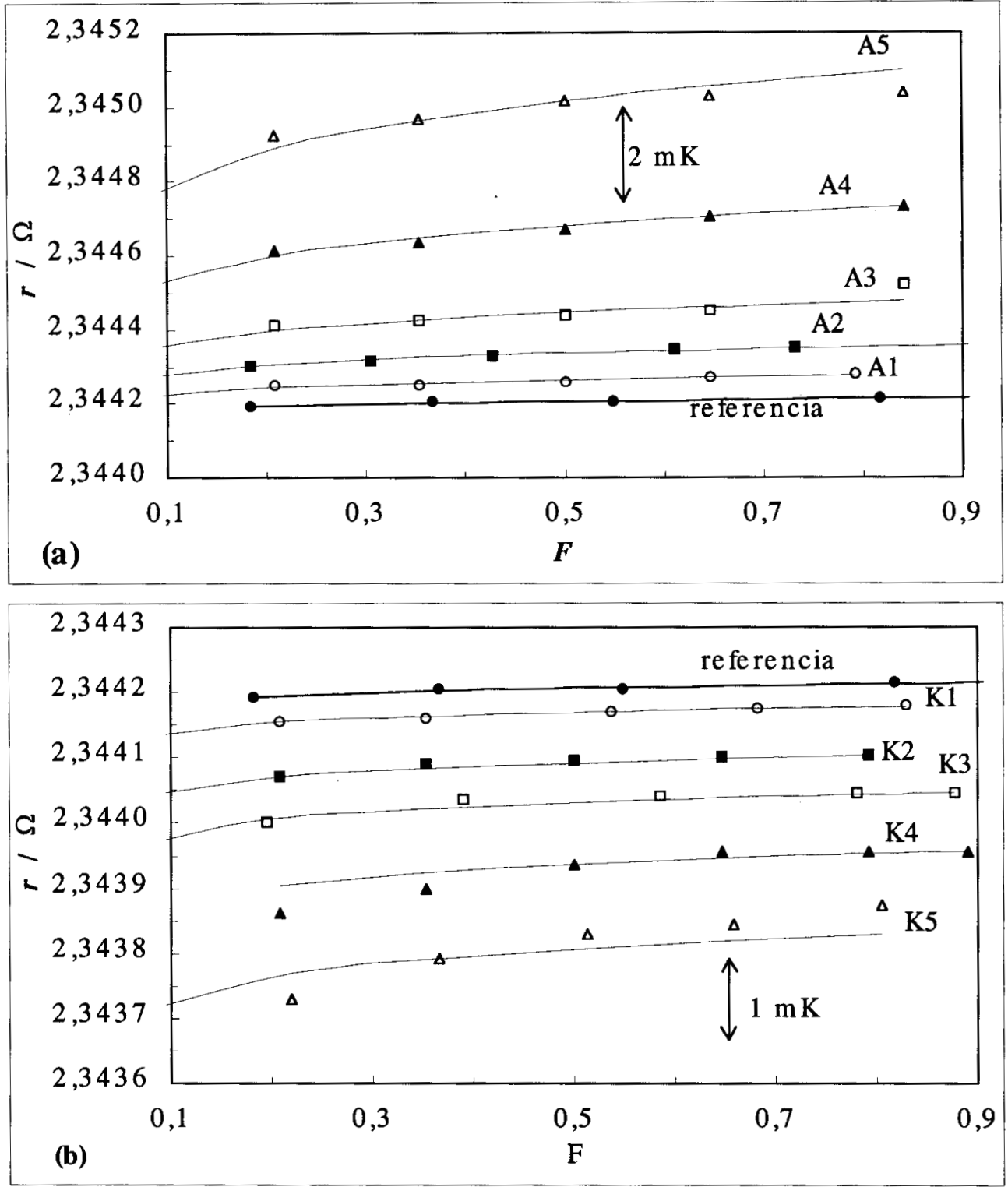

Figura III.1. Curvas de fusión de soluciones de $\mathrm{Ar}$ (gráfica a) y $\mathrm{Kr}$ (gráfica b) en $\mathrm{O}_{2}$. En estas gráficas la muestra de referencia está representada por los círculos llenos (๑). Las lineas de interpolación fueron ajustadas con el modelo compuesto. La temperatura fue medida con un termómetro de resistencia de platino con sensibilidad de $0,11 \Omega / \mathrm{K}$. 


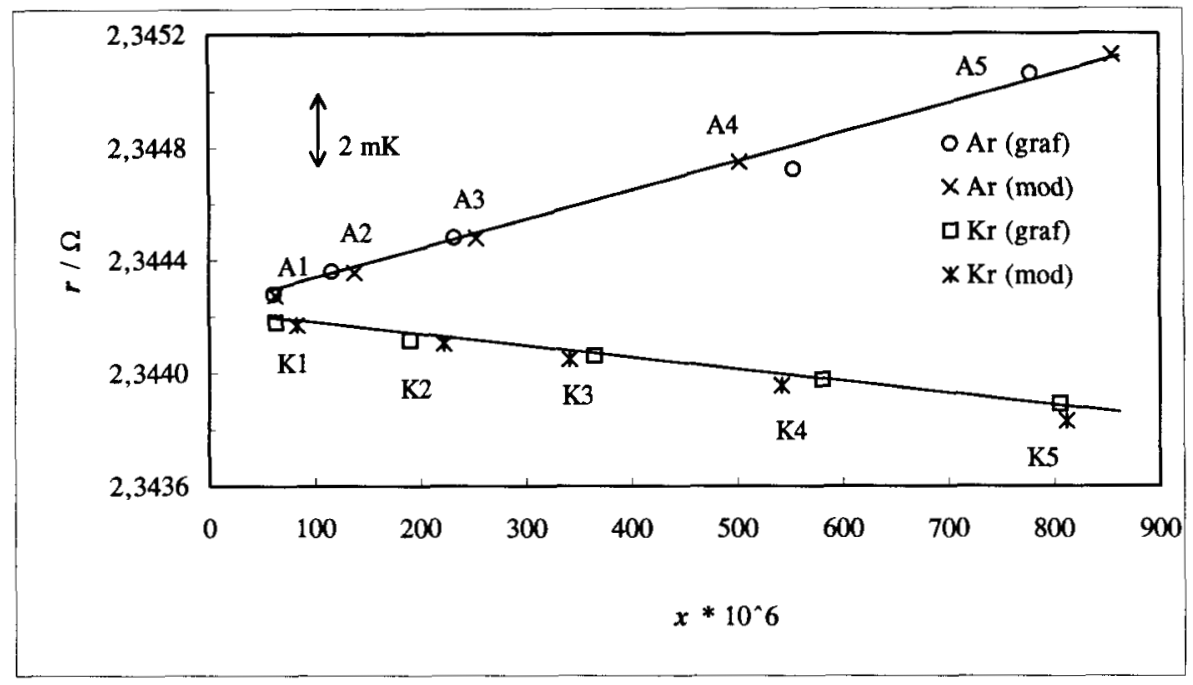

Figura III.2. Dependencia del punto líquidus de soluciones de oxígeno como función de la cantidad de soluto añadido. Los puntos liquidus de las soluciones de $\mathrm{Ar}$ en $\mathrm{O}_{2}$ se obtuvieron gráficamente $(0)$ y posteriormente con el modelo compuesto $(x)$; para las soluciones de $\mathrm{Kr}$ en $\mathrm{O}_{2}$ se obtuvieron por los indicados con los símbolos $\square$ y $*$, respectivamente.

A los puntos experimentales de la gráfica III.1 se les ajustaron gráficamente curvas suaves para la estimación de su punto liquidus. En la fig. III.2 presentamos los puntos liquidus (estimados de esta manera) graficados contra $x$.

Ajustamos líneas rectas a los puntos líquidus (fig. III.2). Con las pendientes calculamos los coeficientes de distribución y obtuvimos 1,179 para Ar y 0.922 para $\mathrm{Kr}$. El valor de la constante crioscópica $(A)$ del oxígeno, usada en los cálculos, es $0,0181 \mathrm{~K}^{-1}$ [4].

El modelo que empleamos para ajustar los parámetros de cada una de las curvas es

$$
T_{l}(F)=T_{0}+\left(\frac{1}{A}\right)\left[\left(k_{A r}-1\right)\left(x_{A r}+\Delta x_{A r}\right) F^{k_{A r}-1}+\left(k_{K r}-1\right)\left(x_{K r}+\Delta x_{K r}\right) F^{k_{K r}-1}\right] \quad \text { III.5 }
$$

donde $x_{A r}$ y $x_{K r}$ son las fracciones de cantidad de sustancia de $\mathrm{Ar}$ y $\mathrm{Kr}$ (respectivamente) presentes en la muestra de referencia. 
El ajuste de los parámetros se hizo simultáneamente para las 11 curvas. Se escribió un programa en una hoja de cálculo comercial que usa el método del gradiente conjugado [5]. Con los parámetros resultantes calculamos el punto liquidus de cada curva. En las tablas III.II y III.III se muestran los resultados para las soluciones de $\mathrm{Ar}$ en $\mathrm{O}_{2}$ y $\mathrm{Kr}$ en $\mathrm{O}_{2}$, respectivamente; las líneas continuas de las gráficas en la fig. III.1 representan a las curvas ajustadas.

Tabla III.II. En las primeras columnas se comparan los valores experimentales de la cantidad de Ar añadida contra la estimada por el modelo. En las últimas columnas se comparan los puntos líquidus obtenidos gráficamente contra los obtenidos con el modelo compuesto.

\begin{tabular}{|c|c|c|c|c|}
\hline curva & $\mathbf{x}^{*} \mathbf{1 0}^{\mathbf{6}}$ (exp) & $\mathbf{x}^{*} \mathbf{1 0}^{\mathbf{6}}$ (mod) & $\mathbf{r}$ (graf) $/ \Omega$ & $\mathbf{r}$ (mod) $/ \Omega$ \\
\hline $\mathbf{A 1}$ & 61 & 63 & 2,34428 & 2,34428 \\
\hline $\mathbf{A 2}$ & 116 & 138 & 2,34436 & 2,34436 \\
\hline $\mathbf{A 3}$ & 232 & 253 & 2,34446 & 2,34448 \\
\hline $\mathbf{A 4}$ & 554 & 503 & 2,34474 & 2,34475 \\
\hline $\mathbf{A 5}$ & 778 & 856 & 2,34506 & 2,34513 \\
\hline
\end{tabular}

Tabla III.III. En las primeras columnas se comparan los valores experimentales de la cantidad de $\mathrm{Kr}$ añadida contra la estimada por el modelo. En las últimas columnas se comparan los puntos líquidus obtenidos gráficamente contra los obtenidos con el modelo compuesto.

\begin{tabular}{|c|c|c|c|c|}
\hline curva & $\mathbf{x}^{*} \mathbf{1 0}^{\mathbf{6}}$ (exp) & $\mathbf{x}^{\star} \mathbf{1 0 ^ { 6 }}$ (mod) & $\mathbf{r}$ (graf) $/ \Omega$ & $\mathbf{r}$ (mod) $/ \Omega$ \\
\hline $\mathbf{K 1}$ & 63 & 83 & 2,34418 & 2,34417 \\
\hline $\mathbf{K 2}$ & 190 & 222 & 2,34412 & 2,34411 \\
\hline $\mathbf{K 3}$ & 365 & 341 & 2,34406 & 2,34405 \\
\hline $\mathbf{K 4}$ & 581 & 542 & 2,34396 & 2,34396 \\
\hline $\mathbf{K 5}$ & 806 & 812 & 2,34389 & 2,34383 \\
\hline
\end{tabular}

Se encontró que la resistencia eléctrica de termómetro correspondiente al 
disolvente puro $r\left(T_{0}\right)$ es $2,344190 \Omega$ y que la muestra de referencia tiene 31 ppm de fracción de cantidad de sustancia de Ar y $22 \mathrm{ppm}$ de $\mathrm{Kr}$. El punto líquidus de la muestra de referencia es 2,344209 que está $0,2 \mathrm{mK}$ por arriba de la temperatura de fusión del disolvente puro.

Tabla III.IV. Valores de la pendiente de la recta aproximada a la curva liquidus y coeficientes de distribución para soluciones de oxigeno.

\begin{tabular}{|c|c|c|}
\hline $\mathbf{O}_{\mathbf{2}}+$ & $\mathbf{C}_{\boldsymbol{l}} / \mathbf{( K / \mathbf { X } )}$ & $\boldsymbol{k}$ \\
\hline $\mathbf{A r}$ & 10,7 & 1,18 \\
\hline $\mathbf{H e}$ & 1,2 & 1,021 \\
\hline $\mathbf{N e}$ & $-1,5$ & 0,97 \\
\hline $\mathbf{K r}$ & $-4,7$ & 0,92 \\
\hline $\mathbf{X e}$ & $-8,0$ & 0,86 \\
\hline $\mathbf{N}_{\mathbf{2}}$ & -12 & 0,78 \\
\hline
\end{tabular}

En la tabla III.IV presentamos los coeficientes de distribución de algunas sustancias en solución en $\mathrm{O}_{2}$. Una muestra de oxigeno puede tener solutos de algunas de las sustancias que aparecen en la tabla, si se conocen su concentración, entonces es posible obtener la curva de fusión con el modelo compuesto. En caso de que sólo se conozcan el tipo de solutos, pero no su fracción de cantidad de sustancia, entonces se pueden obtener esos valores para cada soluto via el ajuste del modelo compuesto.

\section{III.2.3 Análisis de resultados}

a) Puntos líquidus. Los puntos líquidus estimados gráficamente se comparan con los obtenidos con el modelo en las dos últimas columnas de las tablas III.II y III.III. Las discrepancias entre estos valores es del orden de $10 \mu \Omega$, equivalente a $0,1 \mathrm{mK}$, hasta los $550 \mathrm{ppm}$ de fracción de cantidad de sustancia añadida a la muestra de referencia. Las diferencias encontradas tanto en la curva A5 como en la $\mathrm{K} 5$ son del orden de $0,5 \mathrm{mK}$.

Los puntos líquidus de las curvas obtenidas graficados contra $x$ caen en una 
línea recta a excepción del de la curva A4. Desde este punto de vista la aproximación hecha para el cálculo de $C_{l, i}$ es adecuada en todos los casos.

b) Perfil de las curvas de fusión. En las gráficas de la fig. III.1 las lineas continuas ajustadas a la muestra de referencia, y las soluciones A1, A2, A3, A4, $\mathrm{K} 1$, $\mathrm{K} 2 \mathrm{y} \mathrm{K} 3$, obtenidas con el ajuste del modelo compuesto tienen discrepancias del orden de 0,1 mK; las correspondientes a las curvas A5, K4 y $\mathrm{K} 5$ sus discrepancias son del orden de $0,5 \mathrm{mK}$. Además, la curvatura de $\mathrm{K} 4 \mathrm{y}$ K5 discrepa con la obtenida con el modelo compuesto.

c) Temperatura de fusión del disolvente puro. La resistencia calculada para el punto de fusión del disolvente puro es $2,344190 \Omega$. La dispersión de los valores tiene desviación estándar de $2,3^{*} 10^{-6} \Omega$ para obtener una con incertidumbre tipo A de $\pm 1,6^{*} 10^{-6}$, equivalente a $0,02 \mathrm{mK}$ en la determinación de $T_{0}$.

d) Coeficientes de distribución. En la figura III.2 se graficaron los puntos liquidus contra $x$. En la gráfica se muestran lo puntos líquidus estimados gráficamente y los obtenidos con el modelo compuesto. A cada conjunto de datos se calculó su pendiente y (de ésta) el coeficiente de distribución. Así se obtienen dos coeficientes de distribución para cada solución binaria. La discrepancia entre estos dos valores nos da el orden de magnitud de la incertidumbre en su determinación. Obtuvimos que los valores discrepan en

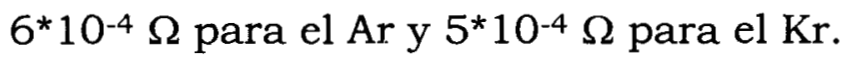

e) Fracción de cantidad de sustancia de cada tipo de soluto. En las tabla III.II y III.III se presentan los valores medidos y los ajustados de las fracciones de cantidad de sustancia añadidas a la solución de referencia. La desviación estándar de su diferencia relativa es del 9 por ciento.

\section{III.3 Modelo pseudoternario}

El modelo pseudoternario es una simplificación del modelo compuesto. La ecuación del modelo es 


$$
T_{l}(F)=T_{0}+\left(\frac{1}{A}\right)\left[\left(k_{+}-1\right) x_{1} F^{k_{+}-1}+\left(k_{-}-1\right) x_{2} F^{k_{-}-1}\right] \quad \text {, III.6 }
$$

donde los subindices "+" indican los parámetros del componente del soluto con k>1 y los subindices "-” los parámetros relacionados con los componentes del soluto con $\mathrm{k}<1$.

A continuación vamos a hacer el análisis de una muestra comercial donde usaremos tanto el modelo compuesto como el pseudoternario.

\section{III.3.1 Análisis de una muestra comercial}

Se obtuvieron puntos experimentales de una muestra de oxigeno de Matheson. Los tipos y fracciones de solutos en la muestra están especificados por el fabricante del gas (tabla III.V) [1]. Con esta información, y los valores de $k$ obtenidos en la sección anterior (tabla III.IV), calculamos los parámetros del modelo compuesto.

En la fig. III.3, los puntos negros son los datos experimentales. La linea a trazos corresponde a la curva generada con el modelo compuesto y los datos del fabricante. Esta curva no ajusta los datos experimentales.

Calculamos un segundo ajuste, donde se dejaron fijos los tipos de soluto, pero no sus cantidades. Los valores calculados de la fracción de cantidad de sustancia de cada soluto se indican en la tercer columna de la tabla III.V. La curva ajustada con el modelo compuesto se representa con la línea continua en la fig. III.3. 


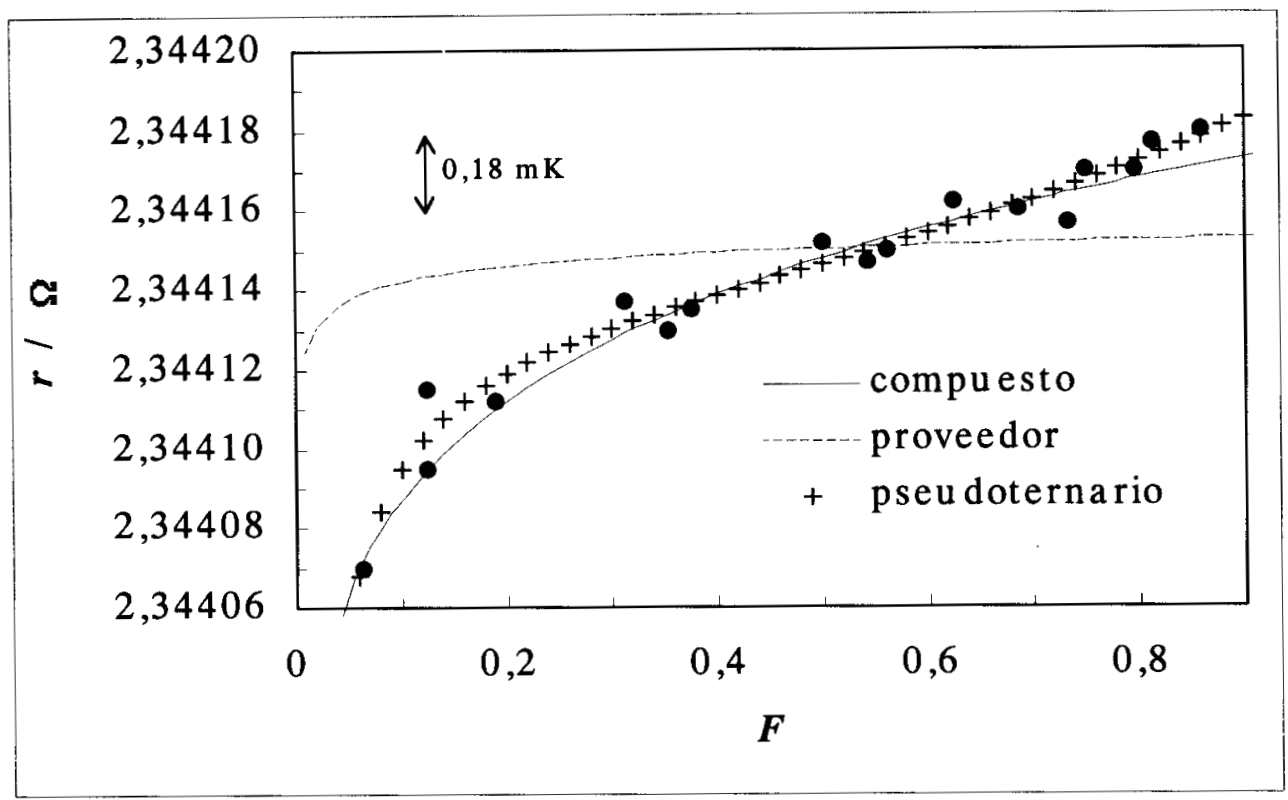

Figura III.3. Curva de fusión de una muestra de oxígeno comercial (Matheson). Los puntos representan los datos experimentales. La línea punteada es la curva que corresponde al análisis quimico proporcionado por el fabricante de la muestra. La línea continua es el ajuste del modelo compuesto y la línea marcada con los símbolos "+" corresponde al ajuste pseudoternario.

De la tabla III.V se tiene que las fracciones de cantidad de sustancia de kriptón y xenón son del mismo orden que las declaradas por el proveedor de la muestra. El contenido de nitrógeno, calculado con el modelo compuesto, es cinco tantos lo manifestado por el fabricante y la mayor discrepancia la encontramos en el contenido de argón. Esta diferencia puede conducir a un error sistemático del orden de $2 \mathrm{mK}$, del orden de 100 veces la resolución de un TRP a esa temperatura.

Ajustamos el modelo pseudoternario a los mismos datos experimentales. Los resultados los presentamos en la tabla III.VI. 
Tabla III.v. Parámetros de ajuste de la curva de fusión de una muestra de $\mathrm{O}_{2}$ comercial (Matheson). Se comparan los valores declarados de las fracciones de cantidad de sustancia de impurezas $\left(x_{m}\right)$ con los obtenidos con el modelo compuesto $x_{\text {mod }}$. En la última columna $\left(x_{d}\right)$ se presentan los parámetros para la muestra después de haber sido degasada.

\begin{tabular}{|c|c|c|c|}
\hline $\mathbf{O}_{\mathbf{2}}+$ & $\boldsymbol{x}_{\boldsymbol{m}}$ * $\mathbf{1 0}^{\mathbf{6}}$ & $\boldsymbol{x}_{\mathbf{m o d}}$ * $\mathbf{1 0}^{\mathbf{6}}$ & $\boldsymbol{x}_{\boldsymbol{d}}$ *106 \\
\hline $\mathbf{A r}$ & 5 & 218 & 195 \\
\hline $\mathbf{K r}$ & 7,6 & 3,6 & 0 \\
\hline $\mathbf{X e}$ & 0,9 & 0,9 & 0 \\
\hline $\mathbf{N}_{\mathbf{2}}$ & 5 & 19 & 0 \\
\hline
\end{tabular}

Tabla III.VI. Parámetros de ajuste del modelo pseudoternario a una curva de fusión de una muestra de oxígeno comercial (Matheson). En la última columna $\left(x_{d}\right)$ se presentan los parámetros para la muestra después de haber sido degasada.

\begin{tabular}{|c|c|c|c|c|}
\hline tipo & $\boldsymbol{k}$ & $\boldsymbol{C}_{l} / \mathrm{K}$ & $\boldsymbol{x} / \mathbf{p p m}$ & $\boldsymbol{x}_{\boldsymbol{d}} / \mathbf{p p m}$ \\
\hline $\boldsymbol{k}>\mathbf{1}$ & 1,20 & 11,0 & 182 & 163 \\
\hline $\boldsymbol{k}<\mathbf{1}$ & 0,85 & $-8,3$ & 60 & 0 \\
\hline
\end{tabular}

La fracción de cantidad de sustancia total de solutos (241,5 ppm), resultado del ajuste del modelo compuesto, coincide con el del modelo pseudoternario (242 ppm). Además, el valor de $k>1(1,2)$ es similar al correspondiente de argón $(1,17)$ y el valor de $k<1(0,85)$ es del mismo orden que el de nitrógeno $(0,73)$ : las dos especies más abundantes en los resultados del modelo compuesto.

La curva ajustada por el modelo pseudoternario se presenta en la gráfica de la fig. III. 3 y se distingue por el signo " + " sobre la linea continua. Este ajuste es indistinguible al obtenido via la determinación de la fracción de cantidad de sustancia de los componentes del soluto. En el primer caso se obtuvo $r\left(T_{0}\right)=$ $2,344029 \Omega$, y en el segundo $r\left(T_{0}\right)=2,344006 \Omega$, su diferencia corresponde a $0,2 \mathrm{mK}$ (la sensibilidad del TRP es $0,11 \Omega / \mathrm{K}$ ). La discrepancia entre los valores para $T_{o}$ obtenidos en los dos ajustes nos permite estimar el error generado por 
el uso del modelo pseudoternario, en lugar del compuesto, en la determinación de $T_{0}: \sim 0,2 \mathrm{mK}$.

\section{III.3.2 Comparación de puntos fijos de la EIT-90}

En trabajos de comparación de la reproducción del punto triple de $\mathrm{O}_{2}$, realizados en diferentes países, Pavese encontró [6] que el punto reproducido por Ancsin [1] estaba 2,3 mK por arriba de la temperatura de la muestra usada como referencia. En su artículo Pavese sugiere que la muestra de Ancsin está contaminada por 190 ppm de fracción de cantidad de sustancia de argón, sin considerar otros solutos. En nuestro análisis encontramos con el modelo compuesto $218 \mathrm{ppm}$ de Ar y, con el modelo pseudoternario, $182 \mathrm{ppm}$. Los valores concuerdan con la estimación de Pavese.

\section{III.3.3 Efecto de degasado}

Después de obtener la curva de fusión de la muestra de oxigeno de Matheson, se calentó la muestra hasta que alcanzó la temperatura de nitrógeno líquido (80 $\mathrm{K})$. En estas condiciones se extrajeron $2 \mathrm{dm}^{3}$ de gas a esa presión de vapor. Luego se obtuvo la curva de fusión de la muestra degasada. En la gráfica de la fig. III.4 los círculos vacíos representan los puntos experimentales de la curva de fusión de esta muestra.

Se calcularon los parámetros para esta curva en los cuales se consideraron fijos el valor de $T_{0}$ y los componentes del soluto en la muestra original al usar el modelo compuesto. Así mismo, se emplearon los parámetros $T_{0}$, y los coeficientes de distribución calculados en el ajuste del modelo pseudoternario. 
La línea continua ajustada a los datos de la muestra degasada (fig. III.4) representa el ajuste del modelo compuesto. Los simbolos "+" se usaron para indicar el ajuste pseudoternario. Se encontró que ambos ajustes son indistinguibles.

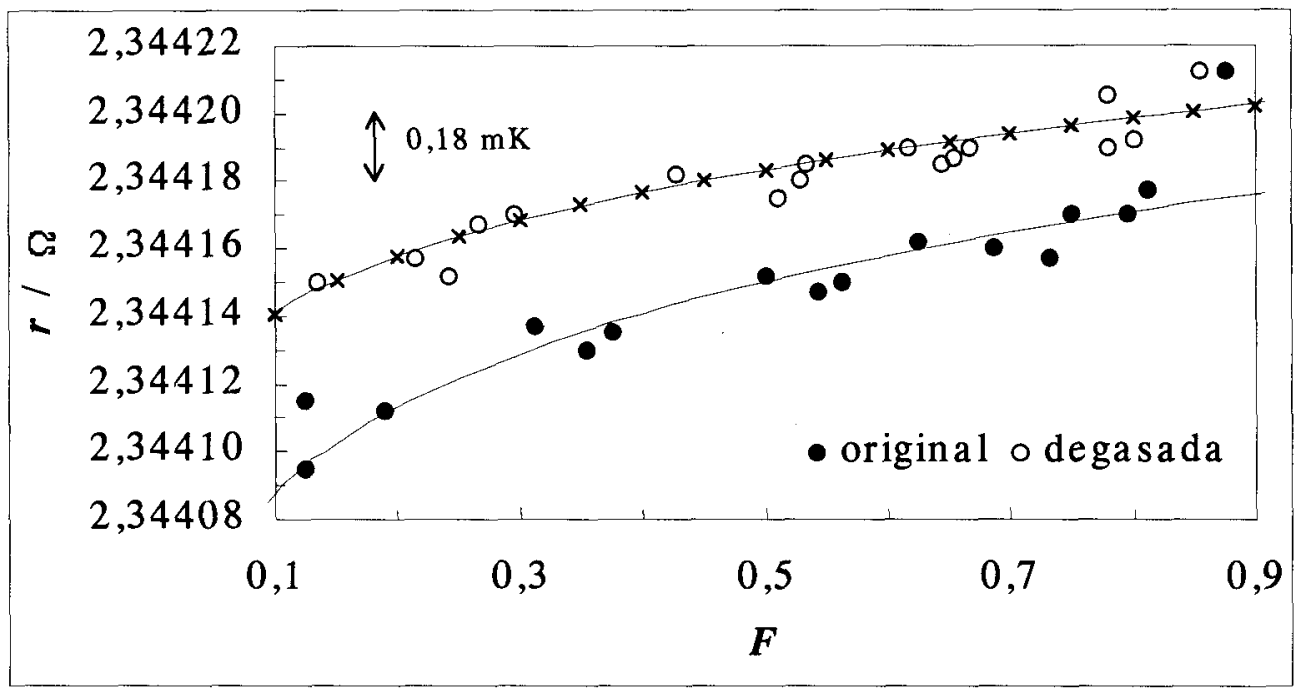

Figura III.4. Efecto de degasado sobre la curvas de fusión de una muestra de oxígeno de Matheson. Los círculos sólidos son los datos experimentales de la curva de fusión de la muestra original. Los circulos vacios se obtuvieron después de degasar a la muestra. Las lineas de interpolación se obtuvieron con el modelo compuesto. El símbolo " $x$ " se usó para indicar el ajuste pseudoternario de los datos de la muestra degasada: Las curvas resultantes de los modelos ajustados son indistinguibles entre ellas.

En la última columna de las tablas III.V y III.VI $\left(x_{\mathrm{d}}\right)$ mostramos los parámetros que obtuvimos en los ajustes de los modelos compuesto y pseudoternario. Los componentes del soluto con $\mathrm{k}<1$ fueron removidos por el degasado en ambos casos.

\section{III.4 Conclusiones}

El modelo compuesto ajusta adecuadamente a los datos experimentales en el caso cuando se tiene un soluto compuesto por varias especies. Los casos presentados indican que para fracciones de cantidad de sustancia de hasta 500 
ppm el modelo compuesto es apropiado para la determinación del punto fusión del disolvente puro y la composición química del soluto: fracciones de cantidad de sustancia y coeficientes de distribución.

La concordancia de los resultados del modelo compuesto y del pseudoternario, es excelente tanto en la estimación de $T_{0}$ como en la fracción de cantidad de sustancia $x_{\mathrm{i}}$ de los componentes del soluto.

Encontramos dos aplicaciones del modelo pseudoternario: a) en la estimación de errores sistemáticos en la reproducción de puntos fijos de la EIT-90 debido a impurezas en las muestras y b) para evaluar la efectividad de los procesos de refinación de materiales aun cuando no se conoce la composición química del soluto.

\section{III.5 Referencias}

1. J. Ancsin (1970). The triple Point of Oxygen and its Change by Noble Gas Impurities. Metrologia, 6, 53-56. Paris, Francia.

2. J. Ancsin (1973). Dew Points, Boiling Points and Triple Points of "Pure" and Impure Oxygen. Metrologia, 9, 26-39. Paris,Francia.

3. J. Ancsin (1998). Comunicación Privada.

4. B. W. Mangum, G. T. Furukawa (1990). Guidlines for Realizing the International Temperature Scale of 1990 (ITS-90). NIST Techical Note 1265, 29. Gaithersburg, EUA.

5. Microsoft Excel Solver. Front Line System, Inc. (c) 1990,1991,1992 y 1995.

6. F. Pavese, D. Ferri, D. Giraudi (1988). Evidence of Unreliability of Factory Analyses. Advances in Cryogenics Engineering, 33, 1039-1043. Plenum. 


\section{CAPÍTULO CUATRO \\ OTROS SISTEMAS}

\section{IV.1 Introducción}

En la reproducción de la EIT-90 en México hemos trabajado con los puntos triples de argón, de mercurio, de agua, el punto de fusión de galio y los puntos de solidificación de indio, de estaño de zinc, de aluminio y de plata. En cada uno de estos puntos se han hecho estudios para determinar su intervalo de fusión, como medida indicadora de su pureza. Además, se han hecho pruebas de consistencia interna [1] y se han intercomparado estos puntos con sus similares de Estados Unidos [2], Canadá [3] y algunos paises de Centro y Sudamérica [4]. Como ejemplo, en este capitulo presentamos los trabajos relacionados con el punto triple de argón.

Durante una estancia de trabajo en el Institute for National Measurement Standards de Canadá (en 1995) el autor reconstruyó el crióstato adiabático usado por Ancsin en su estudio de soluciones de oxígeno [5]. En esta ocasión, el aparato fue configurado para operar con celdas selladas y con TRPs de cápsula. En las pruebas de operación medimos los puntos triples de $\operatorname{Ar}(83 \mathrm{~K})$, $\mathrm{CH}_{4}(90 \mathrm{~K}), \mathrm{Kr}(117 \mathrm{~K}), \mathrm{Xe}(161 \mathrm{~K}), \mathrm{Hg}(234 \mathrm{~K})$ y $\mathrm{H}_{2} \mathrm{O}(273 \mathrm{~K})$ [6]. Como ejemplo, presentamos los resultados obtenidos con la celda de xenón, donde sólo el modelo pseudoternario fue capaz de ajustar a los datos experimentales. 


\section{IV.2 Punto triple de argón}

El punto triple de argón se emplea, de acuerdo a la EIT-90, para la calibración de termómetros de resistencia de platino (TRP) tanto de tallo largo (usados hasta $960^{\circ} \mathrm{C}$ ) como en los de tipo cápsula (usados en criogenia).

Construimos un crióstato para la reproducción de este punto. En este aparato la unidad de medición (bloque igualador) y el contenedor de la muestra (celda) están maquinados en la misma pieza de cobre [7]. El tratamiento de los datos experimentales de las curvas de fusión obtenidas se hizo con los modelos descritos en el capítulo I.

\section{IV.2.1 Crióstato para calibración de TRPs en el punto triple de Ar}

El principio de operación es igual al descrito para los calorímetros adiabáticos del capítulo II. Aunque el aparato fue construido para la calibración de TRPs de tallo largo en el punto triple de argón, también puede ser empleado en la calibración de termómetros por comparación, en el intervalo desde el punto de ebullición de nitrógeno líquido $(\sim 80 \mathrm{~K})$ hasta temperatura ambiente.

\section{Detalles de construcción}

El aparato tiene una unidad de medición construida de un cilindro de cobre de $6 \mathrm{~cm}$ de diámetro y $14,5 \mathrm{~cm}$ de longitud (fig. IV.1). Concéntrica y a lo largo del bloque, se horadó una cavidad $3,2 \mathrm{~cm}$ de diámetro. Con el cilindro en posición vertical, en el extremo inferior (dentro de la cavidad) se colocaron 20 láminas circulares de cobre de $3,2 \mathrm{~cm}$ de diámetro y $1,3 \mathrm{~mm}$ de espesor y separadas 1,3 $\mathrm{mm}$ entre dos láminas sucesivas. El propósito de las láminas es mejorar el 
contacto térmico entre el bloque de cobre con el argón condensado en el extremo inferior de la cavidad y reducir el tiempo de relajación para alcanzar el equilibrio después de un ciclo de calentamiento..

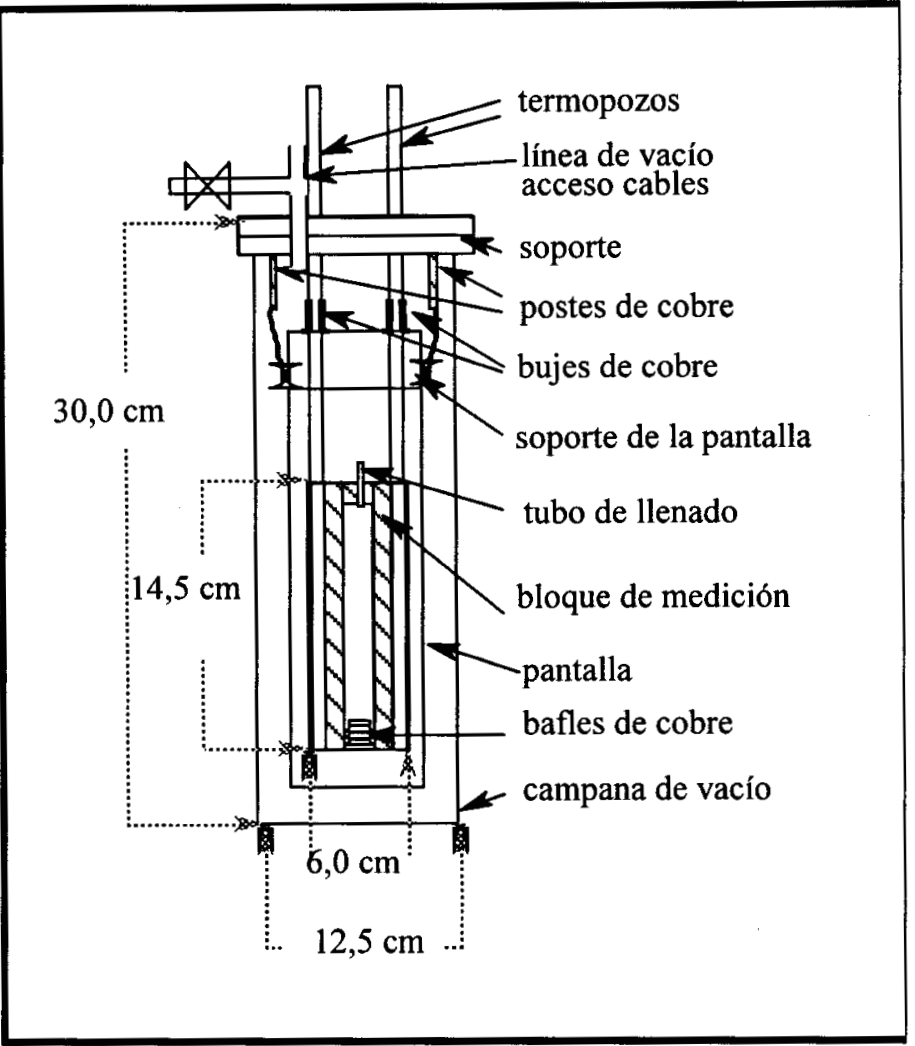

Figura IV.1. Crióstato de argón. La celda esta construida en el mismo bloque de medición.

El extremo superior de la cavidad fue sellado con un tapón de cobre el cual tiene soldado un tubo de cobre de $3 \mathrm{~mm}$ de diámetro para el llenado de la cavidad (celda). La celda se llenó con una muestra de argón de alta pureza a 4,1 MPa a temperatura ambiente. Después del llenado se ocluyó mecánicamente el tubo y se selló con soldadura.

Entre la cavidad y la pared exterior del bloque de cobre se insertaron, y soldaron, cuatro tubos de acero inoxidable de pared delgada $(0,1 \mathrm{~mm})$, separados $90^{\circ}$ entre ellos. La parte inferior de los tubos está cerrada y coincide con el extremo inferior del bloque. Estos tubos son los pozos para los TRPs y, además, sirven para suspender la unidad de medición de la tapa superior del crióstato. 
Se soldó un buje de cobre sobre cada tubo de acero, a 7,5 $\mathrm{cm}$ por encima del extremo superior del bloque de medición. A su vez los bujes se soldaron a un soporte de cobre que se usa para fijar la pantalla de cobre. Sobre el soporte de cobre se tiene un calefactor eléctrico y dos tornillos para fijar alambres de cobre que sirven como anclas térmicas.

Los alambres de cobre están soldados a postes de cobre (de $5 \mathrm{~mm}$ de diámetro) que están fijos a la tapa superior del crióstato y en contacto directo con el baño refrigerante. El calibre del alambre de cobre, que se atornilla al soporte de la pantalla, es tal que permite el balance del intercambio de calor, de la unidad de medición, con el mínimo de potencia disipada en el calefactor del soporte de la pantalla. La pantalla se construyó de lámina de cobre de $1 \mathrm{~mm}$ de espesor.

Para mejorar el aislamiento térmico de la unidad de medición se enrolló sobre ella película de polipropileno y se hizo lo mismo sobre la pantalla de cobre.

El diseño del crióstato es especial para la calibración y comparación de TRPs y no para el estudio de las propiedades termodinámicas del argón. Para estudiar estas propiedades se requiere que el contenedor de la muestra tenga capacidad calorífica pequeña con respecto a la entalpía de fusión y con un tiempo de relajación muy corto (del orden de segundos). En esas condiciones es posible obtener medidas confiables de puntos sobre la curva de fusión aun en la vecindad del punto líquidus [8]. Este crióstato, aunque no es lo mejor para tales mediciones, es útil para medir algunas de estas propiedades con razonable exactitud [7].

\section{IV.2.2 Procedimiento experimental}

En los experimentos de puesta a punto del aparato, trabajamos con dos TRPs de tallo largo, uno (YJ) con funda de sílica fundida (cuarzo) y otro (Rosemount) con funda de acero inoxidable. 
El crióstato se colocó en un Dewar, se colocaron los dos TRPs en los pozos y se llenó el Dewar con nitrógeno líquido (NL). Se inyectó NL en uno de los pozos y, en una hora, la muestra alcanzó la temperatura del NL. Con la muestra de argón sólida (a unos $4 \mathrm{~K}$ por debajo de su punto triple) se hizo vacío y se inició con el control de temperatura de la pantalla. El resto de las mediciones se hicieron como se describió en el capitulo II.

Para la comparación de TRPs la temperatura de la unidad de medición puede fijarse a cualquier valor entre la temperatura ambiente y la de nitrógeno líquido (80 K). En este caso la unidad de medición, en particular el bloque de cobre, actúa como bloque igualador de temperatura. Evidentemente, el anclaje térmico requiere de ajuste si la diferencia de temperatura entre el bloque de cobre y la de NL es muy grande. Sin embargo, alrededor de los $200 \mathrm{~K}$ el baño de NL puede ser reemplazado por uno de $\mathrm{CO}_{2}$ sólido molido.

\section{IV.2.3 Resultados}

El pulso de energía que se entrega al bloque de medición, a través del calefactor, produce un incremento de temperatura del mismo. A su vez, el bloque conduce esta energía a la muestra donde se funde una porción del sólido y la fase liquida aumenta su temperatura. Al transcurrir el tiempo el sistema tiende al equilibrio hasta que alcanza un valor final de temperatura. En este proceso el termómetro indica un pico de temperatura que está varios $\mathrm{mK}$ por arriba del punto triple de la muestra y luego relaja hacia su valor final. El tiempo que tarda el sistema desde que termina el pulso de calor hasta que alcanza el equilibrio térmico se le llama tiempo de relajación.

En los experimentos de puesta a punto de este crióstato, observamos que el tiempo de relajación dependia de la fracción líquida $F$ de la muestra (fig. IV.2). Además, observamos que para mejorar la reproducibilidad de las mediciones era necesario un control estricto del nivel de NL. Ambos hechos nos hicieron sospechar que el balance de las fugas térmicas no era adecuado. Así que, mejoramos el anclaje térmico de los conductores eléctricos al aumentar la 
longitud pegada a la tapa superior del crióstato. Como resultado observamos que el tiempo de relajación es independiente de $F$ (circulos vacios de la fig. IV.2).

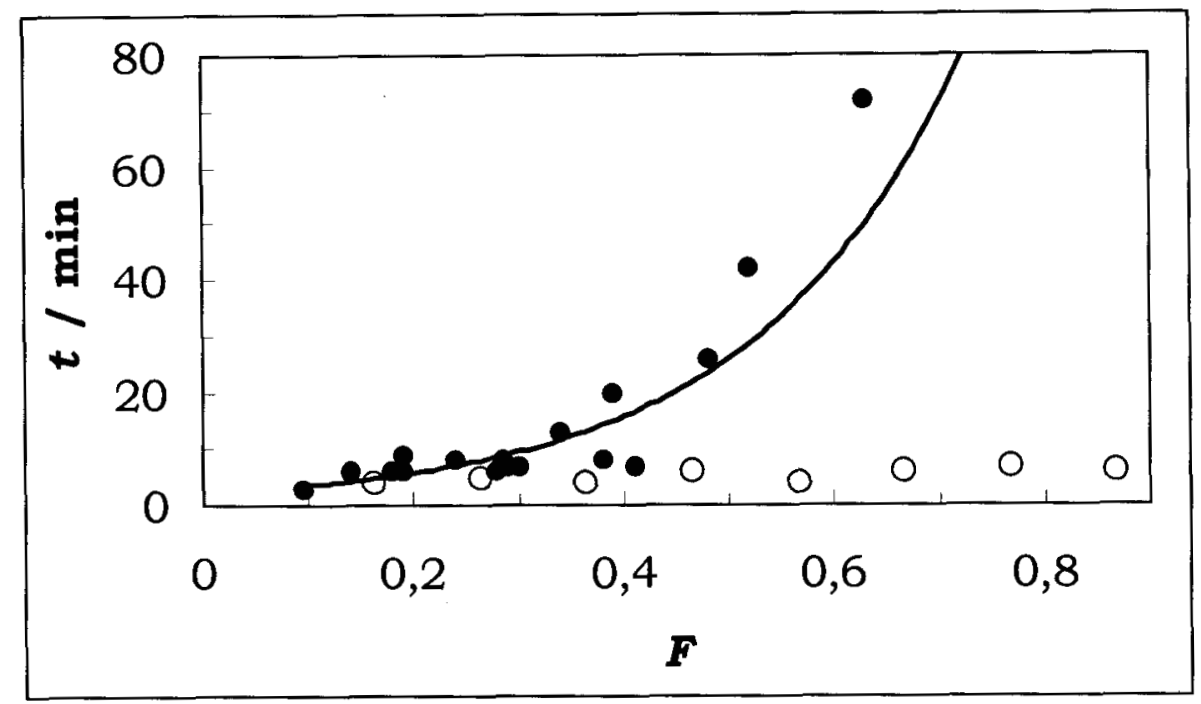

Figura IV.2. Tiempo de relajación después de un ciclo de calefacción. Los círculos llenos se obtuvieron antes de cambiar la configuración de las anclas térmicas. Los círculos vacios indican que el tiempo de relajación es independiente de la fracción liquida $(F)$ de la muestra.

En la fig. IV.3 se muestran los resultados obtenidos de cuatro corridas medidas con el TRP Rosemount. Hicimos el tratamiento de los datos experimentales para ajustar los modelos $1 / F$ (van't Hoff), termodinámico (Mastrangelo), gradiente de concentración (Gulliver) y pseudoternario. La línea continua corresponde al modelo pseudoternario, la dispersión de los puntos experimentales, con respecto a la linea interpolada es menor a $0,3 \mathrm{mK}$.(fig. IV.4)

En la Tabla IV.I se presentan los parámetros, $r$ (resistencia eléctrica delTRP correspondiente a $T_{0}$ )y la estimación de la fracción de cantidad de sustancia de impurezas, obtenidos para los cuatro modelos. Sorprendentemente, todos los modelos predicen el mismo valor para el punto triple de argón. 


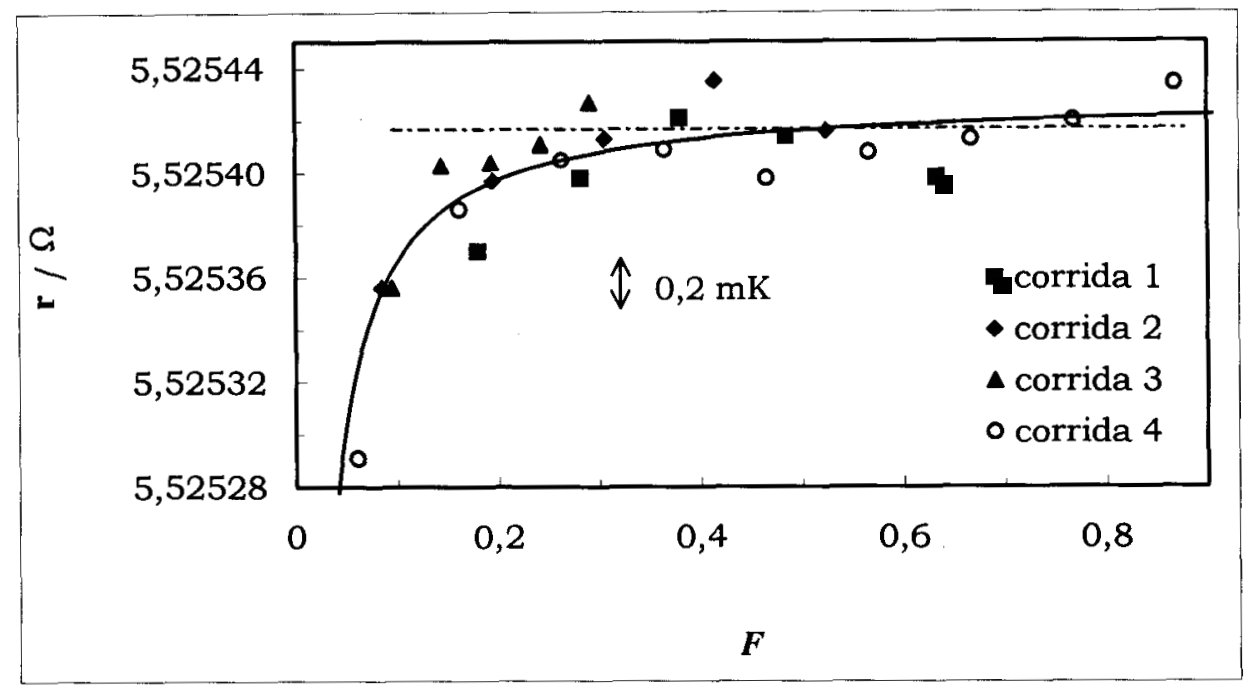

Figura IV.3. Curva de fusión de Ar. La línea continua se ajustó con el modelo pseudoternario; la línea a trazos es la estimación del punto triple del argón puro. La resolución del TRP es del tamaño de las marcas de los datos experimentales. Las corridas 1 a 3 fueron obtenidas antes de cambiar la configuración de las anclas térmicas.

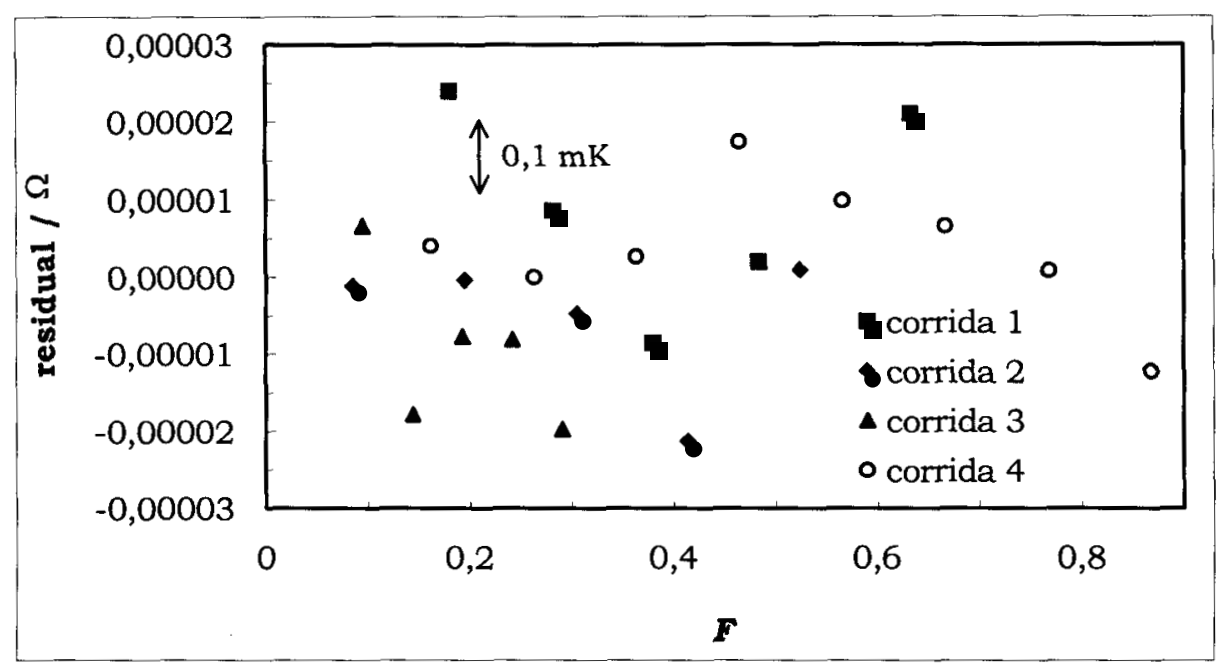

Figura IV.4 Residuales de los datos experimentales de la fig. IV. 3 con respecto a la curva interpolada con el modelo pseudoternario. 
Tabla IV.I. Parámetros $r_{0}$ y fracción de cantidad de sustancia obtenidos del ajuste de los datos experimentales que aparecen en la fig. IV.3. En el modelo pseudoternario el signo entre paréntesis identifica al tipo de impureza: "-" si deprime el punto y "+" si lo eleva.

\begin{tabular}{|c|c|c|}
\hline Modelo & $r_{0} / \Omega$ & $\mathbf{x} * \mathbf{1 0 6}$ \\
\hline van't Hoff & 5,525430 & 1,3 \\
\hline Mastrangelo & 5,525430 & 1,3 \\
\hline Gulliver & 5,525430 & 1,3 \\
\hline pseudoternario & 5,525429 & $1,3(-), 1,7(+)$ \\
\hline
\end{tabular}

\section{IV.2.4 Comparación con otros resultados}

En 1984 Ancsin [9] construyó otro crióstato adiabático que opera con celdas reemplazables y usa TRP de tallo largo o de cápsula. En la figura IV.5 se muestran los resultados de Ancsin (triángulos en la escala vertical de la izquierda) en comparación con los obtenidos en este trabajo (círculos en la escala vertical de la derecha). Como se observa los perfiles de las curvas son indistinguibles.

En 1973 Ancsin publicó un estudio sobre los equilibrios entre fases del argón [8]. En ese estudio se utilizó una celda especial en la que el TRP tipo cápsula estaba en contacto directo con la muestra. Con este diseño se tiene mejor control de las fugas térmicas porque el intercambio de energía entre la ceda y el ambiente, a través del tallo del TRP, no existe en este diseño. Comparamos los resultados de Ancsin (asteriscos en la escala vertical de la izquierda en la fig. IV.6) con los obtenidos en este trabajo (circulos en la escala vertical de la derecha). El intervalo de fusión de los datos de Ancsin es de $1 \mathrm{mK}$ contra el obtenido en este trabajo de $2 \mathrm{mK}$. Además, se puede observar que la dispersión de los datos de Ancsin (obtenidos en tres corridas) es menor a 0,1 mK. Hemos identificado que si bien la funda (parte exterior del tallo del TRP) puede ser 
adecuadamente anclada térmicamente, los alambres de conducción (dentro de la funda) no. Al usar TRP de tallo largo es imposible cancelar la transferencia de calor a través de estos conductores.

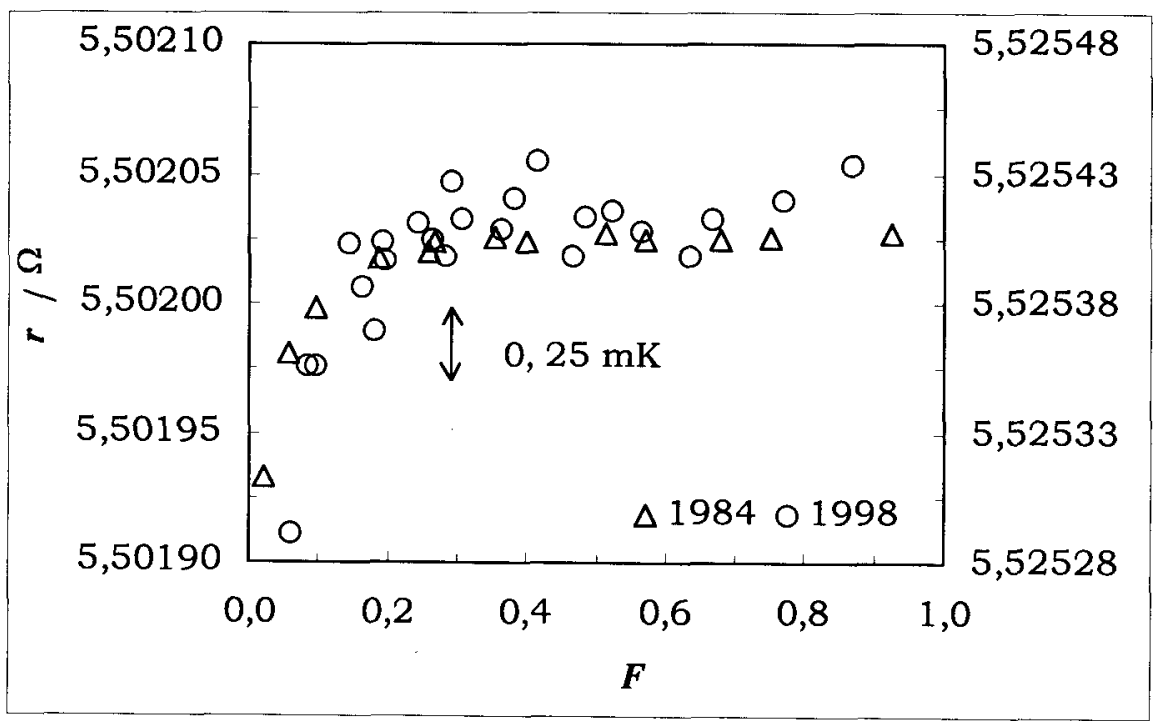

Figura IV.5. Curvas de fusión de Ar. Se comparan dos corridas de aparatos similares, unos datos fueron medidos en 1984 y los otros en 1998. Se desplazaron verticalmente las escalas para que coincidieran los valores de resistencia de los TRP en el punto liquidus.

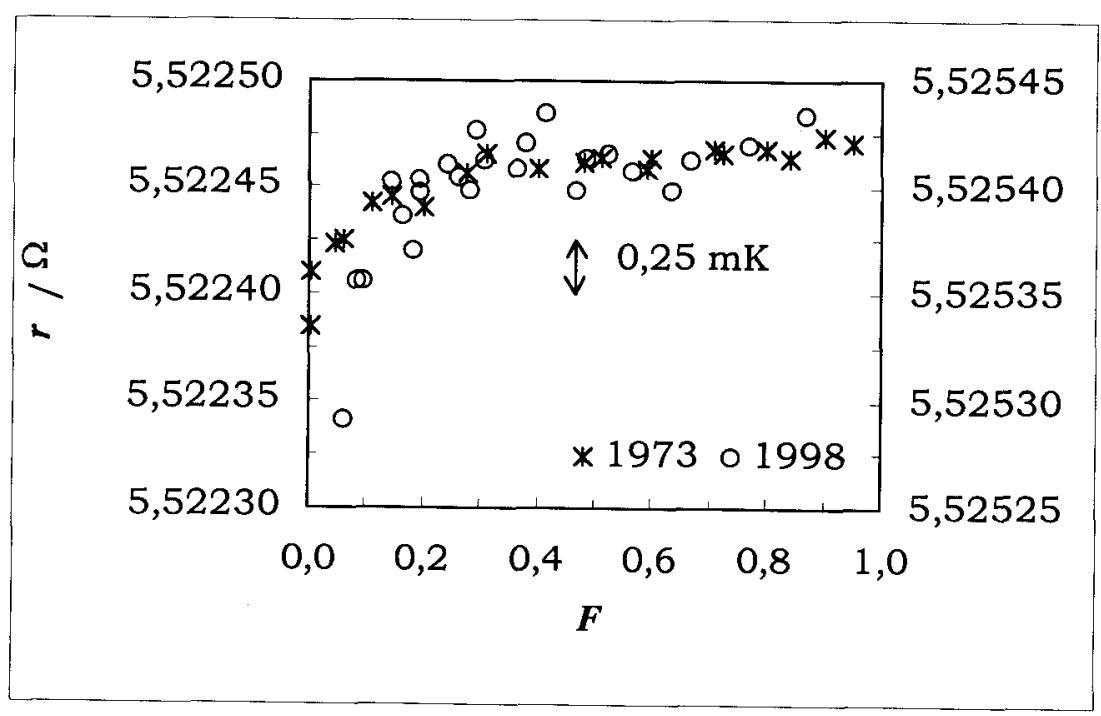

Figura IV.6. Curvas de fusión de Ar. Se comparan los datos obtenidos en 1998 con TRP de tallo largo con los obtenidos en un crióstato con celda de medición en la que el TRP está en contacto directo con la muestra. 
En el experimento de Ancsin se declara el análisis químico de la muestra, hecho por el fabricante. Se identificó al nitrógeno (5 ppm) y al oxígeno (2 ppm) como las principales impurezas, con $C_{l} 0,020 \mathrm{mK} / \mathrm{ppm}$ y $0,024 \mathrm{mK} / \mathrm{ppm}$ respectivamente [8]. Con estos valores, y la constante crioscópica del argón, se calculó el coeficiente de distribución $(k)$ de cada impureza $\left(0,594\right.$ para $\mathrm{N}_{2} \mathrm{y}$ 0,513 para $\mathrm{O}_{2}$ ). Al conocer la fracción de cantidad de sustancia de cada impureza y sus coeficientes de distribución sólo faltaba ajustar el valor de ro. En la tabla IV.II presentamos los resultados de este ajuste (AQ), junto con los de los otros modelos.

Tabla IV.II. Parámetros calculados para una muestra de Ar, donde se cuenta con el análisis químico de la muestra. El signo de las impurezas es positivo si el intervalo de fusión de la solución binaria resultante está por arriba del punto de fusión del disolvente y negativo en caso contrario.

\begin{tabular}{|c|c|c|}
\hline Modelo & ro $/ \Omega$ & $\boldsymbol{x} * \mathbf{1 0}^{\mathbf{6}}$ \\
\hline van't Hoff & 5,522468 & $-1,8$ \\
\hline Mastrangelo & 5,522477 & $-4,4$ \\
\hline Gulliver & 5,522413 & -44 \\
\hline pseudoternario & 5,522500 & $+42,-0,2$ \\
\hline AQ & 5,522482 & -7 \\
\hline compuesto $\left(\mathrm{N}_{2} \mathrm{y} \mathrm{O}_{2}\right)$ & 5,522476 & $-7,+3$ \\
\hline
\end{tabular}

Los parámetros que aparecen en el renglón $\mathrm{AQ}+$ fueron calculados con el modelo compuesto con un término adicional para considerar aquellas impurezas que tienen intervalo de fusión más alto que el punto triple del Ar.

En esta ocasión encontramos que el modelo de Mastrangelo es el que mejor describe los datos experimentales, de hecho es indistinguible al obtenido con el modelo compuesto.

Si en los experimentos anteriores las muestras son similares (como parece ser), entonces las diferencias en los resultados pueden que se hayan generado en el diseño de los experimentos. Los detalles de construcción de la celda de Ancsin, 
así como su concordancia con los datos del análisis químico, permiten considerar a su diseño como el más adecuado para el estudio del equilibrio de fases. Este aparato fue reconstruido por el autor en $1995 \mathrm{y}$ ahora es parte de la infraestructura de medición del CENAM.

\section{IV.2.5 Comparación de TRPs}

Para evaluar el rendimiento del crióstato como aparato para comparación y calibración de TRPs, se calibraron dos TRP (Rosemount y YJ) en el intervalo de $83,8 \mathrm{~K}$ (punto triple de argón) a $273 \mathrm{~K}$ (punto triple de agua). Posteriormente se usó el aparato para comparar las lecturas obtenidas con ambos termómetros en otras dos temperaturas: a $234 \mathrm{~K}$ y $154 \mathrm{~K}$.

Para calibrar un TRP en el intervalo $\mathrm{Ar}-\mathrm{H}_{2} \mathrm{O}$ [10], se mide la resistencia del termómetro en los puntos triples de argón $r(\mathrm{Ar})$, mercurio $r(\mathrm{Hg})$ y agua $\left(R_{0}\right)$. Con estos valores se calculan los cocientes $W(T)$ para $\mathrm{Ar}$ y $\mathrm{Hg}$, donde $W(T)$ está definido por

$$
W(T)=\frac{r(T)}{R_{0}} \quad
$$

IV.1

Con los valores de $W$, se calculan los parámetros de la función de desviación dada por

$$
W(T)-W_{r}(T)=a[W(T)-1]+b[W(T)-1] \ln W(T) \quad, \quad \text { IV.2 }
$$

donde $W_{\mathrm{r}}$ es la función de referencia, de acuerdo al texto de la EIT-90. Un TRP queda calibra cuando se conocen sus parámetros a y b. En la tabla IV.III mostramos los resultados de la calibración. 
Tabla IV.III. Datos y constantes de calibración de los TRPs.

\begin{tabular}{|c|c|c|c|c|}
\hline TRP & W(Ar) & W(Hg) & $\boldsymbol{a}$ & $\boldsymbol{b}$ \\
\hline Rosemount & 0,215961 & 0,844165 & $-5,498 \mathrm{E}-4$ & $-1,33 \mathrm{E}-5$ \\
\hline YJ & 0,215878 & 0,844148 & $-0,396 \mathrm{E}-4$ & $-1,04 \mathrm{E}-5$ \\
\hline
\end{tabular}

Una vez calibrados los termómetros se fijó la temperatura del crióstato a 154,3 $\mathrm{K}$, se midieron los valores de $\eta(T)$ de cada TRP. Posteriormente, se fijó la temperatura a $234,2 \mathrm{~K}$ y se obtuvieron los valores correspondientes de $r(T)$. Finalmente se obtuvieron los valores $R_{0}$ y se calcularon los valores de $W(T)$, de donde se calculó la temperatura $T$. Los valores obtenidos se muestran en la tabla IV.IV.

Tabla IV.IV. Diferencia de temperatura medida por los termómetros calibrados

\begin{tabular}{|c|c|c|c|c|}
\hline TRP & $\begin{array}{c}\text { W en e1 } \\
\text { punto 1 }\end{array}$ & $\begin{array}{c}\text { T / K } \\
\text { (punto 1) }\end{array}$ & $\begin{array}{c}\text { W en el } \\
\text { punto 2 }\end{array}$ & $\begin{array}{c}\text { T / K } \\
\text { (punto 2) }\end{array}$ \\
\hline Rosemount (R) & 0,516376 & 154,2923 & 0,843879 & 234,2451 \\
\hline $\mathrm{YJ}$ & 0,516322 & 154,2919 & 0,843863 & 234,2454 \\
\hline $\mathrm{T}(\mathrm{YJ})-\mathrm{T}(\mathrm{R})$ & - & $-0,4 \mathrm{mK}$ & - & $+0,3 \mathrm{mK}$ \\
\hline
\end{tabular}

Los resultados muestran que el aparato puede ser empleado, en la comparación de TRPs, en todo su intervalo de operación $(80 \mathrm{~K}<T<300 \mathrm{~K})$ con incertidumbre menor a $1 \mathrm{mK}$. Esta exactitud puede aun mejorarse vía la adecuación de las anclas térmicas y el uso $\mathrm{CO}_{2}$ sólido molido como baño refrigerante a temperaturas mayores a $200 \mathrm{~K}$. 


\section{IV.3 Punto triple de xenón}

En 1995 reconstruimos un crióstato adiabático diseñado por Ancsin [11]. En las pruebas de operación del aparato, medimos los puntos triples de argón, metano, kriptón, xenón, mercurio y agua contenidas en celdas metálicas. Las celdas pertenecen al patrón nacional de temperatura de Canadá. Presentaremos los resultados obtenidos al analizar los datos experimentales, de la muestra de xenón, con diferentes modelos de curvas de fusión [12].

\section{IV.3.1 Análisis de datos experimentales}

La muestra está contenida en una celda cilíndrica de $3 \mathrm{~cm}$ de diámetro y $8 \mathrm{~cm}$ de largo. En el centro se tiene un pozo para un TRP tipo cápsula. El crióstato empleado es el mismo que el descrito para los experimentos del capitulo III, donde se remplazó la celda abierta con la celda sellada. En la fig. IV.7 presentamos los puntos experimentales y dos curvas de interpolación, una (a trazos) obtenida con el modelo de $1 / F$ y la otra (continua) con el modelo pseudoternario.

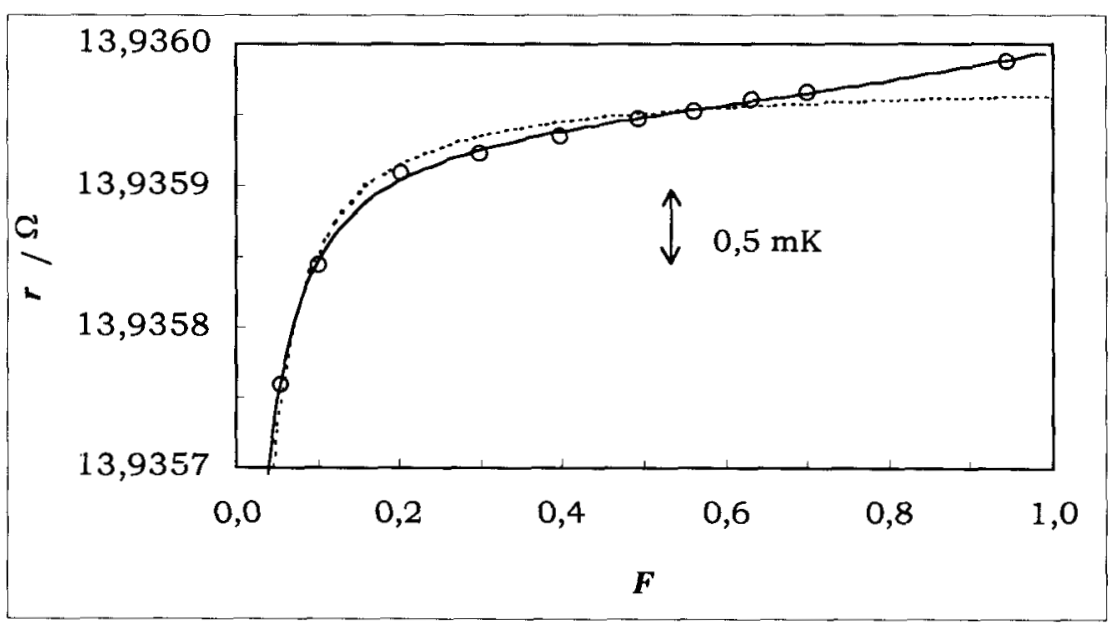

Figura IV.7. Curva de fusión de Xe. La linea a trazos corresponde al modelo $1 / F$, la continua al modelo pseudoternario. 
En la tabla IV.V presentamos los principales parámetros obtenidos del ajuste de los datos experimentales.

Tabla IV.V. Principales parámetros de los modelos ajustados a los datos experimentales de una curva de fusión de xenón. La celda empleada es parte del patrón nacional de temperatura de Canadá.

\begin{tabular}{|c|c|c|}
\hline Modelo & ro $/ \Omega$ & $\mathbf{x}^{* 1 \mathbf{1 0}^{6}}$ \\
\hline $1 / F(\mathrm{vH})$ & 13,935976 & 1,3 \\
\hline termodinámico $(\mathrm{M})$ & 13,935995 & 2,4 \\
\hline gradiente $(\mathrm{G})$ & 13,936035 & 11,2 \\
\hline pseudoternario $(\mathrm{Pt})$ & 13,935975 & 5,9 \\
\hline
\end{tabular}

La máxima diferencia para $r$, entre los modelos ajustados, es equivalente a 0,6 $\mathrm{mK}$. La resolución del TRP-puente empleados es $0,02 \mathrm{mK}$.

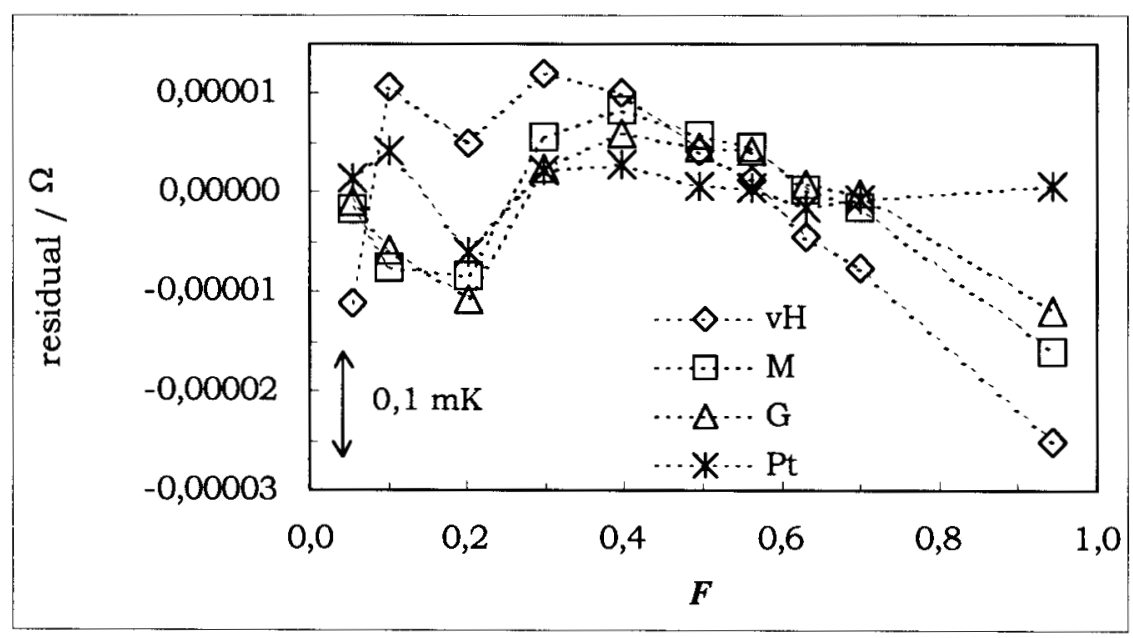

Figura IV.8 Residuales del ajuste de la curva de fusión de Xe. Los modelos probados son: $1 / F(\mathrm{vH})$, termodinámico $(\mathrm{M})$, gradiente de concentración $(\mathrm{G})$ y pseudoternario $(\mathrm{Pt})$. El modelo pseudoternario es el único que ajusta adecuadamente los datos experimentales.

En la fig. IV.8 se presentan los residuales obtenidos para cada uno de los modelos. Se observa que los residuales de todos los modelos tienden a discrepar con los datos experimentales conforme $F$ tiende a uno. En este caso 
se encontró que el modelo pseudoternario ajustó todos los datos experimentales con una dispersión menor a $0,1 \mathrm{mK}$.

\section{IV.4 Otros efectos}

A continuación mencionaremos algunos fenómenos observados que aún no se han incorporado sus efectos en los modelos descritos en este trabajo.

a) Forma macroscópica de los sólidos. Las celdas de punto triple de agua se mantienen en baños que permiten la conservación del punto triple por semanas y aún meses. En ese periodo se observa que los cristales de agua evolucionan en al menos dos tipos: una con secciones esféricas con diámetros de 3 a $5 \mathrm{~mm}$ y la otra con cristales macroscópicamente amorfos entre 1 y $3 \mathrm{~cm}$. Hemos observado que las muestras que desarrollan los cristales en forma de esferas son más estables (en temperatura) que cuando se presentan formas irregulares [13]. Tambiên encontramos que la dependencia de la temperatura del equilibrio sólido-liquido con respecto a la presión es diferente para cada tipo de formas de sólido. Al momento sólo se ha observado este efecto en muestras de agua, queda pendiente su estudio en otros materiales.

b) Efecto del sobreenfriamiento. La temperatura del equilibrio sólido-líquido, después de un sobreenfriamiento de varios grados, sistemáticamente es más baja que cuando el sobreenfriamiento es de un Kelvin o menor [14].

c) Efecto de la presión hidrostática. En celdas donde es posible colocar el TRP en distintas posiciones dentro de ella, el perfil vertical de la temperatura no corresponde a las variaciones de temperatura producidas por las cabezas hidrostáticas $[15,16]$. 


\section{IV.5 Conclusión}

Se diseñó y construyó un nuevo tipo de crióstato adiabático para la reproducción del punto triple de argón. Este aparato permite la calibración simultánea de 4 TRP de tallo largo. También puede ser empleado para estudios de no unicidad de la EIT-90 en el intervalo de $80 \mathrm{~K}$ a $273 \mathrm{~K}$. El crióstato forma parte de la infraestructura de medición del CENAM.

El crióstato reconstruido fue donado por el NRC al CENAM. Este aparato puede ser usado con cámaras abiertas en estudios de efectos de impurezas sobre los puntos fijos de la EIT-90. También puede ser configurado para trabajar con celdas en ambos modos de operación su intervalo de operación es de $4 \mathrm{~K}$ a $300 \mathrm{~K}$. Presentamos los experimentos de la reproducción del punto triple de xenón. Encontramos que sólo el modelo pseudoternario es capaz de ajustarse a los datos experimentales.

Una de las líneas de desarrollo que queda abierta es la incorporación, a los modelos de descripción de curvas de fusión, de los fenómenos indicados en la sección IV.4.

\section{IV.6 Referencias}

1. J. Ancsin (1995). Concerning the consistency of fixed points of the temperature scale. Metrologia 32, 295-300. París Francia.

2. B. W. Mangum, E. R. Pfeiffer, G. F. Strouse, J. Valencia Rodriguez, J. H. Lin, T. I. Yeh, P. Macarino, R. Dematteis, Y. Liu, Q. Zhao, A. T. Ince, F. Çakiroĝlu, H. G. Nubbemeyer, H. J. Jung (1996). Comparisons of some NIST fixed-point cells with similar cells of other standards laboratories. Metrologia 33, 215-225. París, Francia.

3. J. Ancsin, E. Méndez Lango (1996). Comparison of realizations of the thermometric fixed points of the ITS-90 in the range $-38^{\circ} \mathrm{C}$ to $420^{\circ} \mathrm{C}$ between Canada and México. Metrologia 33, 415-420 Paris, Francia. 
4. J. Valencia, E. Méndez, D. Licea, M. Tischler, P.. da Fonseca, S. Garcia Petrovic, L. A. Suarez, P. Young, B. Giron, H. Postigo, L Mussio (1999). Report on the comparison of thermometric fixed-points cells of the national laboratories of the Americas. Sistema Interamericano de Metrologia, 1-16. Querétaro, México.

5. J. Ancsin (1970). The triple point of oxygen and its change by noble gas impurities. Metrologia 6, 53-56. Paris, Francia.

6. E. Méndez Lango (1995). Informe Interno CENAM. Querétaro, México.

7. E. Méndez-Lango, J. Ancsin (1999). Argon triple point realization at CENAM, México. en $7^{\text {th }}$ International Symposium on Temperature and Thermal Measurements in Industry and Science. NMI Van Swinden Laboratorium. 84-88, Delft, Países Bajos.

8. J. Ancsin. (1973) Studies of phase changes in argon. Metrologia 9, 147-154. Paris, Francia.

9. J. Ancsin, J. M. Phillips (1984). Calibration Apparatus for long-stem and capsule type Pt resistance thermometers between the triple point of Ar and In. Rev. Sci. Instrum. 55(8), 1321-1324.

10. H. Preston-Thomas (1990). The International Temperature Scale of 1990 (ITS90). Metrologia 27, 3-10, 107. Paris, Francia.

11. J. Ancsin (1982). Melting curves of $\mathrm{H}_{2} \mathrm{O}$. Temperature 5. ed. American Institute of Physics, 281-284. Nueva York, Estados Unidos.

12. E. Méndez Lango (1999). Estimation of systematic error due to impurities in thermometric fixed points. CCT99-12 en Comité Consultatif de thermometrie, $20^{\mathrm{me}}$ sesion. París, Francia.

13. E. Méndez Lango.(1996) Effect of crystal size, form and stability on the triple point of water, en $6^{\text {th }}$ International Symposium on Temperature and thermal measurements in industry and science. ed. Levrotto Bella, 57-62, Torino, Italia.

14. E. Méndez Lango, M. L. Chávez, F. Guzmán (1992). The triple point of thrichlorofluoromethane. Temperature 6. ed. American Institute of Physics, 277-279. Nueva York, Estados Unidos. 
15. J. Ancsin, E. Méndez Lango (1999). The reproducibility of some thermometric fixed points and the accuracy of temperature measurements using platinum resistance thermometers. Metrologia 36, 117-139. Paris, Francia.

16. E. Méndez-Lango (1997). Temperature profile of a triple point of water cell. en XIV IMEKO world congress: new measurements-challenges and visions. Tampere, Finlandia. 


\section{CAPÍTULO CINCO \\ ANÁLISIS TÉRMICO}

\section{V.1 Introducción}

En este capitulo aplicaremos el modelo pseudoternario a experimentos de determinación de pureza por análisis térmico. Los experimentos fueron realizados en un calorímetro diferencial de barrido (DSC) en el Centro Nacional de Metrologia (CENAM) [1]. Los programas de cálculo para la estimación de la pureza de las muestras, que emplea el DSC, usan el modelo de $1 / F$. Vamos a presentar los resultados de tratamiento de los datos experimentales de dos muestras de indio. Compararemos los resultados de estos casos con los obtenidos con el modelo pseudoternario.

En la segunda parte del capitulo, presentaremos los resultados obtenidos de una muestra de zinc. El experimento se realizó con el método de fusión continua. La celda empleada es parte del patrón nacional de temperatura que mantiene el CENAM y se usa para la calibración de termómetros de resistencia de platino (PRT). Se comparan los resultados del ajuste del modelo pseudoternario a los datos experimentales y se comparan con los del proveedor de la muestra.

\section{V.2. Calorimetro diferencial de barrido}

El análisis térmico diferencial la diferencia de temperatura $\Delta T$ entre una muestra y un material de referencia se registra cuando ambos están sujetos al mismo programa de calentamiento (dT/dt). El sistema de medición está formado por un horno dentro del cual hay un bloque con dos cavidades, una para la muestra y el otra para el material de referencia. Al realizar un 
experimento de fusión, la temperatura de la muestra presenta un retraso con respecto al programa de calentamiento que sigue la referencia. La diferencia de temperatura, como función de la temperatura de la referencia, describe una curva. El área bajo esa curva se relaciona con el cambio de la entalpia en la fusión de la muestra. La fracción fundida $F$ se estima por el área parcial, en cualquier punto del programa de calentamiento con respecto al área total bajo la curva. [2]

La evaluación de los resultados para la determinación de la pureza de la muestra usa el modelo $1 / F[3]$. El requisito para su aplicación es que la impureza sea soluble en la fase liquida e insoluble en la sólida. La referencia citada indica que en caso de que la gráfica de $T$ vs. $1 / F$ no resulte en una linea recta, entonces se realice un ajuste sobre los valores parciales de $F$, a través de prueba error, hasta que se obtenga una linea recta. En nuestro estudio hemos propuesto que esa falta de linealidad se debe a la distribución de la impureza en las fases. Así que aplicamos el modelo pseudoternario a un conjunto de experimentos realizados con dos muestras de indio.

Tabla V.1. Muestras de In usadas en este estudio. La última columna es la estimación de la pureza obtenida con los programas internos del aparato.

\begin{tabular}{|c|c|c|c|}
\hline Fuente & $\begin{array}{c}\text { pureza } \\
\text { declarada }\end{array}$ & $\begin{array}{c}\text { tamaño } \\
\mathrm{m} / \mathrm{mg}\end{array}$ & $\begin{array}{c}\text { pureza } \\
\text { estimada }\end{array}$ \\
\hline Aldrich (12802PG) & $99,999 \%$ & 2,393 & 100,00 \\
\hline TA & - & 2,443 & 100,00 \\
\hline
\end{tabular}

\section{V.2.1 Experimental}

Utilizamos un calorimetro diferencial de barrido (DSC) marca TA Instruments, modelo DSC2920. Las muestras de indio que empleamos están descritas en la tabla V.1. Las muestras se encapsularon en aluminio y durante los experimentos se mantuvo un flujo de nitrógeno extra seco $(100 \mathrm{ml} / \mathrm{min})$ a través de la cámara del aparato. Los programas de calentamiento fueron 
$0,1 \mathrm{~K} / \mathrm{min}, 0,2 \mathrm{~K} / \min$ y $0,4 \mathrm{~K} / \mathrm{min}$. Todas las corridas se iniciaron $5 \mathrm{~K}$ por debajo del punto de fusión y se terminaron $5 \mathrm{~K}$ arriba del punto de fusión.

En la fig. V.1 presentamos los resultados obtenidos con la muestra TA. Los puntos son los datos experimentales, la línea a trazos corresponde al ajuste 1 / $F$ y la linea continua es el ajuste del modelo pseudoternario.

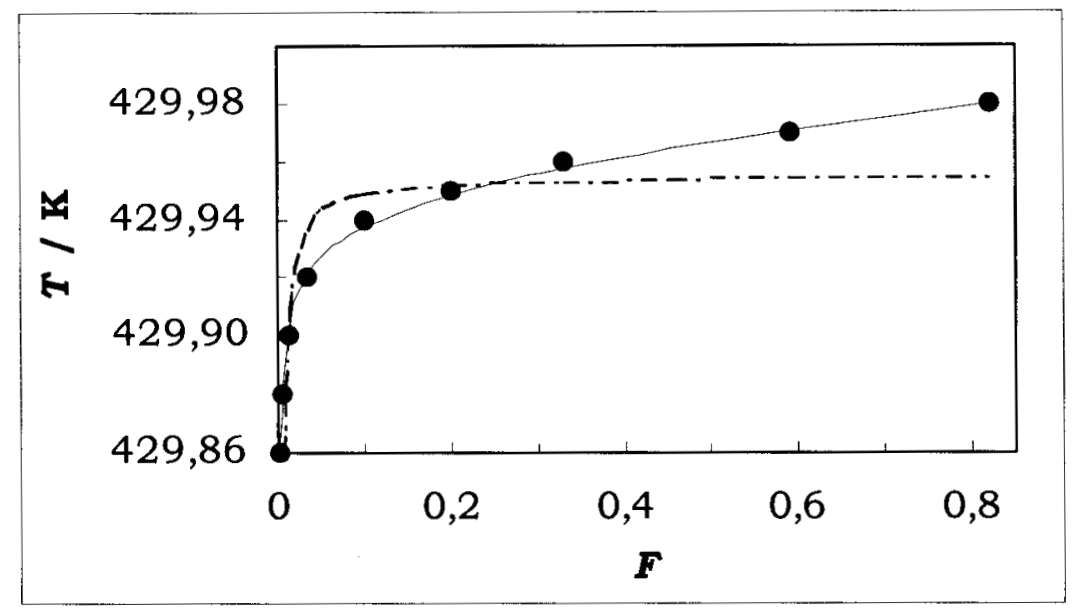

Figura V.1. Curva de fusión de In, muestra TA obtenida en un calorimetro diferencial de barrido. Los puntos representan los datos experimentales. La linea a trazos fue ajustada con el modelo $1 / F$; la linea continua con el modelo pseudoternario.

En la fig. V.2 presentamos un conjunto de curvas obtenidas de la muestra Aldrich.

Se observa que el programa de calentamiento induce errores sistemáticos tanto en el intervalo de fusión como en el punto liquidus. En la tablaV.2 se presentan los parámetros de ajuste del modelo pseudoternario.

Tabla V.2. Parámetros ajustados a las curvas de fusión de In.

\begin{tabular}{|c|c|c|c|c|c|c|c|c|c|c|c|}
\hline parámetro & $\mathbf{A 1}$ & $\mathbf{A 2}$ & $\mathbf{B 1}$ & $\mathbf{B 2}$ & $\mathbf{B 3}$ & $\mathbf{B 4}$ & $\mathbf{C 1}$ & $\mathbf{C 2}$ & $\mathbf{C 3}$ & $\mathbf{C 4}$ & $\mathbf{T A}$ \\
\hline $\mathbf{T}_{\mathbf{0}} / \mathbf{K}$ & $\mathbf{4 3 0 , 0 4}$ & 430,04 & 430,03 & 430,02 & 430,00 & 430,00 & 430,04 & 430,07 & 430,06 & 430,03 & 429,93 \\
\hline $\mathbf{x}_{(-)}{ }^{*} \mathbf{1 0}^{\mathbf{6}}$ & 1,9 & 2,2 & 2,3 & 2,5 & 1,8 & 2,3 & 2,3 & 2,0 & 1,5 & 2,0 & 6,8 \\
\hline $\mathbf{x}_{(++)} \mathbf{1 1 0}^{\mathbf{4}}$ & 4,0 & 4,1 & $\mathbf{3 , 0}$ & 3,0 & 2,9 & 3,0 & 5,8 & 5,6 & 5,2 & 5,7 & 2.1 \\
\hline
\end{tabular}




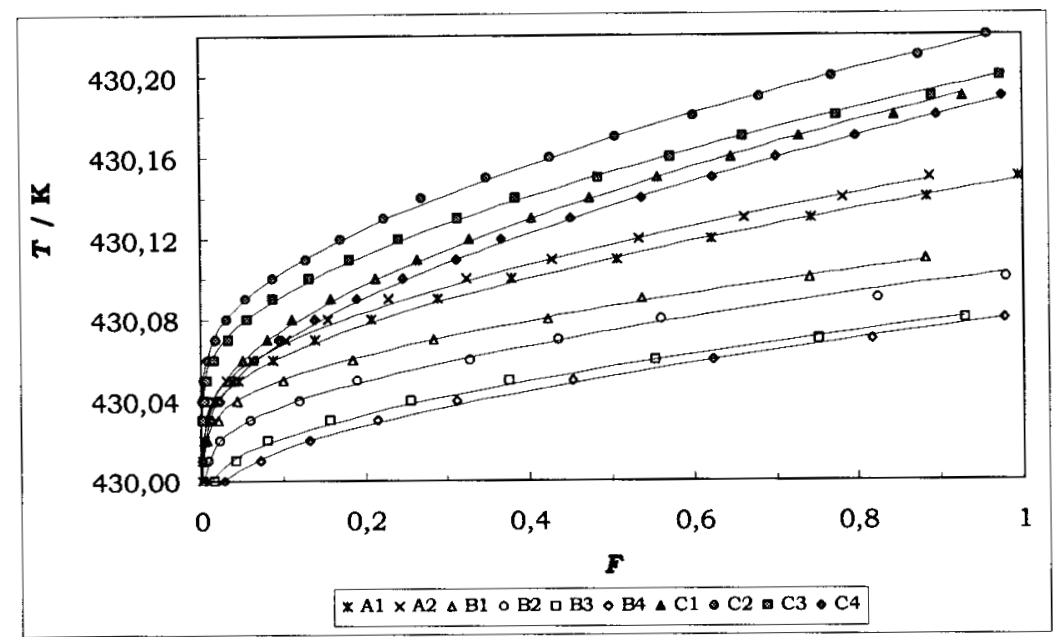

Figura V.2. Curvas de fusión obtenidas para la muestra Aldrich. Los símbolos representan los puntos experimentales. Se distinguen las razones de calentamiento con la nomenclatura de las curvas: An para $0,2 \mathrm{~K} / \mathrm{min}$; Bn para $0,1 \mathrm{~K} / \mathrm{min} \mathrm{y}$ $\mathrm{Cn}$ para $0,4 \mathrm{~K} / \mathrm{min}$. Las lineas se ajustaron con el modelo pseudoternario.

\section{V.2.2 Discusión}

a) En la gráfica en la fig. V.1 comparamos los ajustes obtenidos con los dos modelos. El modelo $1 / F$ no se ajusta a los datos experimentales en cambio el modelo pseudoternario los describe adecuadamente.

b) Efecto del programa de calentamiento:

i. Dado un valor de $F$, por ejemplo 0,8 , sistemáticamente las curvas con mayor razón de calentamiento están a temperaturas más altas;

ii. El intervalo de fusión cambia directamente con la razón de calentamiento;

iii. El parámetro $x_{(+)}$cambia directamente con la razón de calentamiento

De lo anterior concluimos que la razón de calentamiento induce un error sistemático en los parámetros mencionados. Se requiere el desarrollo de procedimientos para evaluar y corregir esos errores. 
c) Estimación de $T_{0}$. La dispersión en temperatura de las curvas con un mismo programa de calentamiento es $0,04 \mathrm{~K}$. De la tabla V.2 encontramos que si asignamos $430,00 \pm 0,03 \mathrm{~K}$ a $T_{0}$ entonces 9 de los 10 vares estimados para ese parámetro, caen en ese intervalo.

d) El valor estimado para $x_{-1}$ fue $2 \times 10^{-6}$ para la muestra de Aldrich y $7 \times 10^{-6}$ para la muestra TA. El programa interno del aparato empleado tiene resolución de $1 \times 10^{-4}$. Con el modelo pseudoternario se obtuvieron dos órdenes de magnitud más en resolución de este parámetro.

\section{V.3 Zinc}

Obtuvimos una curva de fusión de una de las celdas de zinc, del patrón nacional de temperatura. Empleamos la técnica de fusión continua. En el experimento que presentamos, la muestra tardó 15 horas en fundirse. Se estimó $F$ proporcional al tiempo de la fusión completa. En la fig. V.3 los círculos representan algunos de los puntos experimentales sobre la curva de fusión. La linea continua representa el ajuste del modelo pseudoternario.

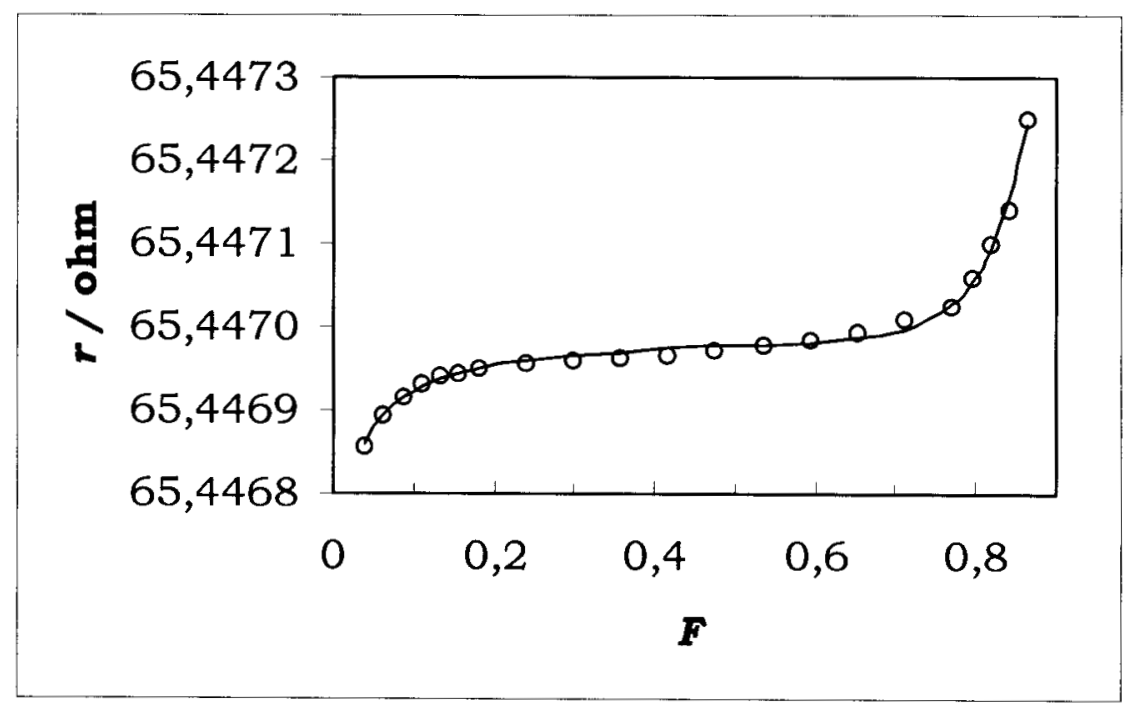

Figura V.3. Curva de fusión de zinc. La muestra pertenece al patrón nacional de temperatura. La escala vertical total es $5 \mathrm{mK}$. Los círculos representan algunos de los puntos 
experimentales a lo largo de la curva de fusión. La línea de interpolación corresponde al modelo pseudoternario.

La estimación de las fracciones de cantidad de sustancia de impurezas son las siguientes. $0,2 \mathrm{ppm}$ de impurezas con $k=0,16$ y $0,76 \mathrm{ppm}$ de impurezas con $k=6,1$ para un total de $0,92 \mathrm{ppm}$. El informe del proveedor indica $3 \times 10^{-7}$ fracción masa de impurezas [4].

La estimación del punto líquidus por método gráfico es 65,447000 , el valor estimado (con el modelo pseudoternario) de la resistencia que corresponde al disolvente puro es 65,446 984. La diferencia entre estos valores es menor a 0,2 $\mathrm{mK}$. Este valor nos da una idea del error sistemático en la realización de la reproducción de este punto de la EIT-90 al usar el punto líquidus como el de referencia de la celda.

\section{V.4 Conclusión}

Encontramos que en los sistemas estudiados el modelo pseudoternario ajusta adecuadamente a los datos experimentales.

En los experimentos de DSC encontramos que el modelo $1 / F$ no es adecuado para el ajuste de la curva de fusión. El modelo pseudoternario ajusta adecuadamente a los datos experimentales y se presenta como una alternativa para la interpretación de datos en la determinación de la pureza de materiales con ese aparato.

La estimación de la concentración de impureza resultado del ajuste del modelo pseudoternario a la curva de fusión de la muestra de zinc resultó consistente con la del proveedor de la muestra.

Este resultado está en concordancia con los obtenidos en la comparación de celdas de puntos fijos de la EIT-90 con similares de Canadá [4] y de los Estados Unidos de Norteamérica [5]. 


\section{V.5 Referencias}

1. E. Méndez-Lango, A. Guardado (2000). New model for interpretation of DSC thermal analysis data. International Conference on Metrology. 110-115. NCSL, CITAC, IMS. Jerusalem Israel.

2. M. E. Brown (1988) Introduction to thermal analysis. Cáp. 4 Diffrential thermal analysis (DTA) and diffrential scanning calorimetry (DSC). Chapman and Hall. Londre, Reino Unido.

3. ASTM Standards (1997). Designation : E 928-96. Estados Unidos.

4. Certificate of Compliance and Analysis (1993). Contract No. 2346-002, lote M2039. Washington, Estados Unidos.

5. J. Ancsin, E. Méndez Lango (1996). Comparison of realizations of the thermometric fixed points of the ITS-90 in the range $-38{ }^{\circ} \mathrm{C}$ to $420^{\circ} \mathrm{C}$ between Canada and México. Metrologia 33, 415-420 Paris, Francia.

6. B. W. Mangum, E. R. Pfeiffer, G. F. Strouse, J. Valencia Rodriguez, J. H. Lin, T. I. Yeh, P. Macarino, R. Dematteis, Y. Liu, Q. Zhao, A. T. Ince, F. Çakiroĝlu, H. G. Nubbemeyer, H. J. Jung (1996). Comparisons of some NIST fixed-point cells with similar cells of other standards laboratories. Metrologia 33, 215-225. Paris, Francia. 
Propusimos el modelo compuesto para describir las curvas de fusión de sustancias puras reales. Los parámetros ajustables del modelo son: el punto de fusión de la sustancia pura, las fracciones de cantidad de sustancia de los componentes de las impurezas y los coeficientes de distribución, de estos compuestos, en las fases sólida y líquida. Este modelo se probó con información experimental generada durante el desarrollo del proyecto así como con la generada por otros investigadores.

En los trabajos que realizamos para la reproducción de los puntos fijos de la EIT-90 encontramos que no habia un modelo adecuado para la interpretación de los datos experimentales de las curvas de fusión de los materiales de referencia (sustancias puras reales). Encontramos que el modelo compuesto describe adecuadamente estos datos experimentales.

Propusimos un modelo simplificado del modelo compuesto: el modelo pseudoternario. Este modelo se aplica cuando no se conoce la composición quimica de la solución. En la prueba de este modelo encontramos que los resultados obtenidos coinciden con los del modelo compuesto, tanto en la estimación del punto de fusión del disolvente puro como en la fracción total de cantidad de sustancia de soluto.

Para el caso en que se conocen los componentes de la solución pero no los coeficientes de distribución, desarrollamos un procedimiento, basándose en el modelo pseudoternario, para medir estos coeficientes; una vez conocidos los usamos en la aplicación del modelo compuesto.

Hemos reproducido y caracterizado los puntos fijos de definición de la EIT-90 de $\mathrm{Ar}, \mathrm{Hg}, \mathrm{H}_{2} \mathrm{O}, \mathrm{Ga}$, In, $\mathrm{Sn}, \mathrm{Zn}$ y Al, que proveen la infraestructura del patrón nacional de temperatura en el intervalo de $84 \mathrm{~K}$ a $660^{\circ} \mathrm{C}$. 
Adicionalmente, encontramos que el modelo pseudoternario describe adecuadamente las curvas de fusión obtenidas con calorimetros diferenciales de barrido.

Con relación a la infraestructura de medición, destacamos que contamos ahora con un crióstato de celda abierta con el cual se pueden realizar mediciones simultáneas de presión y temperatura, en el intervalo de $4 \mathrm{~K}$ a $300 \mathrm{~K}$, para la investigación de modelos de descripción del efecto de las impurezas en los puntos fijos de definición de la EIT-90, estudios de puntos secundarios de referencia y de puntos eutécticos.

Hacia futuro, está la investigación para incorporar al marco teórico de la temperatura de equilibrio entre las fases sólida y líquida de sustancias puras reales, las causas que generan los perfiles de temperatura en los pozos de las celdas y los procesos con tiempos largos de relajación, como el crecimiento de cristales observado en las celdas de punto triple de agua. 


\section{APÉNDICE}

\section{ARTÍCULOS PUBLICADOS DERIVADOS DE LA TESIS}

A. En revistas de circulación internacional

1. J. Ancsin, E. Méndez Lango (1999). About the reproducibility of some thermometric fixed points and the accuracy of temperature measurements using platinum resistance thermometers. Metrologia 36, 117-139. Paris, Francia.

2. J. Ancsin, E. Méndez Lango (1996). Comparison of realizations of the thermometric fixed points of the ITS-90 in the range $-38^{\circ} \mathrm{C}$ to $420^{\circ} \mathrm{C}$ between Canada and Mexico. Metrologia 33, 415-420 París, Francia

3. E. Mendez Lango, J. Ancsin (1996) Triple point and melting point of mercury Thermochimica Acta, 287 183-190, Amsterdam, Países Bajos.

4. E. Méndez Lango, J. Ancsin (1996). Cryostat for measuring the triple point of trichlorofluoromethane (refrigerant 11) under adiabatic conditions. Termochimica Acta 287, 149-154, Amsterdam, Países Bajos.

B. Sometido para su discusión a organismos internacionales

1. E. Mendez Lango (1999). Estimation of systematic error due to impurities in thermometric fuxed points. $20^{\mathrm{me}}$ sesion del Comite Consultatif de thermometrie, CCT99/12, 1-5. Paris Francia

2. J. Valencia, E. Mendez, D. Licea, M. Tischler, P.. da Fonseca, S. Garcia Petrovic, L. A. Suarez, P. Young, B. Giron, H. Postigo, L Mussio (1999). Report on the comparison of thermometric fixed-points cells of the national laboratories of the Americas. Sistema Interamericano de Metrologia, 1-16. Querétaro, México.

C. En extenso, en memorias de congresos internacionales con refereo

1. E. Mendez Lango, J. Ancsin (1999). Argon triple point realization at CENAM, México. 6th International Symposium on Temperature and thermal Measurements in Industry and Science, aceptado para su publicación. Delft, Países Bajos. 
2. E. Mendez Lango (1996). Effect of Crystal Size, Form and Stability on The Triple-Point of Water. 6th International Symposium on Temperature and thermal Measurements in Industry and Science, ed. Lecrotto y Bella, 57-62. Torino, Italia.

D. En extenso en memorias de congresos internacionales

1. E. Mendez Lango, J. Valencia Rodriguez, J. M. Figueroa Estrada (1994). Mercury triple point measurements realized at thermometry laboratory of CENAM. XIII IMEKO world congress: from measurement to innovation, ed IMEKO, 2672-2675. Torino, Italia.

2. E. Méndez Lango, A. Guardado (2000). New model for interpretation of DSC thermal analysis data. International Conference on Metrology Trends and applications in calibration and testing laboratories. NSCL, CITAC, IMS, IMEKO, 110-115. Jerusalem, Israel 